\title{
Relapse Prevention Anorexia Nervosa
}

Tamara Berends 


\section{Relapse Prevention Anorexia Nervosa}

\section{Terugvalpreventie Anorexia Nervosa}

(met een samenvatting in het Nederlands)

Proefschrift

ter verkrijging van de graad van doctor aan de

Universiteit Utrecht

op gezag van de

rector magnificus, prof.dr. H.R.B.M. Kummeling, ingevolge het besluit van het college voor promoties

in het openbaar te verdedigen op

vrijdag 11 december 2020 des middags te 12.45 uur

ISBN: 978-94-93184-59-6

Lay-out and printing: Guus Gijben, www.proefschrift-aio.nl

(c) Tamara Berends, Ilsselstein, The Netherlands, 2020

All rights reserved. No part of this thesis may be reproduced or transmitted in any form or by any means without prior permission of the author.

The studies described in this thesis were performed at Altrecht Eating Disorders Rintveld, Zeist, The Netherlands. Financial support for the publication of this thesis by the Parnassia Groep Academie is gratefully acknowledged.
Tamara Nadine Berends

geboren op 12 november 1976 te Curaçao 
Promotoren:

Prof. dr. A.A. van Elburg

Prof. dr. H.W. Hoek

Copromotor:

Dr. N. Boonstra

\section{Contents}

1. General introduction

2. The Anorexia Relapse Prevention Guideline in Practice: A Case Report

3. Relapse in anorexia nervosa: A systematic review and meta-analysis

4. Rate, timing and predictors of relapse in patients with anorexia nervosa following a relapse prevention program: A cohort study

5. Relapse prevention in anorexia nervosa: Experiences of patients and parents

6. The development of the Anorexia Relapse Prevention INventory (ARPIN)

7. Summary and General discussion

8. Samenvatting en Discussie

Dankwoord

Curriculum Vitae

List of publications 
Anorexia nervosa (AN) is a severe mental disorder characterized by (the drive for) thinness, a low body weight for one's age and height combined with a disturbed body image. Patients often see and experience themselves as fat (Keizer et al., 2011, 2012) while they are in fact very underweight, and do not consider themselves ill, which contrasts with their physical status. They fear weight gain and/or exhibit behaviours that prevent weight gain, such as compulsive exercise or purging. Patients with AN can become extremely underweight, which seriously threatens their physical and mental functioning. As this disorder usually starts in (early) adolescence, it can be a major hindrance to patients' psychosocial development and functioning. Medical complications affect all organs and systems, and are generally due to malnutrition, weight loss and purging behaviours (Treasure et al., 2020). Studies have shown traits such as perfectionism, harm avoidance, anxiety and inhibition in patients with anorexia nervosa (Hill et al., 2016; Klump et al., 2004). The DSM 5 (American Psychiatric Association, 2013) indicates direction to the classification of anorexia nervosa, but does not give information on the personal factors which play an important role in treatment and in relapse prevention strategies.

AN is one of the most chronic disorders in adolescence (Schmidt et al., 2016) and can result in so-called Severe and Enduring Anorexia Nervosa (SE-AN) (Wonderlich et al., 2020). Many patients with prolonged AN experience long-term impairments in social functioning and employment (Treasure et al., 2015; Robinson et al., 2015). Adolescents with AN experience serious impact on their development; e.g. friendships, school performance, development towards adulthood. Compared to their healthy peers, the health-related quality of life of patients with prolonged AN is seriously impacted, and they are associated with increased healthcare utilization and healthcare costs (Ágh et al., 2016)

AN is a disorder that predominantly affects girls and young women. The lifetime prevalence of AN in women is up to 2-4\% (Galmiche et al., 2019; Keski-Rahkonen \& Mustelin, 2016; Smink et al., 2013). The prevalence amongst men is around ten times lower (0.16-0.3\%; Raevouri et al., 2014). The highest prevalence of AN is reported in Europe, North America and Australasia (Hoek, 2016). The overall incidence rate of AN in the total population - i.e. including men and women of all ages - has remained surprisingly stable over the past four decades (i.e. around 5 per 100.000 in mental health care and around 6-8 per 100,000 in primary care) (Hoek, 2016; Smink et al., 2016). Adolescents in the age group of $15-19$ years have the highest incidence rates (Smink et al., 2016). AN has a high crude mortality rate of $5 \%$ per decade and a standardized mortality ratio of around 6 (Arcelus et al., 2011; Fichter \& Quadflieg, 2016; Smink et al., 2013)

\section{Anorexia nervosa 307.1 (F50.01 or F50.02)}

These are the diagnostic criteria for anorexia nervosa according to DSM-5 (American Psychiatric Association, 2013):

A Restriction of energy intake relative to requirements leading to a significantly low body weight in the context of age, sex, developmental trajectory, and physical health. Significantly low weight is defined as a weight that is less than minimally normal or, for children and adolescents, less than that minimally expected.

$B$ Intense fear of gaining weight or becoming fat, or persistent behaviour that interferes with weight gain, even though the person has a significantly low weight. Disturbance in the way in which one's body weight or shape is experienced, undue influence of body weight or shape on self-evaluation, or persistent lack of recognition of the seriousness of the current low body weight.

There are two subtypes:

Restricting type: in the past three months the person has not engaged in binge eating or purging behaviour (i.e., self-induced vomiting or the misuse of laxatives, diuretics, or enemas) during relapse episodes. This subtype is limited to clinical features with which the weight loss mainly comes from dieting, fasting and/or excessive exercising.

Binge eating/purging type: in the past three months the person has engaged in binge eating or purging behaviour (i.e., self-induced vomiting or the misuse of laxatives, diuretics, or enemas) during relapse episodes.

Specify if:

In partial remission: After full criteria for anorexia nervosa were previously met, Criterion $A$ has not been met for a sustained period, but either Criterion B or C is still met.

- In full remission: After full criteria for anorexia nervosa were previously met, none of the criteria have been met for a sustained period of time.

Specify current severity:

The minimum level of severity is based, for adults, on current body mass index (BMI) (see below) or for children and adolescents, on BMI percentile. The ranges below are derived from World Health Organization categories for thinness in adults; for children and adolescents, corresponding BMI percentiles should be used. The level of severity may be increased to reflect clinical symptoms, the degree of functional disability, and the need for supervision.

Mild: $B M I>17 \mathrm{~kg} / \mathrm{m}^{2}$

Moderate: BMI 16-16.99 kg/m²

Severe: $B M I 15-15.99 \mathrm{~kg} / \mathrm{m}^{2}$

Extreme: $B M I<15 \mathrm{~kg} / \mathrm{m}^{2}$ 
Psychiatric co-morbidity with AN has been described as the rule rather than the exception (Treasure et al., 2015, 2020). The most prominent comorbid disorders are: personality disorders, usually an avoidant personality disorder or a compulsive personality disorder; anxiety disorders; affective disorders (including suicidality and self-harm); obsessive compulsive disorders; and autistic traits of clinical significance in terms of repetitive and stereotyped behaviour (Grilo, 2002; Holtkamp et al., 2005; Keski-Rahkonen \& Mustelin, 2016; Pisetsky et al., 2013; Pooni et al., 2012; Serpell et al., 2002; Steinhausen, 2002, 2009).

Despite the seriousness and high chronicity of AN, the research area concerned with AN remains relatively small, with significantly fewer publications than in other fields of mental disorders (Herpertz-Dahlmann et al., 2015). Published studies on outcome show much variation; in the definition of remission, recovery and relapse, variations in the duration of follow-up, and diversity in methodologies used (Carter et al., 2004, 2012; Khalsa et al., 2017; Richard et al., 2005; Strober et al., 1997). In a recent review on relapse, remission and recovery in AN, Khalsa et al. (2017) provided a summary of the different definitions used and concluded that there is limited consensus about these definitions (Khalsa et al., 2017). They proposed a set of standardized criteria for relapse, remission and recovery for $\mathrm{AN}$, which is internally consistent and can facilitate longitudinal assessment by clinicians and researchers. These suggested criteria include objective measures (BMl; observable behaviours of restricting, binging, and purging), subjective measures (fear of gaining weight, disturbance of body image), standardized ratings (Eating Disorder Examination, EDE), and specific durations of follow-up (1, 3, 6, and 12 months) that are conducive to utilization across both clinical and research settings. Figure 1 provides an overview of these definitions.

Recovery from an eating disorder generally takes a long time. The mean length of treatment found across different studies is 4.7 years before stable physical recovery may be achieved. It takes from 6.5 to 9 years for psychosocial recovery (Eckert et al., 1995; Støving et al., 2011, Strober et al., 1997; Zerwas et al., 2013). When the illness has been active for five to seven years or more, it becomes chronical and enduring (Hibbs et al., 2015). Early intervention improves outcomes; therefor, rapid commencement of specialized eating disorder treatment and care rather than watchful waiting is essential (Treasure et al., 2020). Outcome studies show remission rates between 30 $50 \%$, approximately $20-30 \%$ of the patients develop a persistent and sometimes lifelong form of the illness, often punctuated by a series of unsuccessful treatments. The other approximately $30 \%$ show improvement, but do not recover completely (Fichter et al., 2017; Eddy et al., 2017; Steinhausen, 2002; Wonderlich et al., 2020). Relapse is common among AN patients, and reported relapse rates of AN are highly variable

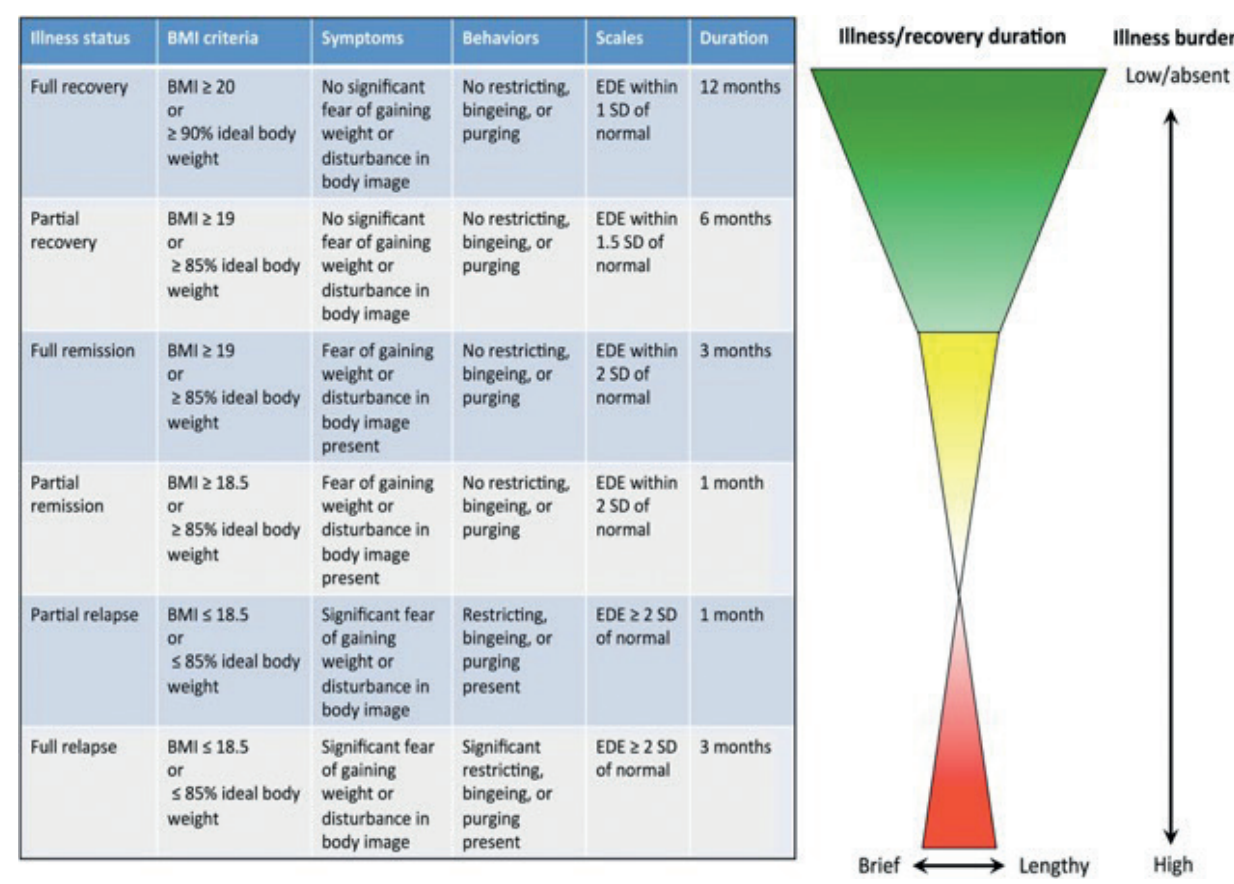

Figure 1: Overview of definitions of recovery, remission and relapse after Khalsa et al. (2017).

ranging from low (9\%) to high (52\%) following treatment, with the majority of studies reporting rates greater than $25 \%$; the risk of relapse is particularly high within the first year post-treatment (Carter et al., 2004, 2012; Khalsa et al., 2017; Strober et al., 1997; Richard et al., 2005).

In the leading guidelines in the field of eating disorders of the USA, United Kingdom, the Netherlands and Australia, the state-of-the-art treatment for AN is documented (American Psychiatric Association, 2006; Dutch Foundation for Quality Development in Mental Healthcare, 2017; National Institute for Health and Care Excellence (NICE), 2017; ANZAED guidelines, Hay et al., 2014; Hilbert et al., 2017). Treatment should focus on:

eating behaviour, body weight and body image;

psychological issues, such as lack of self-esteem, perfectionism, traumas; and

problems with fitting into the system or social functioning.

The aim of treatment for recovery in AN is primarily to restore the physical condition and to normalize eating and compensatory behaviour, for example, by eliminating purging and excessive exercise. A good estimate of the patient's energy intake is 
important to provide valuable nutritional advice and start restoration of body weight. Biological and psychological complications of malnutrition need to be corrected. In addition, treatment is aimed at a normalisation of the overestimation of influence on body shape, weight and food intake and an improvement of psychosocial functioning and self-image. If this complete symptomatic recovery does not seem feasible, the aim of the treatment shifts to improvement of quality of life, with as little hindrance as possible of eating disorder complaints in accordance with the recovery model (Dawson et al., 2014a, 2014b). The guidelines and recent reviews (Brockmeyer et al., 2018; van den Berg et al., 2019) describe the following leading treatment protocols for the treatment of adults with AN: Cognitive Behavioral Therapy-Enhanced (CBT-E) (Fairburn, 2008), the Maudsley Model of Anorexia Treatment in Adults (MANTRA) (Schmidt et al., 2014, 2019), and Specialist Supportive Clinical Management (SSCM) (McIntosh et al., 2006). For adolescents, Family-Based Treatment (FBT) should be prioritized (Fisher et al., 2019; Lock \& le Grange, 2005). The leading guidelines in the field of eating disorders pay very limited attention to relapse prevention, although it is known that relapse rates are high. As relapse prevention after the end of treatment is crucial for patients with AN, there is a need for intensive follow-up. Only the Dutch Guideline for Eating Disorders (2017) advises a form of protocol for relapse prevention and recommends using the Guideline Relapse Prevention Anorexia Nervosa that is described in this thesis.

\section{Guideline Relapse Prevention Anorexia Nervosa}

A decade ago, as there were no practical guidelines for relapse prevention for patients with AN, we felt the need to develop a Guideline Relapse Prevention Anorexia Nervosa (Berends et al., 2010) to provide a structured method for relapse prevention to support mental health professionals in clinical practice. The guideline is freely accessible online, at www.relapse-an.com. It is based on models of previously developed relapse prevention strategies for patients with schizophrenia aimed at prevention of psychotic relapse (van Meijel, 2003), for forensic and juvenile patients to prevent severe aggression (Fluttert et al., 2008; Hage \& van Meijel, 2008), and for patients who self-injure (Bosman \& van Meijel, 2009). This guideline contains three parts: part 1 covers a theoretical framework for relapse and relapse prevention, part 2 translates the recommendations into a manual for mental health professionals, and part 3 is a workbook for patients and their network members.

\section{Aim of thesis}

The aim of this thesis is twofold; 1) to build evidence for the use of the Guideline Relapse Prevention Anorexia Nervosa, and 2) to gain more insight into the different aspects of the process of relapse in order to improve and substantiate work on relapse prevention.

This thesis starts with a case report, presented in Chapter 2, in order to provide an insight into the working mechanisms of the guideline, as well as to illustrate how the guideline may be used in clinical practice both from a patient's and a professional's perspective. Chapter 3 contains a systematic review on relapse in AN, to review the available scientific knowledge on the rate, timing and factors associated with relapse. In Chapter 4, we describe a cohort study that was carried out with the first 100 patients treated in accordance with the Guideline Relapse Prevention Anorexia Nervosa, in which we present these same elements: rate, timing and predictors of relapse. Chapter 5 presents a qualitative study in which the reactions and experiences of patients and parents who worked with the guideline were collected, aimed in particular at the use of self-management strategies for relapse prevention. This study also attempts to identify facilitators and barriers for the successful application of the guideline. Chapter 6 contains a mixed method study that was carried out with the aim of gaining a better insight into the triggers and early warning signs of relapse from the patients' perspective. This resulted in the development of the Anorexia Relapse Prevention INventory (ARPIN). Finally, Chapter 7 contains a summary and general discussion of the outcomes from the various studies and their clinical significance, limitations and ideas for further research. 


\section{References}

Agh, T., Kovács, G., Supina, D., Pawaskar, M., Herman, B. K., Vokó, Z., \& Sheehan, D. V. (2016). A systematic review of the health-related quality of life and economic burdens of anorexia nervosa, bulimia nervosa, and binge eating disorder. International Journal of Eating and Weight Disorders, 21, 353-364. doi: 10.1007/ s40519-016-0264-x

American Psychiatric Association. (2006). Practice Guideline: Treatment of patients with eating disorders. APA. American Psychiatric Association. (2013). Diagnostic and statistical manual of mental disorders (5th ed.). American Psychiatric Publishing

Arcelus, J., Mitchell, A. J., Wales, J., \& Nielsen, S. (2011). Mortality rates in patients with anorexia nervosa and other eating disorders. A meta-analysis of 36 studies. Archives of General Psychiatry, 68(7), 724-731. doi:10.1001/archgenpsychiatry.2011.74

Berends T., van Meijel B., \& van Elburg A. (2010). Richtlijn Terugvalpreventie Anorexia Nervosa (Guideline Relapse Prevention Anorexia Nervosa). Koninklijke Van Gorcum. http://www.relapse-an.com

Bosman, M., \& van Meijel, B. (2009). Guidance of patients who self-injure; a nursing intervention method (Begeleiding van patienten die zelfverwonden: een verpleegkundig interventiepakket). Elsevier Gezondheidszorg.

Brockmeyer, T., Friederich, H. C., \& Schmidt, U. (2018). Advances in the treatment of anorexia nervosa: A review of established and emerging interventions. Psychological Medicine, 48(8), 1228-1256. doi: org/10.1017/ s0033291717002604

Carter, J. C., Blackmore, E., Sutandar-Pinnock, K., \& Woodside, D. B. (2004). Relapse in anorexia nervosa: a survival analysis. Psychological Medicine, 34, 671-679.

Carter, J. C., Mercer-Lynn, K. B., Norwood, S. J., Bewell-Weiss, C. V., Crosby, R. D., Woodside, D. B., \& Olmsted, M. P. (2012). A prospective study of predictors of relapse in anorexia nervosa: implications for relapse prevention. Psychiatry Research, 200, 518-523.

Dawson, L., Rhodes, P., \& Touyz, S. (2014a). 'Doing the impossible': The process of recovery from chronic anorexia nervosa. Qualitative Health Research, 24, 494-505. doi:10.1177/1049732314524029

Dawson, L., Rhodes, P., \& Touyz, S. (2014b). The recovery model and anorexia nervosa. Australian \& New Zealand Journal of Psychiatry, 48(11), 1009-1016.

Dutch Foundation for Quality Development in Mental Healthcare. (2017). Practice guideline for the treatment of eating disorders (Zorgstandaard Eetstoornissen). Utrecht, The Netherlands: Netwerk Kwaliteitsontwikkeling GGz

Eckert, E. D., Halmi, K. A., \& Marchi, P. (1995). Ten year follow-up of anorexia nervosa. Clinical course and outcome. Psychological Medicine, 25, 143-156.

Eddy, K. T., Tabri, N., Thomas, J.J., Murray, H. B., Keshaviah, A., Hastings, E., Edkins, K., Krishna, M., Herzog, D. B., Keel, P. K., \& Franko, D. L. (2017). Recovery From Anorexia Nervosa and Bulimia Nervosa at 22-Year FollowUp. Journal of Clinical Psychiatry, 78(2), 184-189. doi: 10.4088/JCP.15m10393

Fairburn, C. G. (2008) Cognitive Behavior Therapy and Eating Disorders. The Guilford Press.

Fichter, M. M., \& Quadflieg, N. (2016). Mortality in eating disorders - results of a large prospective clinical longitudinal study. International Journal of Eating Disorders, 49(4), 391-401. doi:10.1002/eat.22501

Fichter, M. M., Quadflieg, N., Crosby, R. D., \& Koch, S. (2017). Long-term outcome of anorexia nervosa: Results from a large clinical longitudinal study. International Journal of Eating Disorders, 50(9), 1018-1030. doi:10.1002/ eat. 22736

Fisher, C. A., Skocic, S., Rutherford, K. A., \& Hetrick, S. E. (2019). Family therapy approaches for anorexia nervosa. Cochrane Database of Systematic Reviews, 5, doi: org/10.1002/14651858.CD004780

Fluttert, F., van Meijel, B., Webster, C., Nijman, H., Bartels, A., \& Grypdonck, M. (2008). Risk management by early recognition of warning signs in patients in forensic psychiatric care. Archives of Psychiatric Nursing, 22(4), 208-216.
Galmiche, M. Dechelotte, P., Lambert, G. \& Tavolacci, M. P. (2019). Prevalence of eating disorders over the 2000-2018 period: a systematic literature review. The American Journal of Clinical Nutrition, 109(5), 14021413. doi:10.1093/ajcn/nay342

Grilo, C. (2002). Recent research of relationships among eating disorders and personality disorders. Current Psychiatry Reports, 4, 18-24.

Hage, S., \& van Meijel, B. (2008). Guideline aggressive behavior of juveniles: a guideline for nurses and psychiatric professionals within adolescent psychiatry (Richtlijn agressief gedrag van jeugdigen: een richtlijn voor verpleegkundigen en agogen binnen de jeugdpsychiatrie). Alkmaar, The Netherlands: Hogescho INholland/Triversum.

Hay P., Chinn D., Forbes D., Madden, S., Newton, R., Sugenor, L., Touyz, S., \& Ward, W. (2014). The Royal Australian and New Zealand College of Psychiatrists clinical practice guidelines for the treatment of eating disorders. Australian and New Zealand Journal of Psychiatry, 48, 977-1008

Herpertz-Dahlmann, B., van Elburg, A., Castro-Fornieles, J., \& Schmidt, U. (2015). ESCAP Expert paper: New developments in the diagnosis and treatment of adolescent anorexia nervosa-a European perspective. European Child and adolescent Psychiatry, 24, $1153-1167$.

Hibbs, R., Rhind, C., Leppanen, J., \& Treasure, ]. (2015). Interventions for caregivers of someone with an eating disorder: a meta-analysis. International Journal of Eating Disorders, 48(4), 349-361. doi: 10.1002/ eat.22298

Hilbert, A., Hoek, H. W., \& Schmidt, R. (2017). Evidence-based clinical guidelines for eating disorders: international comparison. Current Opinion in Psychiatry, 30(6), 423-437. doi:10.1097 yco.0000000000000360

Hill, L., Knatz Peck, S., Wierenga, C. E., \& Kaye W. H. (2016). Applying neurobiology to the treatment of adults with anorexia nervosa. Journal of Eating Disorders, 4(31). doi.org/10.1186/540337-016-0119-x

Hoek, H. W. (2016). Review of the worldwide epidemiology of eating disorders. Current Opinion in Psychiatry 29(6), 336-339. doi:10.1097/yco.0000000000000282

Holtkamp, K., Müller, B., Heussem, N., Remschidt, H., \& Herpertz-Dahlman, B. (2005). Depression, anxiety, and obsessionality in long-term recovered patients with adolescent-onset anorexia nervosa. European Child and Adolescent Psychiatry, 14(2), 106-110

Keizer A., Smeets, M. A., Dijkerman, H. C., van den Hout, M., Klugkist, I., van Elburg, A., \& Postma A. (2011) Tactile body image disturbance in anorexia nervosa. Psychiatry Research, 190(1), 115-120.

Keizer, A., Smeets, M. A., Dijkerman, H. C., van Elburg, A., \& Postma A. (2012). Aberrant somatosensory perception in Anorexia Nervosa. Psychiatry Research, 200(2-3),530-537. doi: 10.1016/jpsychres.2012.05.001.

Keski-Rahkonen, A., \& Mustelin, L. (2016). Epidemiology of eating disorders in Europe: prevalence, incidence, comorbidity, course, consequences, and risk factors. Current Opinion in Psychiatry, 29(6), 340 345. doi:10.1097/yco.00000000000000278

Khalsa, S. S., Portnoff, L. C., McCurdy-McKinnon, D., \& Feusner, J. D. (2017). What happens after treatment? A systematic review of relapse, remission, and recovery in anorexia nervosa. Journal of Eating Disorders 5, 20. doi: 10.1186/s40337-017-0145-3

Klump, K., Strober, M., Johnson, C., Thornton, L., Bulik, C., Devlin, C., Fichter, M. M., Halmi, K. A., Kaplan, A. S., Woodside, D. B., Crow, S., Mitchell, J., Rotondo, A., Keel, P. K., Berrettini, W. H., Plotnicov, K., Pollice, C Lilenfeld, L. R. \& Kaye, W. H. (2004). Personality characteristics of women before and after recovery from an eating disorder. Psychological Medicine., 34(8), 1407-1418.

Lock, D., \& le Grange, D. (2005). Family-Based Treatment for Eating Disorders. International Journal of Eating Disorders, 37, 64-67.

McIntosh, V. V., Jordan, J., Luty, S.E., Carter, F. A., McKenzie, J. M., Bulik, C. M., \& Joyce, P. R. (2006). Specialis supportive clinical management for anorexia nervosa. International Journal of Eating Disorders, 39, 625632. doi:10.1002/eat.2029 
van Meijel, B. (2003). Relapse prevention in patients with schizophrenia: a nursing intervention study. University Medical Center Utrecht.

National Institute for Health and Care Excellence (NICE). (September 2017). Eating disorders: recognition and treatment, full guideline. Retrieved from: https://www.nice.org.uk/guidance/ng69

Pooni, J., Ninteman, A., Bryant-Waugh, R., Nicholls, D., \& Mandy, W. (2012). Investigating autism spectrum disorder and autistic traits in early onset eating disorder. International Journal of Eating Disorders, 45, 583-591.

Pisetsky, E. M., Thornton, L. M., Lichtenstein, P., Pedersen, N. L., \& Bulik C. M. (2013). Suicide attempts in women with eating disorders. Journal of Abnormal Psychology, 122, 1042-1056.

Raevuori, A., Keski-Rahkonen, A., \& Hoek, H. W. (2014). A review of eating disorders in males. Current Opinion in Psychiatry, 27, 426-430

Richard, M., Bauer, S., \& Kordy, H. (2005). Relapse in Anorexia and Bulimia Nervosa-A 2.5-Year Follow-Up Study. European Eating Disorders Review, 13,180-190.

Roberts, G., \& Wolfson, P. (2004) The rediscovery of recovery: Open to all. Advances in Psychiatric Treatment, 10, 37-49.

Robinson P. H., Kukucksa R., Guidetti, G., \& Leavey, G. (2015). Severe and Enduring Anorexia Nervosa (SEEDAN): Qualitative Study of Patients with 20+ Years of Anorexia Nervosa. European Eating Disorders Review, 23, 318-326.

Schmidt U, Wade TD, \& Treasure J. (2014). The Maudsley Model of Anorexia Nervosa Treatment for Adults (MANTRA): Development, key features and preliminary evidence. Journal of Cognitive Psychotherapy, 28, 48-71. doi.org/10.1891/0889-8391.28.1.48

Schmidt, U., Startup, H., \& Treasure, J. (2019). Therapy Workbookfor Treating Anorexia Nervosa: The Maudsley Model. Routledge.

Schmidt, U., Adan, R., Böhm, I., Campbell, I. C., Dingemans, A., Ehrlich, S., Elzakkers, I., Favaro, A., Giel, K., Harrison, A., Himmerich, H., Hoek, H. W., Herpertz-Dahlmann, B., Kas, M. J., Seitz, J., Smeets, P., Sternheim L., Tenconi, E., van Elburg, A., ... Zipfel, S. (2016). Eating Disorders: the big issue. The Lancet, 3, 313-315.

Serpell, L., Livingstone, A., Neiderman, M., \& Lask, B. (2002). Anorexia nervosa: obsessive-compulsive
disorder obsessive-compulsive personality disorder or neither? Clinical Psychology Review, $22,647-669$

Slade, M., Amering, M., Farkas, M., Hamilton, B., O'Hagan, M., Panther, G., Perkins, R., Shephert, G., Tse, S., \& Whitley, R. (2014). Uses and abuses of recovery: implementing recovery-orientated practices in mental health systems. World Psychiatry, 13, 12-20.

Smink, F. R., van Hoeken, D., \& Hoek, H. W. (2013). Epidemiology, course, and outcome of eating disorders. Current Opinion in Psychiatry, 26(6), 543-548.

Smink F. R. E., van Hoeken D., Donker G. A., Susser E. S., Oldehinkel, A. J., \& Hoek, H. W. (2016). Three decades of eating disorders in Dutch primary care: decreasing incidence of bulimia nervosa but not of anorexia nervosa. Psychological Medicine, 46, $1189-1196$ doi:10.1017/5003329171500272X

Steinhausen H. C. (2002). The Outcome of Anorexia Nervosa in the 20th Century. American Journal of Psychiatry, 159, 1284-1293.

Steinhausen, H. C. (2009). Outcome of eating disorders. Child and adolescent psychiatric clinics of North America, 18, 225-242.

Støving, R. K., Andries, A., Brixen, K., Billenberg, N., \& Hørder, K. (2011). Gender differences in outcome of eating disorders: a retrospective cohort study. Psychiatry Research, 186, 362-366.

Strober, M., Freeman, R., \& Morrell, W. (1997). The long-term course of severe anorexia nervosa in adolescents: survival analysis of recovery, relapse, and outcome predictors over 10-15 years in a prospective study. International Journal of Eating Disorders, 22, 339-360.
Treasure, I., Zipfel, S., Micali, N., Wade, T., Stice, E., Claudino, A. Schmidt, U., Frank, G. K., Bulik, C. M., \& Wentz, E. (2015). Anorexia nervosa. Nature Reviews, Disease Primers, published online, 15074. doi: 10.1038 nrdp.2015.4

.

van den Berg, E., Houtzager, L., de Vos, J., Daemen, I., Katsaragaki, G., Karyotaki, E., Cuijpers, P., \& Dekker, (2019). Meta-analysis on the efficacy of psychological treatments for anorexia nervosa. European Eating Disorders Review, 27(4), 331-351. doi: org/10.1002/erv.2683

Wonderlich, S.A., Bulik, C.M., Schmidt, U., Steiger, H., \& Hoek H. W. (2020). Severe and Enduring Anorexia Nervosa: Update and Observations about the Current Clinical Reality. International Journal of Eating Disorders, online ahead of print. doi: 10.1002/eat.23283

Zerwas, S, Lund, B.C., Von Holle, A., Thornton, L.M., Berrettini, W.H., Brandt, H., Crawford, S., Fichter, M. M Halmi, K. A., Johnson, C., Kaplan, A. S., La Via, M., Mitchell, J., Rotondo, A., Strober, M., Woodside, D. B. Kaye, W. H., \& Bulik, C. M. (2013). Factors associated with recovery from anorexia nervosa. Journal of Psychiatric research, 47(7), 972-979. doi: 10.1016/j.jpsychires.2013.02.011 
The Anorexia Relapse Prevention Guidelines: A case report.

Berends, T.', van Meijel, B. ${ }^{2,3,4}$, \& van Elburg, A.,.$^{1,5}$

' Altrecht Eating Disorders Rintveld, Altrecht Mental Health Institute, Zeist, The Netherlands 2 INholland University for Applied Sciences, Amsterdam, The Netherlands

${ }^{3}$ Amsterdam UMC (loc VUmc), Amsterdam, The Netherlands

${ }^{4}$ Parnassia Psychiatric Institute, The Hague, The Netherlands

${ }^{5}$ Department of Social Sciences, Utrecht University, Utrecht, The Netherlands

${ }^{6}$ Utrecht Research Group Eating Disorders, Utrecht, The Netherlands

Perspectives in Psychiatric Care, 2012, 48(3), 149-155.

Acknowledgement of author contributions:

The manuscript has been written in cooperation between all authors, with the first author taking the lead. 


\section{Introduction}

Anorexia nervosa is a serious psychiatric disorder which can be defined as a person's refusal to maintain body weight at or above a minimally normal weight for age and height (APA, 2001). Anorexia patients are often extremely underweight, and both their physical and psychosocial functioning are under serious threat as a result of the disorder. Anorexia nervosa predominantly affects girls and young women. The largest group at risk are teenagers aged 15 to 19.

The state of the art in the treatment of anorexia nervosa has been documented in various guidelines (The Dutch Committee for the Development of Multidisciplinary Guidelines in Mental Health Care, 2006; the American Psychiatric Association, 2006). Generally, the focus of treatment is on the patient's eating habits, body weight, and body image, although the impact of psychological problems, such as lack of selfesteem, perfectionism, traumas, as well as problems with fitting into the system or functioning in society, is also given due consideration.

Despite the treatment offered, however, the risk of relapse remains considerable. An estimated $30-50 \%$ of all in-patients successfully treated for their eating disorders relapse (Pike, 1998), especially during the first two years after their discharge from the clinic (Strober et al., 1997; Carter et al., 2004). Carter et al. (2004) conducted a survival analyses among 51 weight restored AN patients and concluded that the risk of relapse is highest from 6 to 17 months after discharge. The risk of relapse diminished with time and reduced to virtually zero after 18 months.

Relapse is defined in this context as the recurrence of a number of diagnostic key symptoms following an initial positive response to treatment (Pike, 1998; Berends et al., 2010). The key symptoms in question are:

(1) Weight loss leading to an BMI below 18.5 or to body weight less than $85 \%$ of that expected;

(2) Tighter food intake restrictions resulting in weight loss

(3) Increase in behavioural symptoms such as over-evaluating body weight and body shape;

(4) Increase in compensatory behaviour, e.g. self-induced vomiting, misuse of laxatives, diuretics, or enemas, binge-eating;

(5) Cessation or disturbance of menstrual cycles (if restored during the earlier stages of recovery);

6) Onset of medical problems connected with the eating disorder, for example, hypotension, bradycardia, hair loss, cold hands and feet, and dizziness.
As is evident from available guidelines, there is general consensus that relapse prevention in the target group of anorexia patients is a matter of essence. Even so, however, there is not much practical information available about how to structure preventative actions in nursing practice. This is why we have developed the Anorexia Relapse Prevention Guidelines, a scientifically based tool for nurses to approach relapse prevention in a structu

This article describes the mechanisms of the Anorexia Relapse Prevention Guideline in the form of a case report. As a preface, the main characteristics of the Guideline will be briefly explained first.

\section{The Anorexia Relapse Prevention Guideline}

The Guideline is made up of three parts: (1) a theoretic framework for relapse and relapse prevention, developed on the basis of both the literature and practical experience of experts, including a number of conclusions and recommendations; (2) a practical manual for nurses; and (3) a workbook for patients. The task of the nurses in this context is to use the practical manual and the workbook to draw up a Relapse Prevention Plan in close collaboration with the patient. An overview of the Guideline is provided in table 1.

\section{Guideline Overview}

General information about relapse and relapse prevention

Inventory of strengths of the patient

inventory of risk factors

Describing potential triggers

Describing early warning signs

Cescribing preventive oc

Choosing auxiliaries

Drawing up the Relapse Prevention Plan

Table 1: Guideline overview

An essential aim of the relapse prevention methodology is that nurse, patient and their family work together to gain a better understanding of a patient's individua process of relapse. To achieve that aim, a number of steps must be taken: firstly, a joint evaluation of the relapse riskfactors that apply; secondly, an inventory of specific factors in everyday life that trigger anorexic thoughts and behaviour (triggers) and that may mark the beginning of a process of relapse; thirdly, a detailed specification of individual early warning signs, such as feelings, thoughts, behaviour and body signs warning against the onset of a relapse. The essence of the relapse prevention 
strategy is to ensure that action is taken as early as possible at the recognition of early warning signs. The sooner action is taken, the lower the damage will be and the quicker the patient will recover.

The process can be illustrated as follows in figure 1.

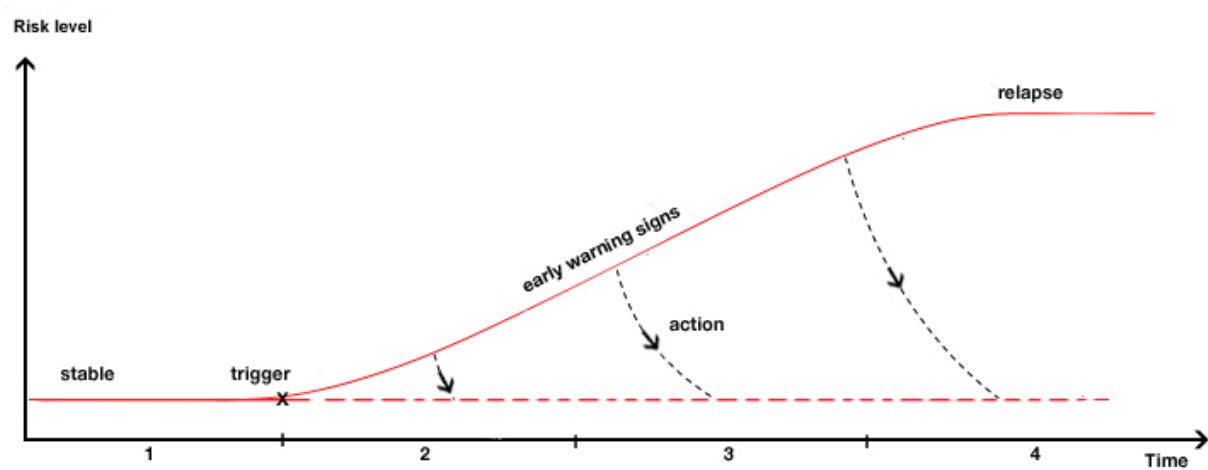

Figure 1: Process of relapse

The process of relapse can be sub-divided into four phases:

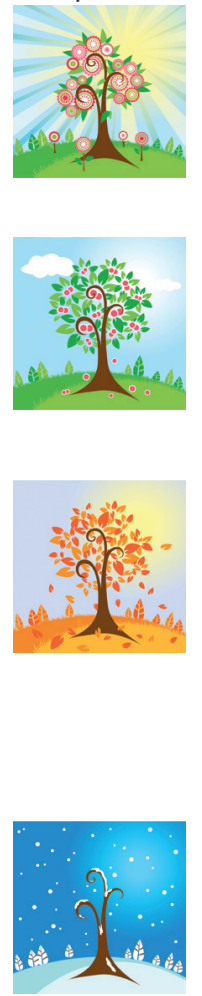

Phase 1: Stable: the patient is able to maintain a body weight commensurate with her age and height; the patient functions well at home and in society and although the patient may have anorexic thoughts, she does not act upon them

Phase 2: Mild relapse: anorexic thoughts intensify and the patient occasionally shows signs of behaviour indicating the recurrence of the eating disorder, e.g. by occasionally choosing 'safe' products or not eating between-meal snacks.

Phase 3: Moderate relapse: anorexic thoughts take the upper hand and the patient increasingly acts on those thoughts by starting to eat less, exercise more, or exhibit purging behaviour (vomiting, use of laxatives); the patient's behaviour is visible to the outside world, to some extent at least, and she starts to lose weight.

Phase 4: Full relapse: the patient's body weight drops below $85 \%$ of that expected, and she ceases to menstruate; anorexic thoughts dominate the patient continuously, she withdraws from her family and friends, and engages in purging behaviour.
Treatment of AN is a multidisciplinary matter, as is the use of relapse prevention strategies. The nurse who has a close and intensive professional relationship with the patient, is in the most favorable position to work effectively with the patient and her relatives on relapse prevention. However, good coordination and communication with the other members of the multidisciplinary team is of paramount importance.

Drawing up a fully-fledged relapse prevention plan requires approximately 6 meetings between patient and nurse. Initial practical experience with the Guideline showed that individual sessions should last approximately 45 minutes and should preferably be scheduled every other week. After each session, the patients were given homework which they had to make either individually or together with people close to them. The Guideline is suitable for use with inpatients, outpatients, and daycare patients.

\section{Case Report ${ }^{1}$}

Susan is a young woman of 21 years who has been diagnosed with anorexia nervosa. She lives at home with her parents and a sister. In October 2007, when she was 17 , Susan first started to have eating problems. She ate less and began to lose weight. When her mother forbade her to ride her bike to school every day (a distance of 35 kilometres), she started to eat even less in order to achieve the desired loss of body weight. In December, her general practitioner referred her to a centre for mental health care. After the first intake, the centre informed her that they were unable to treat her for lack of time. Susan's parents eventually took her to a dietician. After 4 sessions, however, her somatic condition had deteriorated to such an extent that the general practitioner referred her to a paediatrician. She was immediately sent to a general hospital for a week in order to be tube-fed. After that, Susan was referred to a specialist clinic for eating disorders.

Having successfully received treatment in the specialist clinic as an inpatient for a period of 5 months plus additional day-care treatment for 8 months, Susan was discharged. Both she and her parents were very satisfied with the treatment program followed.

However, things went wrong during the first summer holiday. Abandonment of the tightly structured eating schedule and a confrontation with unfamiliar foods during the holiday period caused a relapse. Susan lost 5 kilos, and her dread of eating and

Note: To protect the privacy of the patient, the patient information has been slightly altered in this case report, without this having any effect on the essence of the report 
fear of body gain resurfaced with vigour. Her parents brought Susan back to the specialist clinic for eating disorders, where she was admitted immediately. After a brief period of clinical treatment combined with dietetic counselling and cognitive behavioural therapy, she received follow-up treatment in the clinic's day-care facility. During the latter period, Susan started to work on a relapse prevention plan. It took 6 sessions to complete the plan.

\section{Relapse Prevention Plan}

\section{First Session}

The first session was attended by Susan and her parents. In order for a relapse prevention plan to be successful, both the patient and her parents (or other parties directly involved) need to be willing and motivated to cooperate. Susan and her parents received information on the risk of relapse and the importance of prevention. They were also shown how a relapse prevention plan could help reduce the risk of relapse.

Specific examples were given to explain to them the principles of early recognition and early intervention. Susan and her parents were then able to recall triggers, early warning signs and helpful interventions from their own experience. Possible ways to intervene that were taught during treatment were discussed and analysed. Susan indicated that distractions, such as writing in her diary, had helped her during difficult times and that she had always found it very comforting when other people assumed responsibility for her eating and exercising patterns and gave her instructions on how to change her behaviour.

The next step during this first session was to identify Susan's strengths. Patients sometimes find it difficult to emphasise their strengths (as opposed to their weaknesses), but the strong points in a patient's personality and functioning are very important to the process of preventing an imminent relapse. The patient's inner power must be fostered to that end. One of Susan's strengths was the ease with which she connected to other people. Another strength was her persistence in achieving her goals. All relevant information collected in this first session was recorded in the workbook, which was given to Susan to take back home.

\section{Second session}

The second session was used to work with Susan on identifying all relevant relapse risk factors. Potential risk factors are known from the literature and are regarded as having predictive value (see table 2). A translation of the general risk factors to Susan's specific situation was to contribute to a realistic assessment of her actual exposure to the onset of a relapse. In Susan's workbook, risk factors 1,3 and 4 were given specific consideration.
Table 2: Relapse risk factors

\section{Potential relapse risk factors}

1) Anorexic thoughts about body weight and body image at the time of discharge (Pike 1998: Carter et ol 2004. Keel et al .2005; Federici \& Kaplan, 2007)

Compulsive urge to exercise at the time of discharge (Strober et al. 1997: Carter et al. 2004: Federici \& Kaplan, 2007) Prolonged disorder/ earlier treatment (Carter et al. 2004)

4) Low psychosocial level of functioning (Keel et al.. 2005). which is defined as the inability of a patien to deal with psychosocia

The next step in the process was to identify and analyse relevant triggers, i.e. factors (usually in the patient's direct environment) which can trigger behaviour typical of an eating disorder and, therefore, increase the risk of a relapse. The origin of Susan's eating disorder and her first relapse were discussed to that end. The following triggering factors were recorded in the workbook: 'going away on holiday', 'loss of structure surrounding daily meals' and 'unfamiliar foreign foods'. In Susan's view, these factors had been mostly responsible for the fact that she had been unable to adhere to her healthy eating patterns. As homework, Susan was asked to look ahead 6 months (together with her parents) and identify the most difficult events that were likely to occur during that period. The idea was that, by looking ahead, Susan would be able to prepare for those situations.

\section{Third Session}

The third session started with an evaluation of the homework. Susan had described 3 potential triggers for the next 6 months:

1. Independent living: this was a trigger because it meant that she would have to provide for herself;

2. Falling ill (influenza): Susan generally went down with flu in the autumn; she did not feel like eating much at such times and immediately lost weight; after recovery, she always had trouble re-establishing a healthy eating pattern;

3. Reduced body weight control after treatment: this made Susan insecure because she found it difficult to assess weight stability.

These triggers were noted in the workbook.

After that, the early warning signs were identified and worked out in greater detail. Early warning signs can be described as feelings, thoughts, behaviour, and body signs which precede the onset of a relapse and should accordingly be treated as a warning that a relapse may occur. 
In the workbook, 5 categories of early warning signs were distinguished, described in the first person to create 'aha' moments of recognition in the patient:

Eating pattern (I'm going to throw away my lunch)

2. Physical symptoms (My hands and feet are getting cold)

3. Exercising (I'll bike really fast when I'm going somewhere)

4. Cognition (I worry more and more about how I look and whether others appreciate me)

5. Social functioning (l've stopped seeing my friends)

To identify relevant warning signs, Susan was asked to reflect on the beginning of her eating disorder as well as the relapse she had suffered. She experienced this process of reflection as highly confrontational and emotional, which showed how stressful this period had been for her. During these previous episodes she had told many lies about her eating and exercise pattern. This provoked many feelings of guilt. But above all she had felt very sick and weak, with many somatic complaints and depressed mood. These experiences contributed to Susan's strong motivation not to relapse again.

At the end of this session, Susan was instructed to sit with her parents and identify possible other early warning signs. She was also asked to work out all warning signs in greater detail and fit them into the 4 relapse phases described above.

\section{Fourth session}

The fourth session again started with an evaluation of the homework. Susan's parents had been able to add a number of other early warning signs. They described, for example, how Susan tended to cut her bread in tiny pieces and spread the pieces out over her plate when she was in phase 3 of the process of relapse. Susan had been unaware of this fact. The analysis of the early warning signs was successful: Susan was capable of allocating the various warning signs to the different relapse phases.

The remainder of the fourth session was spent on developing possible actions to prevent an imminent relapse. The actions were divided into 2 groups: actions to respond to triggers and actions to respond to early warning signs.

First, the subject of potential triggers was addressed once more. For example, Susan's consistent and immediate response to any comment on her body was to eat less. She was, therefore, asked to think about alternative ways to respond, without relapsing into the eating disorder. How, for instance, did her friends respond in similar situations? All triggers were addressed in this way and appropriate actions were described. Susan discovered that she generally acted in one of the following ways when being confronted with a trigger: (1) find a distraction by going for a stroll, (2) talk to her mother or a friend, (3) write in her diary, or (4) think positively to counter her negative feelings.

Secondly, the subject of early warning signs and possible actions to respond to those signs were discussed in greater detail. One of the issues addressed was that Susan's ability to take responsibility for her own health diminished as the process of relapse evolved. It was important, therefore, that others took over at least some of that responsibility in such situations, and that Susan was offered a tightly structured environment to prevent a further relapse.

The following actions were defined, all of which pertained to her eating pattern:

Phase 1 (stable): I'll stick to a varied diet.

Phase 2: I'll return to a tight structure of meals.

Phase 3 I'll follow the dietician's nutritional advice to the letter.

Phase 4: l'll eat under the supervision of my parents, or one of them.

All actions were noted in the workbook.

After all possible actions were defined, a search was launched for "auxiliaries" people who would be able to help Susan recognise triggers, early warning signs and prevent a relapse through early intervention. The availability of "auxiliaries" was essential because Susan tended to rely solely on herself in finding solutions to her problems. She had learned from the past that it was very difficult for her to admit to herself or to others that she was having problems. Together with Susan, efforts were made to recruit both 'active' and 'passive' auxiliaries. Active auxiliaries were people she felt close to and people whom she could comfortably turn to for help and support. Active support was marked by a two-way communication system: Susan could take the initiative in seeking help, but active auxiliaries would also be permitted to confront Susan with her eating patterns whenever they observed increased symptoms of the eating disorder. Passive auxiliaries were people whom Susan could approach if she needed support or, in other words, who would be there when Susan needed them. In Susan's case, her mother was listed as an active auxiliary and her father as a passive auxiliary. Susan preferred not to involve outside people: she knew no other adult person who she felt was close enough to support her as a formal auxiliary; and she did not want to discuss the relapse prevention plan with her friends. To them, she wanted to be 'normal Susan'. 
At the end of the fourth session, after all items of the relapse prevention plan had been addressed, Susan's motivation to make use of the plan in future was given special attention. Potential setbacks were identified and analysed with a view to ensuring adherence to the relapse prevention plan in such adverse situations. In addition, emphasis was placed on the positive effects of having control over the eating disorder. Susan was asked to describe those positive effects as detailed as possible in the workbook. A few of the positive effects mentioned were: (1) the chance to enrol in a new study programme; (2) the ability to go out with friends without being inhibited by the eating disorder; and (3) healthy exercising.

\section{Fifth session}

In the fifth session, all items and issues discussed and worked out were combined into one encompassing relapse prevention plan. Such a plan generally consists of only 1 page on which all triggers are listed, as well as the early warning signs by phase and the proposed response actions. See table 3 for more details on Susan's relapse prevention plan. Specific agreements were made about the method of implementation, the persons to be involved, and the tasks to be assigned to each person

\section{Sixth session}

The sixth and final session was a joint meeting between the nurse, Susan, and her parents to discuss all details of the relapse prevention plan once again and document the responsibilities expected of all people involved. This feedback process proved to be very difficult to Susan, as she was asked to be completely open about many aspects of her eating disorder which she had kept hidden from her family and friends until then. Susan's parents stated that the clear actions described in the plan might give them a good foothold to overcome obstacles. They felt that they now had a tool to intervene and prevent a serious relapse, especially at times when Susan denied having a relapse, out of embarrassment or fear.
Table 3: Relapse Prevention Plan

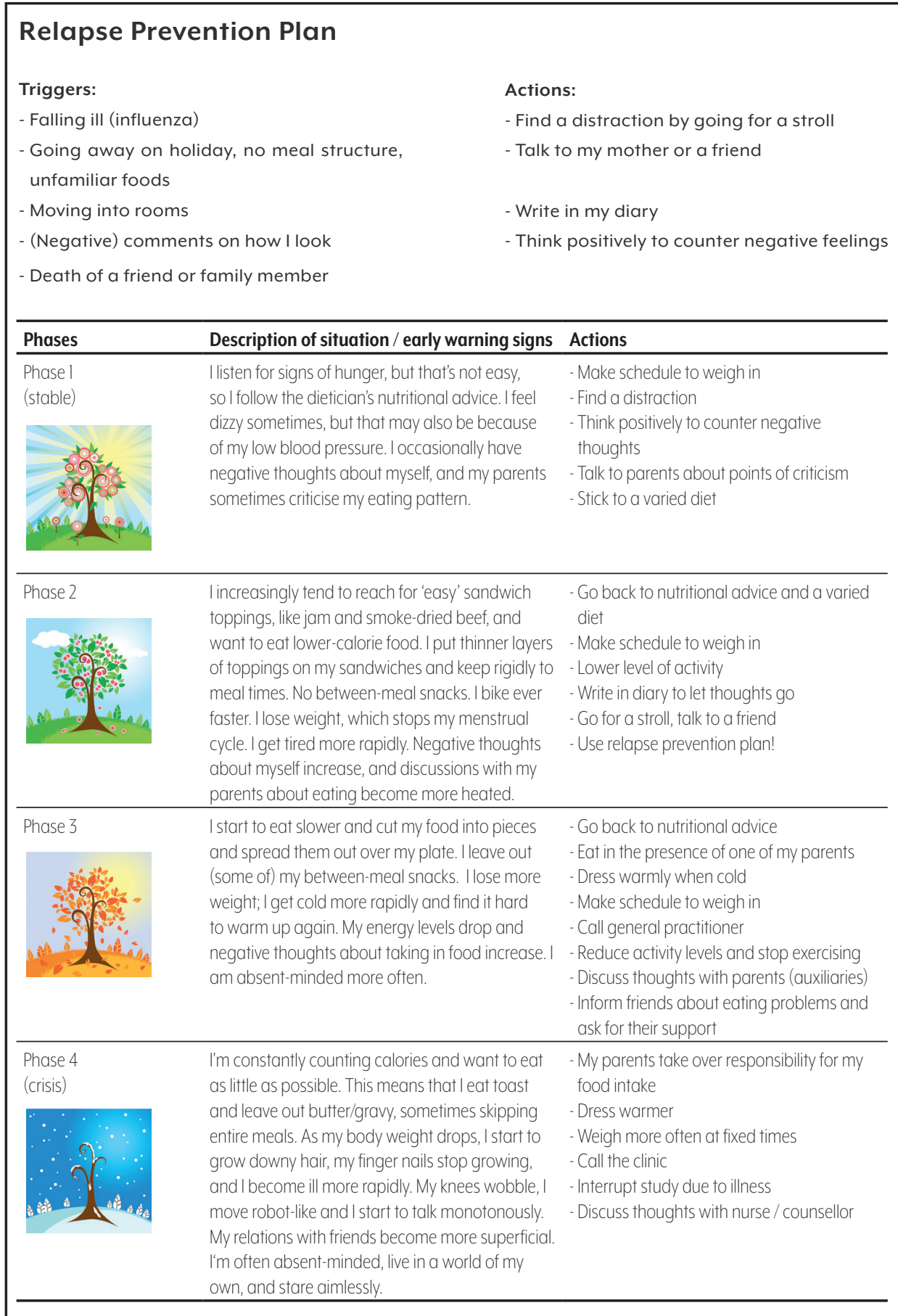




\section{Follow-up}

After completion of the relapse prevention plan, Susan was placed in an after-care programme. She was invited to follow-up meetings, with fairly long intervals, in order to assess her situation on the basis of the relapse prevention plan. The first follow-up meeting took place after 3 months. Susan told that everything went well and that she had been able to maintain a stable body weight. She and her mother had sat down to discuss her situation every two weeks. At first, it had been difficult to talk about the relapse prevention plan. Susan's mother had not really known what questions to ask, and Susan had found it difficult to be open as she was afraid that her mother would start to check on her again. However, as they continued their talks, they had gradually established a relationship of trust and improved their communication with each other.

The relapse prevention plan was re-evaluated and adjusted on some points on the basis of recent experiences. Again, potentially stressful situations arising in the nearby future were taken into consideration, including the start of her new study programme, which she dreaded and regarded as a possible trigger for a relapse. It was agreed that she should strictly adhere to mealtimes and food quantities during the relevant weeks. This procedure should be sufficient for Susan to prepare for the months ahead of her.

\section{Discussion}

The purpose of this case report is to illustrate how the Relapse Prevention Guideline can be used in nursing practice. Working with this Guideline has proven to have a number of advantages, not only for the patient, but also for her parents and the nurse.

The Guideline provides an effective tool for relapse prevention: they ease the suffering of both the patient and her parents; they are conducive to the patients' psychosocial recovery process; and they contribute to the cost-effectiveness of treatment and care. Furthermore, the Guideline encourages open communication during the process of writing the relapse prevention plan, which helps the patient to accept her own situation. Matters pertaining to the eating disorder are deliberately made explicit, which makes it impossible for patients to continue their strategy of denial and also helps them cope with the feelings of sorrow and loss that are inherent in persons who suffer from a very serious eating disorder.
By working on relapse prevention, patients no longer feel that a relapse is something that just befalls them. They gain a better understanding of the relapse process, and that enables them to change the course of the process and move towards recovery. The active involvement of the patient and her parents also improves the patient's capability of self-management and enhances communications between the patient and her parents. The relapse prevention plan allocates clear tasks to the various parties involved and defines where the responsibility of the patient and each of her parents and counsellors begins or ends. This, in turn, provides reassurance and reduces the level of (over)protectiveness of the parents.

\section{Implications for Nursing Practice}

For anorexia counselling nurses, the Guideline offers a way to give effect to a wellstructured professional procedure which is expected to yield a clear health benefit for the patient. The Guideline fills an obvious gap in nursing practice: although it is clear from both the literature and nursing practice that relapse prevention in anorexia patients is of the essence, our previously conducted literature review during the preparation stage of guideline development revealed no structured relapse prevention methods for patients with anorexia nervosa. Because of their close and intensive professional relationship with the anorexia patients, nurses are in a very good position to work with anorexia patients on establishing a relapse prevention plan.

One of the essential conditions for an effective use of the Guideline is that the patient must be intrinsically motivated to prevent any future relapse. Consequently, the patient's motivation should be evaluated regularly in order to determine whether measures must be taken to boost that inner motivation. Nurses should take precautions to ensure at all times that their reliance on a patient's motivation is firmly based on reality. Use of the Guideline requires specific skills: motivating patients and removing resistance are activities that demand advanced nursing competencies. Only nurses who have built up ample working experience with the target group are sufficiently skilled in providing good nursing care and avoiding the pitfalls of socially desirable responding. Moreover, use of the Guideline presupposes a great deal of methodical and analytical skills. All of this means that additional training will be necessary for nurses to make effective use of the Guideline.

It is evident from practical experience that the Guideline are highly suitable as a too to work with anorexia patient on the prevention of potential relapses, but further scientific research will be required to establish the effectiveness of that tool. 


\section{References}

American Psychiatric Association. (2001). Diagnostic and Statistical Manual of Mental Disorders DSM-IV-TR Fourth Edition. APA.

American Psychiatric Association. (2006). Practice Guideline: Treatment of patients with eating disorders. APA Berends, T., van Meijel, B., \& van Elburg, A. (2010). Anorexia Relapse Prevention Guidelines. Koninklijke Van Gorcum.

Carter, J. C., Blackmore, E., Sutandar-Pinnock, K., \& Woodside, D. B. (2004). Relapse in anorexia nervosa: a survival analysis. Psychological Medicine, 34, 671-679.

Dutch Committee for the Development of Multidisciplinary Guidelines in Mental Health Care. (2006). Multidisciplinary Guidelines Eating Disorders. Utrecht The Netherlands: Trimbos Institute.

Federici, A., \& Kaplan, A. S. (2007). The Patient's Account of Relapse and Recovery in Anorexia Nervosa: A Qualitative Study. European Eating Disorders Review, 16, 1-10.

Keel, P. K., Dorer, D. J., Franko, D. L., Jackson, S. C., \& Herzog, D. B. (2005). Postremission predictors of relapse in women with eating disorders. American Journal of Psychiatry, 162, 2263-2268.

Pike, K. M. (1998). Long-term course of anorexia nervosa: response, relapse, remission, and recovery. Clinical Psychological Review, 18, 447-475.

Strober, M., Freeman, R., \& Morrell, W. (1997). The long-term course of severe anorexia nervosa in adolescents: survival analysis of recovery, relapse, and outcome predictors over 10-15 years in a prospective study. International Journal of Eating Disorders, 22, 339-360. 


\section{Abstract}

\section{Purpose of review}

Relapse is common in patients with anorexia nervosa (AN). The aim of this study is to systematically review the existing literature on relapse in AN.

\section{Recent findings}

A systematic literature search was conducted in PubMed, Psychlnfo and CINAHL published up to April 2018. Of the 1527 studies screened, 16 studies were included in the present review.

\section{Summary}

This analysis shows that, of the patients included in this review, 31\% relapsed after treatment. The highest risk of relapse is during the first year after discharge and this risk continues for up to two years. An overview was made of all factors significantly associated with a higher risk of relapse, resulting in the following four clusters: eating disorder variables, comorbidity symptoms, process treatment variables, and demographic variables. Future research on relapse prevention is necessary to further unravel the mechanisms that might lead to relapse.

\section{Keywords}

anorexia nervosa, relapse, rate, timing, predictors, risk factors

\section{Introduction}

Anorexia nervosa (AN) is a severe mental disorder with a lifetime prevalence among women of $2-4 \%$ (Keski-Rahkonen et al., 2007), whereas the prevalence among men is ten times lower (Raevouri et al., 2014). High mortality rates of $5 \%$ are reported (Arcelus et al., 2011). The overall incidence rate has remained stable over the past decades (i.e. 6.0 per 100,000), and the age-specific incidence is highest in the age group 15-19 years (Smink et al., 2016). It is estimated that $46 \%$ of the patients completely recover from AN, $34 \%$ improve partially with residual symptoms of AN, and $20 \%$ develop a chronic course of the disorder (Steinhausen, 2002).

Evidence-based clinical guidelines represent an important step toward dissemination and implementations of evidence-based treatments into clinical practice. Despite advances in clinical research on eating disorders, a growing body of literature demonstrates that individuals with eating disorders often do not receive an evidencebased treatment for their disorder (Hilbert et al., 2017). In leading guidelines in the field of eating disorders (American Psychiatric Association, 2006; Hay et al., 2014; National Institute for Health and Care Excellence, 2017) consensus exists that relapse of an eating disorder is a common phenomenon and relapse prevention is essential. However, a major problem is the lack of structured methods for relapse prevention to support professionals in clinical practice. Thus, there is a need for the developmen of sound, scientifically-based interventions that contribute to relapse prevention in this patient group.

In a 2017 review on relapse, remission and recovery in anorexia nervosa, Khalsa et al. provided a summary of the different definitions used and concluded that there is limited consensus about these definitions (Khalsa et al., 2017). They proposed a set of standardised criteria for relapse, recovery and remission for AN, which is internally consistent and can facilitate longitudinal assessment by clinicians and researchers. Besides the required use of unambiguous definitions, future intervention programs on relapse prevention should be based on existing scientific evidence, in particular with respect to rates of relapse (in different subpopulations), timing of relapse, and factors associated with relapse. With this knowledge, preventive strategies can be deployed at the right time and after appropriate treatment duration, with a focus on high-risk patient groups.

The present study aims to review the available scientific evidence on these topics, i.e. relapse rate, timing, and factors associated with relapse in AN. This overview of knowledge can form the basis for the development and testing of future relapse 
prevention programs for patients with $\mathrm{AN}$, and, thereby, contribute to better recovery and improved quality of life in patients treated for AN.

\section{Methods}

\section{Literature search}

This systematic review using the PRISMA guidelines was conducted in 2016 and updated in March 2018 to include latest published articles. Relevant articles were identified through a search in the following electronic databases of PubMed, PsychINFO and CINAHL, which was performed in close collaboration with an experienced librarian. Databases were searched combining the terms 'Anorexia Nervosa' with 'Relapse', as well as their relevant synonyms.

\section{Data extractions and quality assessment}

Figure 1 presents the selection procedure. English language papers focusing on anorexia nervosa with relapse as a primary outcome, measured using a clear definition, were considered for inclusion. After removing duplicates, the remaining papers were screened independently by two researchers based on title and abstract. Any disagreement between the reviewers was resolved through discussion. All disagreements were related to the decision as to whether the inclusion criteria were applicable. For example, a paper based on outcome mentioned relapse but did not present a clear definition of relapse. In such cases, the first author (TB) read the full text, after which follow-up discussion took place until consensus was reached. Papers fulfilling the inclusion criteria were considered for full-text review.

Excluded from this review were: i) studies with a sample size, $n<40$, ii) studies combining patients with anorexia nervosa and bulimia nervosa, and iii) studies using the same/duplicate study sample. The remaining studies were included in the qualitative analysis.

The standard quality assessment criteria for evaluating primary research papers from a variety of fields, as described by Kmet et al. (2004), were used to assess the methodological quality of the individual papers, using a standardised approach.

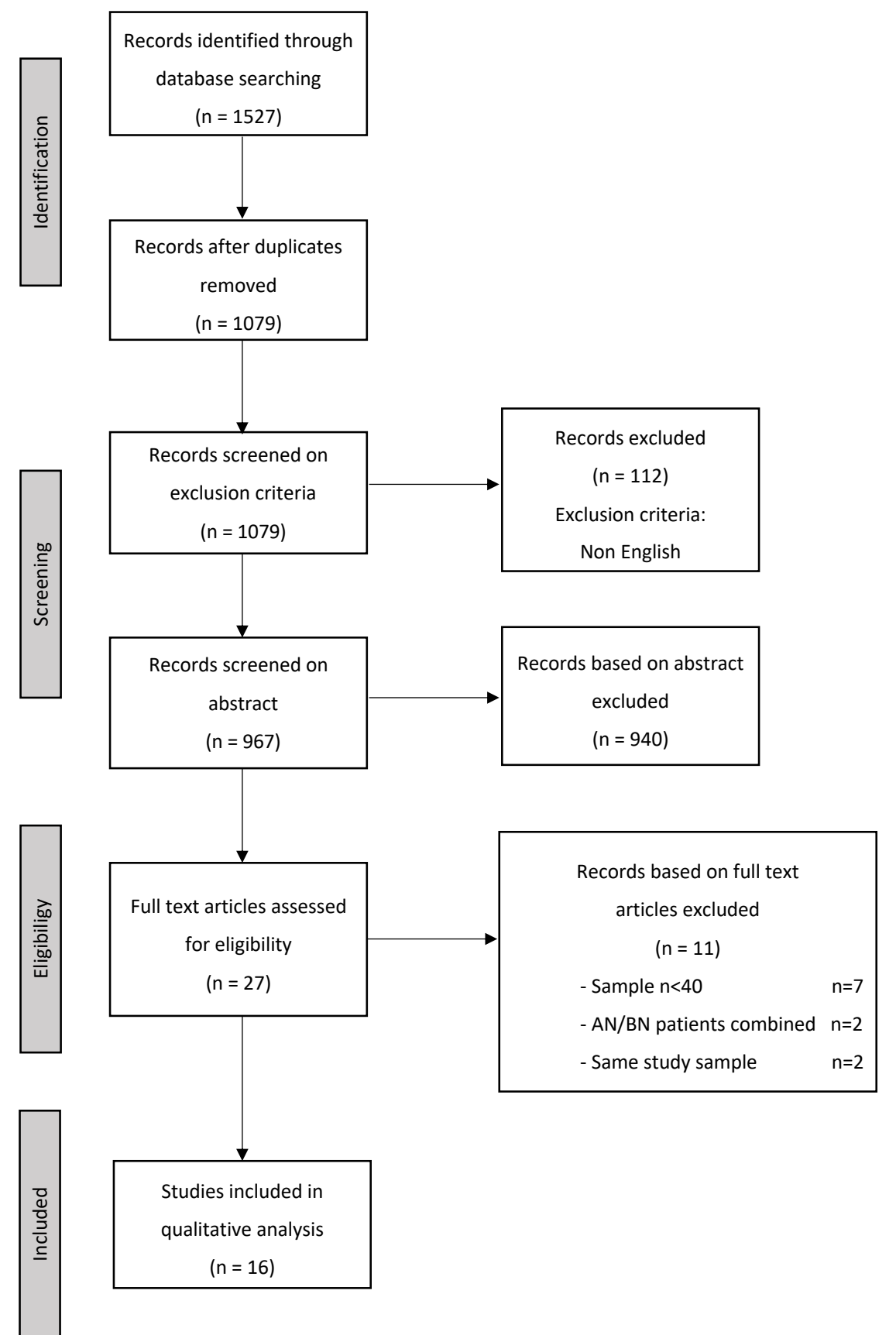

Figure 1. PRISMA flowchart, inclusion process. 


\section{Statistical analyses}

\section{Rate of relapse}

Assuming that the estimates differed between populations in the different studies, as well as the definitions and instruments used, a random effects model was used for meta-analysis. A meta-regression was performed to examine the influence of the mean age of participants on event rate magnitude. When results are compared in a meta-analysis, ideally, the studies are uniform in their use of protocols. However, since this was not the case for the present meta-analysis, study heterogeneity was examined and reported using the $\mathrm{Q}$ and $\mathrm{l}^{2}$ statistic (Higgins et al., 2003). The $\mathrm{I}^{2}$ ranges from $0 \%$ (no observed heterogeneity) to 100\% (high heterogeneity). Also, because publication bias can be a problem with meta-analyses, Egger's test was applied to identify such bias (Egger et al., 1997). All analyses were conducted using Comprehensive Meta-Analysis (Borenstein et al., 2005). A value of $0 \%$ indicates no observed heterogeneity and larger values show increasing heterogeneity.

\section{Factors associated with relapse}

The factors associated with relapse were extracted from each study and the list of factors was categorised into specific clusters, independently, by two researchers. Finally, through discussion, consensus on the clusters was reached.

\section{Results}

The initial search yielded 1527 articles (Figure 1); of these, 448 duplicates and 112 non-English language studies were excluded. After two independent reviewers had screened the remaining 967 abstracts, 27 articles remained after screening on title and abstract. After careful review, 16 articles (Avnon et al., 2017; Berends et al., 2016; Carter et al., 2004, 2012; Castellini et al., 2011; Deter \& Herzog, 1994; Eckert et al., 1995; Eddy et al., 2002; van Elburg et al., 2012; Helverskov et al., 2010; Herzog et al., 1999; Isager et al., 1985; Keel et al., 2005; Richard et al., 2005; Strober et al., 1997; Walsh et al., 2006) were included in the present qualitative analyses.

\section{Sample}

Sample characteristics of all included studies are presented in Table 1. All studies examined the rate of relapse in patients with anorexia nervosa and were included in the meta-analyses. Eight studies presented the period of occurrence of relapse and the period of the highest risk of relapse (Berends et al., 2016; Carter et al, 2004, 2012; Eckert et al., 1995; Herzog et al., 1999; Isager et al., 1985; Richard et al., 2005; Strober et al., 1997); eight studies also presented the factors associated with relapse

(Berends et al., 2016; Carter et al., 2004, 2012; Deter \& Herzog, 1994; Isager et al., 1985; Keel et al., 2005; Richard et al., 2005; Strober et al., 1997). The (mean) age of all participants ranged from 15.4-26.9 years. Studies were conducted in the USA (Eckert et al., 1995; Eddy et al., 2002; Herzog et al., 1999; Keel et al., 2005; Strober et al., 1997; Walsh et al., 2006), Canada (Carter et al., 2004, 2012; Walsh et al., 2006), Denmark (Helverskov et al., 2010; Isager et al., 1985), Germany (Deter \& Herzorg, 1994; Richard et al., 2005), the Netherlands (Berends et al., 2016; van Elburg et al., 2012), Italy (Castellini et al., 2011), and Israel (Avnon et al., 2017).

\section{Rate of relapse}

Figure 2 is a forest plot of the meta-analysis. The summary statistic shows that the overall estimated event rate equals $30.8 \%$ ( $\mathrm{Cl} 24.9 \%-37.5 \%, p<0.001)$. There was considerable heterogeneity between the studies $\left(Q(15)=92.15, p<0.001, I^{2}=84 \%\right)$. Meta regression shows that the mean age of participants had no influence on the magnitude of the event rate $(\beta=0.02, p=0.30)$. For this analysis, the study of Strober et al. (1997) was excluded because no mean age of participants was available. The Egger's test revealed a marginal indication of publication bias $(p=0.097)$. The nature of this bias is difficult to confirm because a relatively large proportion of the studies (i.e. 6 of 16) fall outside the confidence interval around the estimated effect given the standard error on the ordinate axis. There seems to be a counterintuitive

\section{Study name}

Avnon et al. (2017)
Berends et al. (2016)
Carter et al. (2004)
Carter et al. (2012)
Castellini et al. (2011)
Deter et al. (1994)
Eckert et al. (1995)
Eddy et al. (2002)
Elburg et al. (2012)
Helverskov et al. (2010)
Herzog et al. (1999)
Isager et al. (1985)
Keel et al. (2005)
Richard et al. (2005)
Strober et al. (1997)
Walsh et al. (2006)

Statistics for each study

Event Lower Upper

rate limit limit Z-Value $p$-Value

$\begin{array}{lllll}0,341 & 0,217 & 0,491 & -2,073 & 0,038\end{array}$ $\begin{array}{lllll}0,108 & 0,057 & 0,195 & -5,968 & 0,000\end{array}$ $\begin{array}{lllll}0,108 & 0,057 & 0,195 & -5,968 & 0,000 \\ 0,353 & 0,235 & 0,492 & -2,069 & 0,039\end{array}$ $\begin{array}{lllll}0,353 & 0,235 & 0,492 & -2,069 & 0,039 \\ 0,410 & 0,318 & 0,509 & -1,790 & 0,073\end{array}$ $\begin{array}{lllll}0,410 & 0,318 & 0,509 & -1,790 & 0,073 \\ 0,261 & 0,199 & 0,333 & -5,880 & 0,000\end{array}$ $\begin{array}{rrrrr}0,261 & 0,199 & 0,333 & -5,880 & 0,000 \\ 0,202 & 0,130 & 0,302 & -5,050 & 0,000\end{array}$ $\begin{array}{lllll}0,202 & 0,130 & 0,302 & -5,050 & 0,000\end{array}$ $\begin{array}{llllll}0,545 & 0,425 & 0,661 & 0,738 & 0,461\end{array}$ $\begin{array}{lllll}0,574 & 0,489 & 0,654 & 1,709 & 0,088\end{array}$ $\begin{array}{lllll}0,174 & 0,102 & 0,282 & -4,906 & 0,000\end{array}$ $\begin{array}{lllll}0,190 & 0,108 & 0,311 & -4,336 & 0,000\end{array}$ $\begin{array}{llllll}0,391 & 0,262 & 0,538 & -1,462 & 0,144\end{array}$ $\begin{array}{lllll}0,391 & 0,262 & 0,538 & -1,462 & 0,144 \\ 0,258 & 0,188 & 0,344 & -5,057 & 0,000\end{array}$ $\begin{array}{lllll}0,258 & 0,188 & 0,344 & -5,057 & 0,000 \\ 0,357 & 0,228 & 0,511 & -1,825 & 0,068\end{array}$ $\begin{array}{lllll}0,326 & 0,252 & 0,409 & -3,957 & 0,000\end{array}$ $\begin{array}{llllll}0,295 & 0,212 & 0,394 & -3,877 & 0,000\end{array}$ $\begin{array}{llllll}0,280 & 0,198 & 0,379 & -4,097 & 0,000\end{array}$ $\begin{array}{lllll}0,308 & 0,249 & 0,375 & -5,328 & 0,000\end{array}$

\section{Event rate and $95 \% \mathrm{Cl}$}

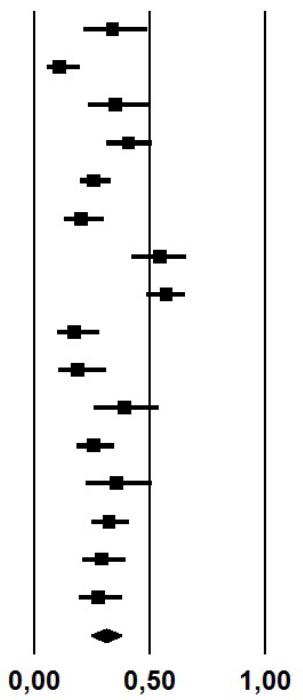

Figure 2. Forest plot of the meta-analysis of rate of relapse. 

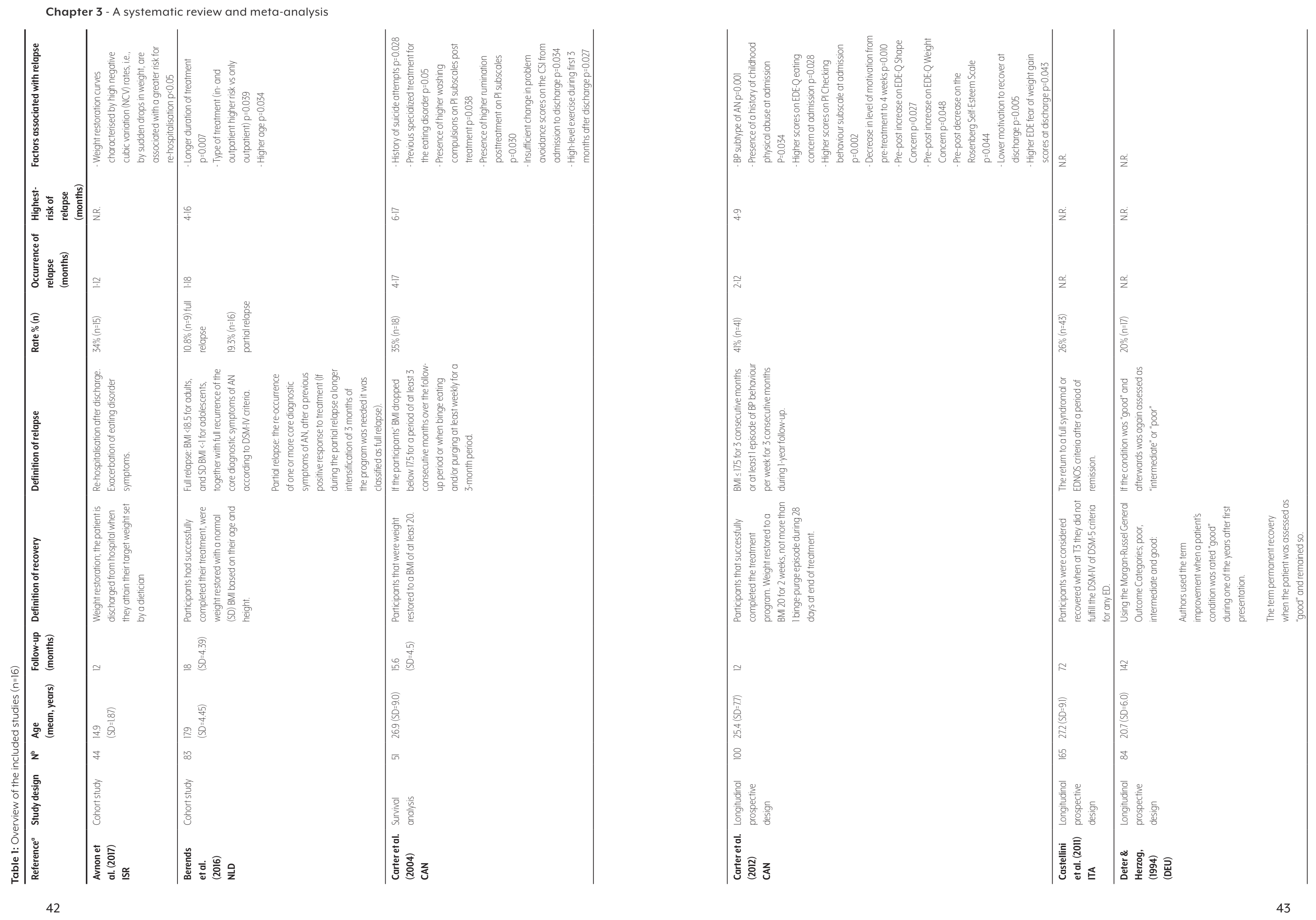

3 
Chapter 3 - A systematic review and meta-analysis
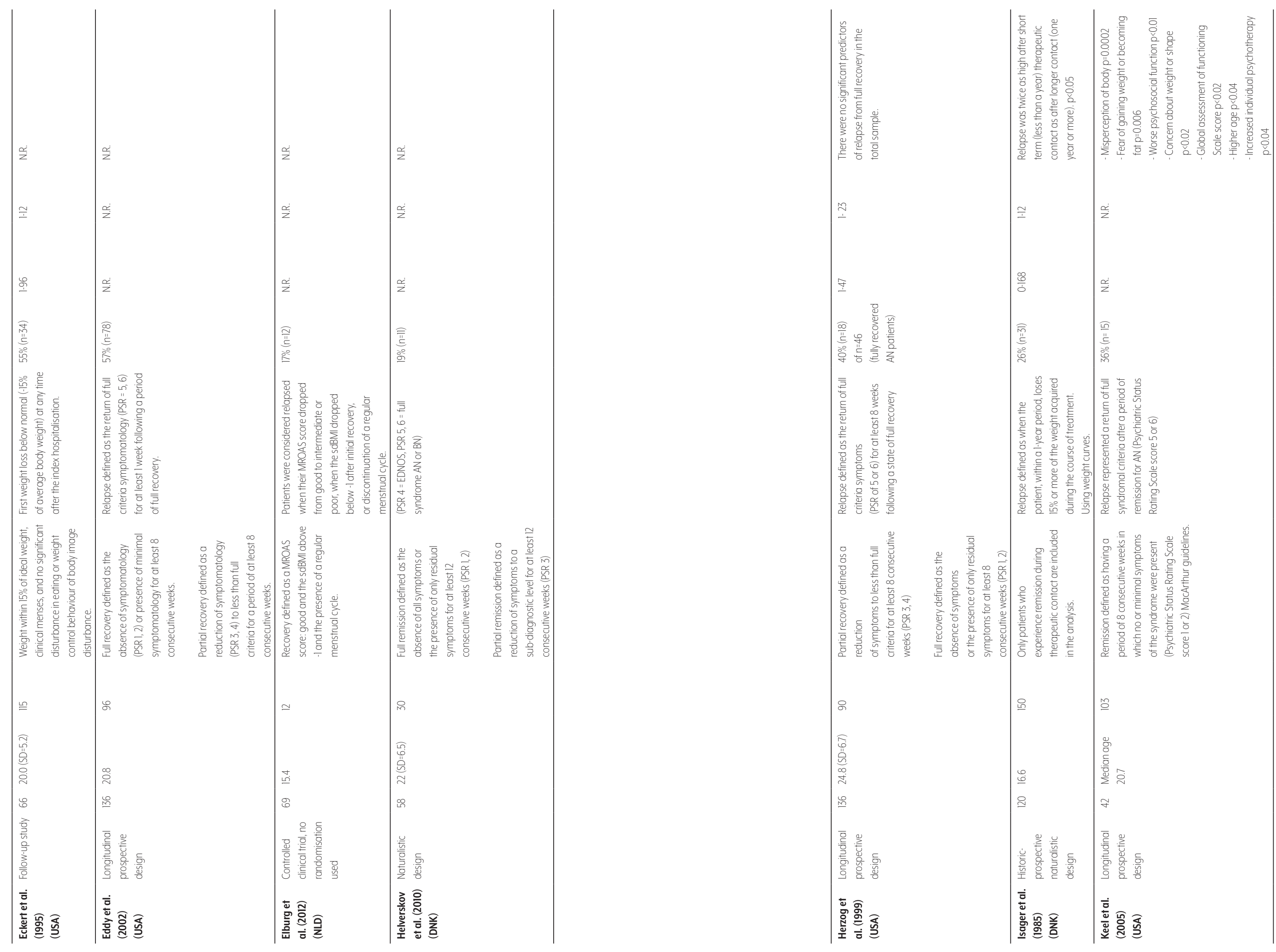
Chapter 3 - A systematic review and meta-analysis
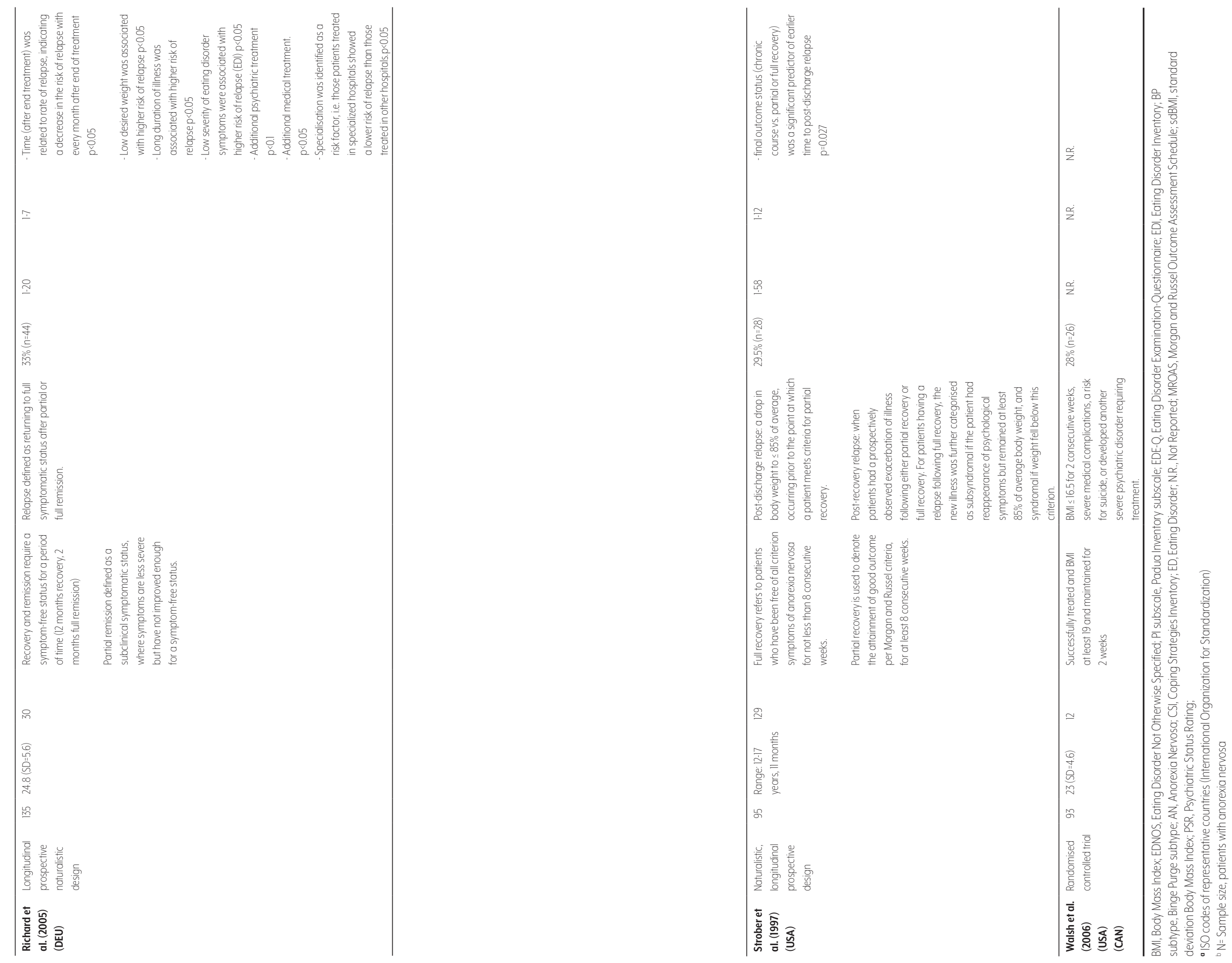
tendency for studies with low (logit) event rates to be published when there is low precision (or small sample size, indicated by a higher standard error), while higher (logit) event rates are more likely to be published when precision is higher.

\section{Timing of relapse}

Nine of the 16 studies reported the period of occurrence of relapse, with substantial variability in the duration of follow-up. Studies with a longer duration of follow-up, ranging from a (mean) follow-up of 30-265 months (Eckert et al., 1995; Herzog et al., 1997; Isager et al., 1985; Richard et al., 2005; Strober et al., 1997), reported an occurrence of relapse ranging from 1-168 months. Studies with a shorter duration of follow-up, ranging from a (mean) follow-up of 12-18 months, reported an occurrence of relapse ranging from 1-18 months (Avnon et al., 2017; Berends et al., 2016; Carter et al., 2004, 2012). However, in studies with both a shorter and longer follow-up, the highest risk of relapse was reported in the first year after discharge from treatment Carter et al., 2012; Eckert et al., 2002; Isager et al., 1985; Richard et al., 2005; Strober et al., 1997); moreover, some studies reported a high risk of relapse through to the second year after discharge, i.e. at 16 months (Berends et al., 2016), 17 months (Carter et al., 2004), and 23 months (Herzog et al., 1990).

\section{Factors associated with relapse}

Eight studies reported significant factors associated with relapse (Avnon et al., 2017; Berends et al., 2016; Carter et al., 2004, 2012; Isager et al., 1985; Keel et al., 2005; Richard et al., 2005; Strober et al. 1997). Since there was substantial variability on the procedures and instruments used to identify factors associated with relapse, there was also substantial variability in the factors found, which complicates the present analysis. Factors significantly associated with relapse were selected and, after consensus was reached, divided into four main clusters (Table 2): i) eating disorder variables, ii) comorbidity symptoms, iii) process treatment variables, iv) and demographic variables.

Table 2. Factors associated with relapse

\begin{tabular}{llll}
\hline Eating disorder variables: & Measure moment / timing of risk & p-value & References \\
\hline - Increase on EDE-Q Shape Concern & Pre-posttreatment & 0.027 & Carter et al., 2012 [18] \\
- Increase on EDE-Q Weight Concern & Pre-posttreatment & 0.048 & Carter et al., 2012 [18] \\
- Concern about weight or shape & After remission & 0.02 & Keel et al., 2005 [27] \\
- Fear of gaining weight or becoming fat & After remission & 0.006 & Keel et al., 2005 [27] \\
- Higher EDE fear of weight gain scores & At discharge & 0.043 & Carter et al., 2012 [18] \\
- Low desired weight & N.R. & $<0.05$ & Richard et al., 2005 [28] \\
- Misperception of body & After remission & 0.0002 & Keel et al., 2005 [27]
\end{tabular}

\begin{tabular}{|c|c|c|c|}
\hline Higher scores on EDE-Q eating concern & At admission & 0.028 & Carter et al., $2012[18]$ \\
\hline $\begin{array}{l}\text { Weight restoration curves characterised by } \\
\text { high NCV, i.e., by sudden drops in weight }\end{array}$ & During treatment & $<0.05$ & Avnon et al., 2017 [15] \\
\hline BP subtype of AN & At admission & 0.001 & Carter et al., 2012 [18] \\
\hline -High-level exercise & During first 3 months after discharge & 0.027 & Carter et al., $2004[17]$ \\
\hline $\begin{array}{l}\text { Low severity of eating disorder symptoms } \\
\text { (EDI) }\end{array}$ & N.R. & $<0.05$ & Richard et al., 2005 [28] \\
\hline \multicolumn{4}{|l|}{ Comorbidity symptoms: } \\
\hline $\begin{array}{l}\text { - Higher scores on PI Checking behaviour } \\
\text { subscale }\end{array}$ & At admission & 0.002 & Carter et al., $2012[18]$ \\
\hline $\begin{array}{l}\text { Higher discharge scores on Washing } \\
\text { compulsions (PI scale) }\end{array}$ & Posttreatment & 0.038 & Carter et al., $2004[17]$ \\
\hline $\begin{array}{l}\text { Higher discharge scores on Rumination (PI } \\
\text { scale) }\end{array}$ & Posttreatment & 0.030 & Carter et al., $2004[17]$ \\
\hline $\begin{array}{l}\text { - Insufficient change in problem avoidance } \\
\text { scores (CSI) }\end{array}$ & Pre-postreatment & 0.034 & Carter et al., 2004 [17] \\
\hline $\begin{array}{l}\text { - Decrease in level of motivation } \\
\text { - Lower motivation to recover }\end{array}$ & $\begin{array}{l}\text { Pre-treatment to } 4 \text { weeks } \\
\text { At discharge }\end{array}$ & $\begin{array}{l}0.010 \\
0.005\end{array}$ & $\begin{array}{l}\text { Carter et al., } 2012[18] \\
\text { Carter et al., } 2012 \text { [18] }\end{array}$ \\
\hline $\begin{array}{l}\text { Decrease on the Rosenberg Self- Esteem } \\
\text { Scale }\end{array}$ & Pre-posttreatment & 0.044 & Carter et al., 2012 [18] \\
\hline - Worse psychosocial function & After remission & 0.01 & Keel et al., 2005 [27] \\
\hline History of childhood physical abuse & At admission & 0.034 & Carter et al., 2012 [18] \\
\hline -History of suicide attempts & At admission & 0.028 & Carter et al., 2004 [17] \\
\hline $\begin{array}{l}\text { - Worse global assessment of functioning } \\
\text { scale scores }\end{array}$ & After remission & 0.02 & Keel et al., 2005 [27] \\
\hline \multicolumn{4}{|l|}{ Process treatment variables: } \\
\hline - Longer duration of treatment & At start affercare program & 0.007 & Berends et al., 2016 [16] \\
\hline $\begin{array}{l}\text { - Type of treatment (in- and outpatient higher } \\
\text { risk vs only outpatient) }\end{array}$ & Treatment process & 0.039 & Berends et al., 2016 [16] \\
\hline $\begin{array}{l}\text { - Previous specialized treatment for eating } \\
\text { disorder }\end{array}$ & At admission & 0.05 & Carter et al., $2004[17]$ \\
\hline $\begin{array}{l}\text { - Relapse twice as high after short term (less } \\
\text { than a year) therapeutic contact as after } \\
\text { longer contact (one year or more). }\end{array}$ & Treatment process & $<0.05$ & Isager et al., 1985 [26] \\
\hline - Increased individual psychotherapy & After remission & 0.04 & Keel et al., 2005 [27] \\
\hline - Additional psychiatric treatment & During follow-up & $<0.1$ & Richard et al., 2005 [28] \\
\hline - Additional medical treatment & During follow-up & $<0.05$ & Richard et al., 2005 [28] \\
\hline - Treatment in a non-specialized hospital & Treatment process & $<0.05$ & Richard et al., 2005 [28] \\
\hline \multicolumn{4}{|l|}{ Demographic variables: } \\
\hline Higher age & $\begin{array}{l}\text { After remission } \\
\text { At start aftercare program }\end{array}$ & $\begin{array}{l}0.04 \\
0.034\end{array}$ & $\begin{array}{l}\text { Keel et al., } 2005 \text { [27] } \\
\text { Berends, } 2016 \text { [16] }\end{array}$ \\
\hline - Long duration of illness & N.R. & $<0.05$ & Richard et al., 2005 [28] \\
\hline $\begin{array}{l}\text { - Final outcome status (chronic course vs. } \\
\text { partial or full recovery) }\end{array}$ & Post-discharge & 0.027 & Strober et al., 1997 [29] \\
\hline
\end{tabular}

DE-Q, Eating Disorder Examination-Questionnaire; NCV, negative cubic variation; BP subtype, Binge Purge subtype; AN, Anorexia Nervosa; EDI, Eating Disorder Inventory; PI subscale, Padua Inventory subscale; CSI, Coping Strategies Inventory, N.R. Not Reported 


\section{Discussion}

This review summarises the outcomes of 16 studies by examining the rate, timing and factors associated with relapse in anorexia nervosa.

\section{Rate of relapse}

Of all patients included in these studies, the overall estimated rate of relapse was $31 \%$. This result was irrespective of the mean age of participants, implying that younger patients with anorexia nervosa are at the same risk of relapse as older patients. Although the definitions of recovery and relapse used in the studies were divergent, in all definitions some similarities were present. For example, all studies defining recovery used weight restoration as a measuring point, with the lowest measuring point of weight within $15 \%$ of ideal body weight. Also, all studies used a decrease in weight to define relapse, with the measuring point a body mass index (BMI) $<18.5$ or $-15 \%$ of average body weight. Nine studies included the recurrence of eating disorder symptoms in their definition of relapse (Avnon et al., 2017; Berends et al., 2016; Castellini et al., 2011; Eddy et al., 2002; Helverskov et al., 2010; Herzog et al., 1999; Keel et al., 2005; Richard et al., 2005; Strober et al., 1997).

\section{Timing of relapse}

The highest risk of relapse occurred during the first year after discharge; however, it appeared that this risk could continue for up to 2 years. During this period, patients should be guided and supported with a personalized relapse prevention strategy. Currently, the leading protocols for the treatment of AN are the Maudsley Model of Anorexia Treatment in Adults (MANTRA) (Schmidt \& Trasure, 2006), Specialist Supportive Clinical Management (SSCM) (Dalle Grave, 2012), Cognitive Behavioral Therapy-Enhanced (CBT-E) (Mclntosh et al., 2006), and Family-Based Treatment (FBT) (Lock \& Le Grange, 2005). The MANTRA and the SSCM protocol have a 4-month follow-up, CBT-E has a 5-month follow-up, and the last phase of the FBT protocol insists on three completing sessions during 3 months without any followup. Although all these protocols address the importance of relapse, their followup might be too short when considering the length of the period of highest risk of relapse, i.e. up to 2 years.

We support the recommendation of Khalsa et al. (2017) to standardise definitions of relapse, remission and recovery, and suggest that relapse prevention strategies should already start with achieving partial remission: defined by Khalsa et al. as: BMI 18.5 or $85 \%$ ideal body weight, fear of gaining weight or disturbance in body image present, no restricting, binging or purging, scores on the Eating Disorder
Examination (EDE) within 2 SD of normal, and duration 1 month (Khalsa et al., 2017). Patients should receive relapse prevention interventions for up to 2 year after discharge but, preferably, until achieving full recovery: defined by Khalsa et al. as BMI $>20$ or $90 \%$ of ideal body weight, no significant fear of gaining weight or disturbance in body image, no restricting, binging or purging, EDE within 1 SD or normal, duration 12 months (Khalsa et al., 2017).

\section{Factors associated with relapse}

An overview is presented of all factors significantly associated with a higher risk of relapse, which led to the formation of the following clusters: eating disorder variables, comorbidity symptoms, process treatment variables, and demographic variables. A limitation is that there was substantial variability in the factors associated with relapse, due to the different procedures and instruments used in the studies to identify predictors of relapse.

Within the cluster of eating disorder variables, those related to weight and shape concern were prominent because 6 of the 12 factors mentioned in this cluster referred to these topics. At all stages of treatment, these cognitive distortions should be targeted and, at the end of treatment, patients should be informed (by means of objective measurements) to what extent these variables might still be present Khalsa et al. (2017) suggest that the EDE (Fairburn \& Cooper, 1993) should be used to unambiguously determine the definitions of remission and recovery. Additionally, the outcome of the EDE scores could be used in relapse prevention programs to inform patients and to personalise relapse prevention plans.

Within the cluster of comorbidity variables, obsessions and compulsions were present, this makes patients with AN more susceptible to relapse. Teaching patients appropriate coping mechanisms, and how to deal with problems related to their selfesteem, psychosocial functioning and level of motivation, should also be important elements of treatment and relapse prevention programs. The treatment variables, together with the demographic variables, show that i) patients needing a longe duration of treatment or more intensive treatment are at higher risk of relapse, and ii) older patients with a longer duration of illness are also at higher risk of relapse.

Since the range of factors associated with relapse is wide, extensive screening is required during treatment to determine the presence of relevant factors. With this knowledge, the relapse prevention plans can be personalized. We suggest that patients be consistently, but low frequently, monitored throughout the high-risk period after discharge. 


\section{Relapse prevention strategies}

Overall, few relapse prevention strategies for anorexia nervosa have been extensively researched. Some strategies focus on relapse prevention during treatment: e.g. internet-based relapse prevention by Fichter et al. (2013), the use of Relapse Management Cards by Page et al. (2002) and the Recovery Record application by Tregarthen and Argue (www.recoveryrecord.eu). The Guideline Relapse Prevention developed by Berends et al. (2010) focuses on relapse prevention at the end of treatment (www.relapse-an.com); this guideline provides a structured method to set up a personalized relapse prevention plan, focuses on self-management, and provides a low-frequency checking system during 18 months up to 5 years. Our earlier cohort study found a relapse rate of $11 \%$ (Berends et al., 2016).

\section{Future research}

Additional research on relapse prevention is necessary to further unravel the mechanisms related to relapse. Preferably, these should be longitudinal studies with a follow-up of $\geq 24$ months and including data on the rate of relapse using the definitions proposed by Khalsa et al. (2017). To identify factors of relapse, instruments used should include (at least) the four clusters identified here (i.e. eating disorder variables, comorbidity factors, process treatment variables, and demographic variables) in order to develop a standardized prognostic model.

\section{Conclusion}

Based on 16 studies, this review shows that one third of the patients with anorexia nervosa relapses. Because the greatest risk of relapse is within the first two years after discharge, personalized relapse prevention interventions should be applied during this period. A pattern emerged between the severity of the eating disorder and comorbid symptoms, and the level of risk of relapse. Moreover, since the risk of relapse increases with longer duration of illness and longer period of treatment, besides good relapse prevention, early adequate treatment is required to improve the chance of recovery.

\section{Acknowledgements}

The authors thank Caroline Planting (librarian) for her assistance with the search; Janine Prinssen, Jiska Aardoom and Suzanne Kieft for their valuable assistance in the selection procedure, Mathijs Deen for his knowledge and assistance with the statistics, and Marjolein Rijken for her assistance in categorizing the clusters.

\section{Financial support and sponsorship}

None.

\section{Conflicts of interest}

The authors confirm there are no conflicts of interest. 


\section{KEY POINTS}

- The overall estimated rate of relapse is $31 \%$, irrespective of age.

Since relapse occurs mainly in the first year and up to 2 years posttreatment, relapse prevention interventions during this period are essential.

- Factors associated with relapse should be better organised and future procedures should (preferably) encompass four main clusters; eating disorder factors, comorbid factors, treatment factors, and demographic factors.

Definitions of remission, recovery and relapse should be unified as proposed by Khalsa et al. (2017).

- The guideline 'Relapse Prevention Anorexia Nervosa' provides a structured method for relapse prevention (Berends et al., 2010).

\section{References and recommended reading:}

Recent papers of particular interest, published have been indicated as follows:

- of special interes

.. of outstanding interes

American Psychiatric Association. (2006). Practice Guideline: Treatment of patients with eating disorders Washington DC: APA.

Arcelus J., Mitchell A. J., Wales J., \& Nielsen S. (2011). Mortality rates in patients with anorexia nervosa and other eating disorders. A meta-analysis of 36 studies. Archives of General Psychiatry, 68, 724-731.

- Avnon, A., Orkaby, N., Hadas, A., Berger, U., Brunstein Klomek, A., \& Fennig, S. (2017). Inpatient weight curve trajectory as a prognostic factor among adolescents with anorexia nervosa: a preliminary report. Eating and Weight Disorders. doi:10.1007/540519-017-0415-8

This study is recent with findings specific on the weight curve trajectory as a predictor of relapse.

Berends T., van Meijel B., \& van Elburg A. (2010). Richtlijn Terugvalpreventie Anorexia Nervosa (Guideline Relapse Prevention Anorexia Nervosa). Assen, The Netherlands: Koninklijke Van Gorcum. Retrieved from http://www.relapse-an.com

- Berends, T., van Meijel, B., Nugteren, W., Deen, M., Danner, U. N., Hoek, H. W., \& van Elburg, A.A. (2016) Rate, timing and predictors of relapse in patients with anorexia nervosa following a relapse prevention program: a cohort study. BMC Psychiatry, 16(1), 316. doi:10.1186/s12888-016-1019-y

This study highlights the rate, timing and predictors of relapse while working with a relapse prevention program. They present a low rate of relapse.

Borenstein, M., Hedges, L., Higgins, ।., \& Rothstein, H. (2005). Comprehensive Meta-Analysis, Version 2. Biostat, Englewood, N. Retrieved from http://www.meta-analysis.com

Carter, J. C., Blackmore, E., Sutandar-Pinnock, K., \& Woodside, D. B. (2004). Relapse in anorexia nervosa: a survival analysis. Psychological Medicine, 34, 671-679.

Carter, I. C., Mercer-Lynn, K. B., Norwood, S. I., Bewell-Weiss, C. V., Crosby, R. D., Woodside, D. B., \& Olmsted M.P. (2012). A prospective study of predictors of relapse in anorexia nervosa: implications for relapse prevention. Psychiatry Research, 200, 518-523.

Lo Sauro, C., Mannucci, E., Ravaldi, C., Rotella, C. M., Faravelli, C., \& Ricca, V. (2011). Diagnostic Crossover and Outcome Predictors in Eating Disorders According to DSM-IV and DSM-V Proposed Criteria: A 6-Year Follow-Up Study. Psychosomatic Medicine, 73, 270-279 doi:10.1097/PSY.0b013e31820a1838.

Dalle Grave, R. (2012). Intensive cognitive behavior therapy for eating disorders. New York: Nova Science Publishers

Deter, H. C., \& Herzog, W. (1994). Anorexia Nervosa in a Long-Term Perspective: Results of the HeidelbergMannheim Study. Psychosomatic Medicine, 56, 20-27.

Eckert, E. D., Halmi, K. A., Marchi, P., Grove, W., \& Crosby, R. (1995). Ten-year follow-up of anorexia nervosa: clinical course and outcome. Psychological Medicine, l, 143-156.

Eddy, K. T., Keel, P. K., Dorer, D. J., Delinsky, S. S., Franko, D. L., \& Herzog, D. B. (2002). Longitudinal Comparison of Anorexia Nervosa Subtypes. International Journal of Eating Disorders, 31, 191-201.

Egger, M., Smith, G., Schneider, M., \& Minder, C. (1997). Bias in meta-analysis detected by a simple, graphica test. British Medical Journal, 315, 629-634.

Fairburn, C. G., \& Cooper, Z. The eating disorder examination. In: Fairburn, C. G., Wilson, G. T. (Eds.) (1993). Binge Eating: Nature, Assessment, and Treatment, 12 $2^{\text {th }}$ Ed. Guilford Press. p.317-360.

Fichter, M. M., Quadflieg, N., \& Lindner, S. (2013). Internet-based relapse prevention for anorexia nervosa: nine- month follow-up. Journal of Eating Disorders, 1, 23. doi:10.1186/2050-2974-1-23

- Hay P., Chinn D., Forbes D., Madden, S., Newton, R., Sugenor, L., Touyz, S., \& Ward, W. (2014). The Roya Australian and New Zealand College of Psychiatrists clinical practice guidelines for the treatment of eating disorders. Australian and New Zealand Journal of Psychiatry, 48, 977-1008. 
This guideline provides a structured overview on evidence based interventions for the treatment of eating disorders

Helverskov, J. L., Clausen, L., Mors, O., Frydenberg, M., Thomsen, P. H., \& Rokkedal, K. (2010). Trans-diagnostic outcome of eating disorders: A 30-month follow-up study of 629 patients. European Eating Disorder Review, 18, 453-463. doi:10.1002/erv.1025

Herzog, D. B., Dorer, D. J., Keel, P. K., Selwyn, S. E., Ekeblad, E. R., Flores, A. T., Greenwood, D. N., \& Keller, M. B. (1999). Recovery and relapse in anorexia and bulimia nervosa: a 7.5-year follow-up study. Journal of the American Academy of Child and Adolescent Psychiatry, 38, 829-37.

Higgins, J., Thompson, S. G., Deeks, J.., \& Altman, D. G. (2003). Measuring inconsistency in meta-analyses. British Medical Journal, 327, 557-560

Hilbert A., Hoek H. W., \& Schmidt R. (2017). Evidence-based clinical guidelines for eating disorders international comparison. Current Opinion in Psychiatry, 30, 423-437. doi:10.1097/YCO.0000000000000360 This review on clinical guidelines provides a overview on evidence based treatment interventions.

Isager, T., Brinch, M., Kreiner, S., \& Tolstrup, K. (1985). Death and relapse in anorexia nervosa: survival analysis of 151 cases. Journal of Psychiatric Research, 19, 515-521.

Keel, P. K., Dorer, D. J., Franko, D.L., Jackson, S. C., \& Herzog, D. B. (2005). Postremission predictors of relapse in women with eating disorders. American Journal of Psychiatry, 62, 2263-2268.

Keski-Rahkonen A., Hoek H. W., Susser E. S., Linna, M.S., Sihvola, E., Raevouri, A., Bulik, C. M., Kaprio, J., \& Rissanen, A. (2007). Epidemiology and course of anorexia nervosa in the community. American Journal of Psychiatry, 164, 1259-1265.

- Khalsa, S. S., Portnoff, L. C., McCurdy-McKinnon, D., \& Feusner, J. D. (2017). What happens after treatment? A systematic review of relapse, remission, and recovery in anorexia nervosa. Journal of Eating Disorders, 5, 20. doi:10.1186/540337-017-0145-3

This is the most recent review that provides an overview on definitions on relapse, remission and recover They propose a structured set of definitions which are important to improve research on relapse.

Kmet, L. M., Lee, R. C., \& Cook, L. S. (2004). Standard quality assessment criteria for evaluating primary research papers from a variety of fields. Edmonton: Alberta Heritage Foundation for Medical Research (AHFMR).

Lock, D., \& Le Grange, D. (2005). Family-Based Treatment for Eating Disorders. International Journal of Eating Disorders, 37, 64-67.

McIntosh, V. V., Jordan, J., Luty, S. E., Carter, F. A., McKenzie, J. M., Bulik, C. M., \& Joyce, P. R. (2006). Specialist supportive clinical management for anorexia nervosa. International Journal of Eating Disorders, 39, 62 632. doi:10.1002/eat.20297.

National Institute for Health and Care Excellence (NICE). (2017). Eating disorders: recognition and treatment, full guideline. Retrieved from: http://www.nice.org.uk/guidance/ng69/

This guideline provides a structured overview on evidence based interventions for the treatment of eating disorders.

Page, L. A., Sutherby, K., \& Treasure, J. L. (2002). A Preliminary Description of the Use of'Relapse Management Cards' in Anorexia Nervosa. European Eating Disorders Review, 10, 281-291. doi:10.1002/erv.467.

Raevuori A., Keski-Rahkonen A., \& Hoek H. W. (2014). A review of eating disorders in males. Current Opinion in Psychiatry, 27, 426-430.

Richard, M., Bauer, S., \& Kordy, H. (2005). Relapse in Anorexia and Bulimia Nervosa-A 2.5-Year Follow-Up Study. European Eating Disorders Review, 13, 180-190.

Schmidt, U., \& Treasure, J. (2006). Anorexia nervosa: valued and visible. A cognitive-interpersonal maintenance model and its implications for research and practice. British Journal of Clinical Psychology, 8/014466505X53902

Smink F. R. E., van Hoeken D., Donker G. A., Susser E. S., Oldehinkel, A. J., \& Hoek, H. W. (2016). Three decades of eating disorders in Dutch primary care: decreasing incidence of bulimia nervosa but not of anorexia nervosa. Psychological Medicine, 46, 1189-1196 dol:10.1017/5003329171500272X
Steinhausen H. C. (2002). The Outcome of Anorexia Nervosa in the 20th Century. American Journal of Psychiatry, 159, 1284-1293.

Strober, M., Freeman, R., \& Morrell, W. (1997). The long-term course of severe anorexia nervosa in adolescents: survival analysis of recovery, relapse, and outcome predictors over 10-15 years in a prospective study.

Tregarthen, J., \& Argue, S. Recovery Record application. Retrieved from https://www.recoveryrecord.eu/

van Elburg, A. A., Hillebrand, J. G., Huyser, C., Snoek, M., Kas, M. J., Hoek, W. H., \& Adan, R. A. (2012). Mandom A. A, Hit of Eating Disorders, 45, 193-201. doi:10.1002/eat.20918

Walsh, B. T., Kaplan, A. S., Attia, E., Olmsted, M., Parides, M., Carter, J. C., Pike, K. M., Devlin, M. J., Woodside, B., Roberto, C. A., \& Rockert, W. (2006). Fluoxetine after weight restoration in anorexia nervosa: randomized controlled trial. Journal of the American Medical Association, 295, 2605-2612. 
Chapter 4

Rate, timing and predictors of relapse in patients with anorexia nervosa following a relapse prevention program: A cohort study.

Berends, T.', van Meijel, B. ${ }^{2,3,4}$, Nugteren, W. ${ }^{4}$, Deen, M. ${ }^{4,5}$, Danner, U. N. ${ }^{1,6}$, Hoek, H. W. ${ }^{14,6,7,8}$, \& van Elburg, A. A. ${ }^{1.6,9}$

' Altrecht Eating Disorders Rintveld, Zeist, The Netherlands

${ }^{2}$ INholland University for Applied Sciences, Amsterdam, The Netherlands

${ }^{3}$ Amsterdam UMC (loc VUmc), Amsterdam, The Netherlands

${ }^{4}$ Parnassia Psychiatric Institute, The Hague, The Netherlands

${ }^{5}$ Institute of Psychology, Methodology and Statistics Unit, Leiden University, Leiden, the Netherlands

${ }^{6}$ Utrecht Research Group Eating Disorders, Utrecht, the Netherlands

${ }^{7}$ Department of Psychiatry, University Medical Center Groningen, University of Groningen, Groningen, The Netherlands

${ }^{8}$ Department of Epidemiology, Columbia University, Mailman School of Public Health, New York, United States

${ }^{9}$ Department of Social Sciences, Utrecht University, Utrecht, The Netherlands

BMC Psychiatry, 2016, 16(1), 316

Acknowledgement of author contributions:

The first author (TB) and BVM developed the original concept of the cohort study. TB, BVM, AvE, UD and HH drafted the original protocol, design and statistical methods. TB was responsible for data collection. TB, WN and MD performed the analysis and interpretation of the data. The fina manuscript was written up with the first author taking the lead and in cooperation with all authors. 


\section{Abstract}

\section{Background}

Relapse is common among recovered anorexia nervosa (AN) patients. Studies on relapse prevention with an average follow-up period of 18 months found relapse rates between $35 \%$ and $41 \%$. In leading guidelines there is general consensus that relapse prevention in patients treated for AN is a matter of essence. However, lack of methodological support hinders the practical implementation of relapse prevention strategies in clinical practice. For this reason we developed the Guideline Relapse Prevention Anorexia Nervosa. In this study we examine the rate, timing and predictors of relapse when using this guideline.

\section{Method}

Cohort study with 83 AN patients who were enrolled in a relapse prevention program for anorexia nervosa with 18 months follow-up. Data were analyzed using KaplanMeijer survival analyses and Cox regression.

\section{Results}

Eleven percent of the participants experienced a full relapse, 19\% a partial relapse, $70 \%$ did not relapse. Survival analyses indicated that in the first four months of the program no full relapses occurred. The highest risk of full relapse was between months 4 and 16. None of the variables remained a significant predictor of relapse in the multivariate Cox regression analysis.

\section{Conclusion}

The guideline offers structured procedures for relapse prevention. In this study the relapse rates were relatively low compared to relapse rates in previous studies. We recommend that all patients with AN set up a personalized relapse prevention plan at the end of their treatment and be monitored at least 18 months after discharge. It may significantly contribute to the reduction of relapse rates.

\section{Keywords}

Anorexia nervosa, relapse, relapse intervention, relapse prevention, survival analysis.

\section{Background}

Anorexia nervosa (AN) is a severe mental disorder with a life-time prevalence among women of $2 \%$ (Keski-Rahkonen et al., 2007; Smink et al., 2012) and high mortality rates of $5 \%$ per decade (Arcelus et al., 2011; Smink et al., 2012). Relapse is common among AN patients who previously showed full remission of the eating disorder Studies have reported a wide range of estimates of relapse rates in AN, depending upon the definitions of relapse used, the length of follow-up, and the methodologies employed (Carter et al., 2012).

Relapse rates in studies with longer follow-up periods, and without targeted prevention strategies differ from 6 to 57\% (Eckert et al., 1995; Herzog et al., 1999; Kee et al., 2005; Le Grange et al., 2014; Richard et al., 2005; Strober et al., 1997; Walsh et al., 2006).

In three comparable studies on relapse prevention with an average follow-up period of 18 months, full relapse rates of $35 \%, 41 \%$ and $41 \%$ were found (Carter et al., 2004 , 2012; McFarlane et al., 2008). These studies demonstrated with survival analyses that the highest risk of relapse was between 4 and 17 months post-treatment. In the Netherlands, where also the present study has been conducted, research by van Elburg (2007) showed a relapse rate of more than $50 \%$ over a period of five years. In none of these studies a structured relapse prevention program was applied.

In leading guidelines in the field of eating disorders (American Psychiatric Association 2006; Dutch Committee for the Development of Multidisciplinary Guidelines in Mental Health Care, 2006; NICE Guideline, 2004), general consensus exists that relapse prevention in patients with AN is essential. However, a major problem is the lack of structured methods for relapse prevention to support professionals in clinical practice. Therefor the Guideline Relapse Prevention Anorexia Nervosa (GRP) was developed, intended for use by both professionals and patients to apply relapse prevention strategies in a structured manner (Berends et al., 2010). This Guideline was implemented in specialized treatment setting for eating disorders in The Netherlands.

The aim of the present study is to examine the rate, timing and predictors of relapse of patients who were treated with the GRP. 


\section{Method}

\section{Design}

Cohort study of patients successfully treated for AN included in a relapse prevention program for AN, with a follow-up of 18 months.

\section{Participants and Setting}

The following inclusion criteria were applied: in- and outpatients, age 12 years and older, meeting the diagnostic criteria of the DSM-IV (American Psychiatric Association, 1994) for AN or EDNOS clinically referred to as AN (for example women meeting all criteria for AN, except that the individual has menses. In 33 cases the diagnosis was determined according to the DSM-IV criteria and ascertained by eating disorder experts (all psychiatrists), supported by questions from the EDE (Eating Disorder Examination) (Fairburn \& Cooper, 1993; Jansen, 2000). In 50 cases the actual EDE interview was administered to confirm the eating disorder diagnosis that was determined by the psychiatrist in accordance with the DSM-IV criteria.

Participants had successfully completed their treatment, were weight restored with a normal (SD) BMl based on their age and height. For inclusion it was further required that they had drawn up a relapse prevention plan (RPP) at the end of their treatment.

Ninety-six patients were eligible to participate in the after-care program between 2009 and 2012, where the Guideline Relapse Prevention Anorexia Nervosa (GRP) was implemented. Thirteen participants did not meet the inclusion criteria: seven participants did not have a complete RPP, two patients were re-admitted for treatment during the drafting of the RPP, two participants refused to participate in the after-care program after making a RPP, one patient moved abroad before starting the after-care program, and one patient was admitted to a closed ward during this study due to severe comorbidity (severe depression with a risk of suicide). The remaining 83 participants were included in the analyses.

The study was carried out in a specialized treatment centre for eating disorders in the Netherlands, Altrecht Eating Disorders Rintveld. The treatment provided in this specialized setting is based on the state-of-the-art evidence- and practice-based knowledge as described in three guidelines: The Dutch Multidisciplinary Guideline Eating Disorders (2006), the NICE guidelines Eating Disorders (2004) and the American Psychiatric Association Practice Guideline: Treatment of Patients with Eating Disorders (2006). Treatment focuses on three areas: (1) eating habits, body weight, and body image; (2) psychological aspects of functioning, such as selfesteem, perfectionism, and traumas; and (3) social functioning within the family system and in society. In our centre, patients are basically treated on an outpatient basis, and only admitted for short periods at a time, followed by outpatient treatment. All patients who started the relapse prevention program received prior outpatient treatment. Only when remission was reached during outpatient treatment were patients eligible for participation in the aftercare program. Comorbidity is managed either in the centre itself or by co-treatment in a different specialized centre.

\section{Definition of Relapse}

In the present study the primary outcome was the occurrence of relapse. The distinction was made between full and partial relapse. A full relapse was defined as: $\mathrm{BMI}<18.5$ for adults and SD BMI $<-1$ for adolescents, together with full recurrence of the core diagnostic symptoms of AN according to DSM-IV criteria, in the first instance assessed by the professional, and next confirmed in a multidisciplinary consensus meeting. In case of confirmation, this formed an indication for renewed treatmen Partial relapse was defined as the re-occurrence of one or more core diagnostic symptoms of AN, after a previous positive response to treatment. As a response to the re-occurrence of symptoms, a temporary intensification of the after-care program for a period up to three months was needed to achieve full recovery again. If a longer intensification of the program was needed the relapse was classified as a full relapse.

\section{The Guideline Relapse Prevention Anorexia Nervosa (GRP)}

The primary aim of the guideline is that the professional, patient and her relatives work closely together to gain a better understanding of the patient's individual process of relapse. Triggers and early warning signs that preceded previous relapses are identified and elaborated for the individual patient, and actions are formulated that can be performed in the event of a new impending relapse. All this information is summarized in a Relapse Prevention Plan (RPP). The essence of the relapse prevention strategy is to ensure that appropriate action is taken as early as possible when early warning signs of relapse occur.

The guideline is made up of three parts: (a) a theoretic framework for relapse and relapse prevention, developed on the basis of both the literature and practica experience of experts and patients, leading to conclusions and recommendations for clinical practice; (b) a practical manual for the professional; and (c) a workbook for patients. For a complete description of the application of the GRP, see the case report by Berends et al. (2012). The GRP is freely accessible via the internet. 
Drawing up a fully fledged relapse prevention plan requires approximately six meetings of patient, relatives and the professional. Practical experience with the application of the GRP showed that individual sessions should last approximately 45 minutes and should preferably be scheduled every other week. After each session, the patient receives homework assignments, to be carried out either individually or together with relatives.

After a RPP is drawn-up, the aftercare-program starts. This is a low-frequent individual program and has a minimum duration of 18 months. During the aftercarevisits the condition of the patient is thoroughly monitored and discussed. Two scenarios can occur during these visits: 1) The patient is stable, in which case the focus is on maintaining this stable condition by promoting good physical health and optimal personal and social functioning. Actual or possible stressful life events in the near future are discussed and anticipated on. 2) The patient shows one or more early signs of impending relapse, in which case the main focus during the visit is on obtaining a thorough understanding of the actual triggers of relapse, and how to deal with these in order to promote recovery. In this context specific arrangements are made and actions are planned, based on the content of the previously established relapse prevention plan (RPP)

The frequency of the aftercare visits depends on the patient's condition and the need for treatment and care. For example, patients who are stable will come for a visit after four to six months. If the patient is less stable the visits can be planned every two months. The patient and the professional can decide to extend the aftercare period after 18 months in case of prolonged vulnerability to relapse, with a maximum of five years.

The visits last 45 minutes and are attended by both the patient and her relatives. At each visit the patient is weighed and her condition is evaluated. During the visit, two main topics are discussed, i.e. psychological and social functioning (school, friends, sports, overall moods, etc.) and the presence of AN-symptoms (anorectic cognitions, abnormal eating habits, excessive exercise pattern et cetera). Based on this information, the RPP is updated if necessary. At the end of the visit a new appointment is made for the next visit. The patient's record contains the following details of each visit: weight, possible stage of relapse, and the arrangements made during the visit.

Between the formal visits, a patient or her relatives can contact the professional at any time in case of need for help.

\section{Data collection}

Data were collected on:

1. Demographic and clinical characteristics: age, age of onset, severity of the eating disorder, treatment duration, duration of the eating disorder, BMI, in- o outpatient treatment, number of sessions in the aftercare program, subtype of AN (restrictive type (ANR) or binge/purging type (ANBP)), and comorbidity (as ascertained by psychiatrists at the start of treatment and confirmed in a consensus meeting by the clinical team).

2. Data concerning full and partial relapse: weight, stage of relapse, and the agreements made during the visit.

- When a participant had a full relapse the indication for renewed treatment was documented.

- When a participant had a partial relapse the stage of relapse was documented, as well as the intensification of the aftercare-visits. When a participant crossed the three-month duration of partial relapse, it was registered as a full relapse.

\section{Data-analysis}

1. Kaplan-Meier survival analysis was used to analyze the rate and timing of full relapse.

2. Demographic and clinical characteristics between the group of patients with either full or partial relapse, and the group of patients with no relapse are presented with percentages and means.

3. In order to identify significant predictors of relapse, Cox regression was used to assess the predictive value of demographic and clinical characteristics with respect to relapse. First, the variables were tested univariate, after which predictors with a $p$-value $<.10$ were entered in a multivariate Cox regression model. SPSS for Windows (version 21.0) was used to perform all statistical procedures.

\section{Results}

\section{Baseline characteristics participants}

The 83 participants had a mean age of 17.9 years $(S D=4.45)$, measured at the star of the aftercare-program. Their mean BMI was $16.4 \mathrm{~kg} / \mathrm{m}^{2}(S D=2.13)$ at the start of the initial treatment, and $20.0 \mathrm{~kg} / \mathrm{m}^{2}(S D=1.54)$ at the end of treatment, which is at the start of the aftercare-program. Since 58 participants were younger than 19 years, SD BMI was collected and therefor converted to BMI. The mean age of onset was 14.3 years $(S D=3.40)$. Of the participants $84.3 \%(n=70)$ was diagnosed with anorexia nervosa restrictive type (ANR), and $15.7 \%(n=13)$ with anorexia nervosa 
binge purging type (ANBP). According to the DSM-5 severity scale, $13.3 \%$ of the participants had a mild disorder at the start of treatment, $18.1 \%$ moderate, $12 \%$ severe and $56.6 \%$ extreme. There were no significant differences between full and partial relapsers concerning severity of the disorder. The average time of participation in the aftercare-program was 18.4 months $(S D=4.39)$. The mean number of sessions during the aftercare program for the non-relapse group was $4.14(S D=1.89)$ sessions; for the partial relapse group it was significantly higher at $6.69(S D=5.00)$ sessions $(p=0.008)$. For the full relapse group, the mean number of sessions was $7.11(S D=7.49)$ sessions $(p=0.269)$

\section{Rate and timing of relapse}

During the aftercare program, $10.8 \%(n=9)$ of the participants experienced a full relapse, whereas $19.3 \%(n=16)$ had a partial relapse and $69.9 \%(n=58)$ did not relapse. Figure 1 presents the survival curve for the 83 participants showing full relapse. No full relapses occurred in the first four months of the program. The highest risk of full relapse was between months 4 and 16 . After 16 months no full relapse occurred while 61 participants still participated in the aftercare-program at that point in time.

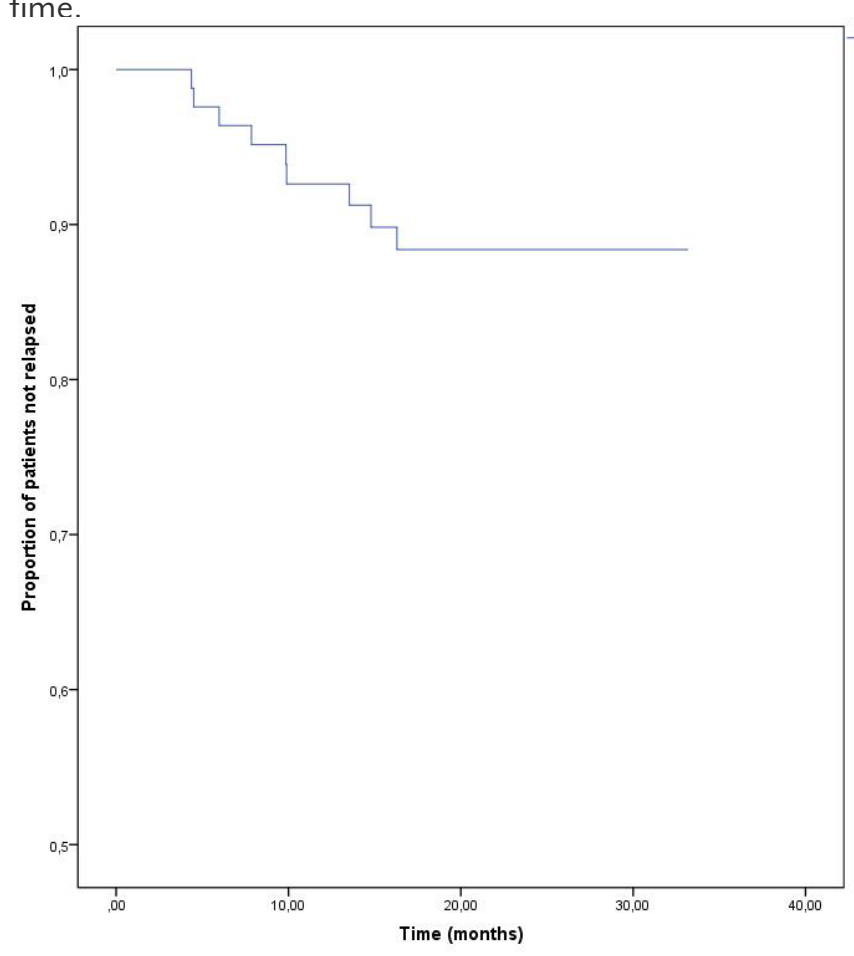

Figure 1: Survival function for full relapse

\section{Identification of predictors of relapse}

In order to identify significant predictors of relapse, first univariable analyses were performed on demographic and clinical characteristics using univariate Cox regression (Table 1). 'Duration of treatment' $(p=0.007)$, 'Type of treatment' $(p$ $0.039)$ and 'Age' ( $p=0.034)$ were the only variables to significantly predict time unti relapse. When entered in a multivariate Cox regression model none of the variables were statistically significant.

Table 1: Demographic and clinical characteristics of the participants per group (full and partial relapse vs. nonrelapse) including outcome univariate Cox regression.

\begin{tabular}{|c|c|c|c|c|}
\hline Variable & $\begin{array}{l}\text { Full and partial } \\
\text { relapse group } \\
(n=25)\end{array}$ & $\begin{array}{c}\text { Non relapse } \\
\text { group } \\
(\mathrm{n}=58)\end{array}$ & $\begin{array}{c}\text { univariate Cox } \\
\text { regression } \\
\text { p value }\end{array}$ & $\begin{array}{c}\text { univariate Cox } \\
\text { regression } \\
\operatorname{Exp}(\mathrm{B})\end{array}$ \\
\hline Onset eating disorder (years) & 15.1 & 14.1 & 0.440 & 1.034 \\
\hline Duration of the eating disorder (years) & 3.7 & 3.4 & 0.447 & 1.055 \\
\hline $\begin{array}{l}\text { Duration of treatment before the affercare-program } \\
\text { (months) }\end{array}$ & 25.6 & 16.2 & $0.007^{*}$ & 1.028 \\
\hline BMl at start treatment $\left(\mathrm{kg} / \mathrm{m}^{2}\right)$ & 16.3 & 16.4 & 0.621 & 0.954 \\
\hline BMl at start of aftercare program & 19.9 & 20.0 & 0.776 & 0.965 \\
\hline BMl at the end of aftercare program & 19.9 & 20.4 & 0.166 & 0.865 \\
\hline Age 18 years or younger & $22,4 \%(n=13)$ & $77,6 \%(n=45)$ & / & I \\
\hline Age 19 years or older & $48 \%(n=12)$ & $52 \%(n=13)$ & $0.034 *$ & 2.344 \\
\hline Subtype ANBP & $23.1 \%(n=3)$ & $76.9 \%(n=10)$ & / & / \\
\hline Subtype ANR & $31.4 \%(n=22)$ & $68.6 \%(n=48)$ & 0.709 & 1.259 \\
\hline $\begin{array}{l}\text { Type of treatment before the aftercare-program } \\
\text { (patients received only outpatient treatment) }\end{array}$ & $32 \%(n=8)$ & $56,9 \%(n=33)$ & I & I \\
\hline $\begin{array}{l}\text { Type of treatment before the aftercare-program } \\
\text { (patients received in- and outpatient treatment) }\end{array}$ & $68 \%(n=17)$ & $43.1 \%(\mathrm{n}=25)$ & $0.039 *$ & 2.425 \\
\hline Severity eating disorder DSM 5: Mild & $16 \%(n=4)$ & $12.1 \%(n=7)$ & 0.764 & 1.179 \\
\hline Severity eating disorder DSM 5: Moderate & $12 \%(n=3)$ & $20.7 \%(n=12)$ & 0.321 & 0.543 \\
\hline Severity eating disorder DSM 5: Severe & $8 \%(n=2)$ & $13.8 \%(n=8)$ & 0.447 & 0.571 \\
\hline Severity eating disorder DSM 5: Extreme & $64 \%(n=16)$ & $53.4 \%(n=31)$ & 0.266 & 1.591 \\
\hline Comorbidity & $52 \%(n=13)$ & $51.7 \%(n=30)$ & 0.948 & 1.027 \\
\hline Anxiety disorder & $0 \%(n=0)$ & $6.9 \%(n=4)$ & 0.458 & 0.046 \\
\hline Depressive disorder & $24 \%(n=6)$ & $8.6 \%(n=5)$ & 0.151 & 1.963 \\
\hline Dysthymia & $0 \%(n=0)$ & $5.2 \%(n=3)$ & 0.515 & 0.047 \\
\hline Obsessive compulsive disorder & $0 \%(n=0)$ & $6.9 \%(n=4)$ & 0.426 & 0.046 \\
\hline Parent-Child Relational Problem & $24 \%(n=6)$ & $19 \%(n=11)$ & 0.363 & 1.533 \\
\hline Autism & $0 \%(n=0)$ & $1.7 \%(n=1)$ & 0.660 & 0.048 \\
\hline Personality disorder & $8 \%(n=2)$ & $10.3 \%(n=6)$ & 0.730 & 0.775 \\
\hline
\end{tabular}

BMI = Body Mass Index, ANR = anorexia nervosa restrictive, $A N B P=$ anorexia nervosa binge purge. 
Table 2: BMI of the participants with a full relapse compared to the non full relapse group, including test outcome/statistics

\begin{tabular}{lllll}
\hline Variable & $\begin{array}{l}\text { Full relapsed } \\
\text { group } \\
(\mathbf{n}=\mathbf{9})\end{array}$ & $\begin{array}{l}\text { Non full } \\
\text { relapsed group } \\
(\mathbf{n}=74)\end{array}$ & $\begin{array}{l}\text { T-test } \\
\mathbf{p} \text {-value }\end{array}$ & $\begin{array}{l}\text { Fisher's Exact } \\
\text { test (2-sided) } \\
\mathbf{p} \text {-value }\end{array}$ \\
\hline BMl at start fftercare-program & 19.46 & 20.07 & 0.12 & - \\
BMl at the end of the aftercare-program & 18.47 & 20.52 & $0.002^{*}$ & - \\
\hline
\end{tabular}

\section{Discussion}

The purpose of this study was to examine the rate, timing and predictors of relapse in a group of recovered AN patients who participated in an aftercare-program using the Guideline Relapse Prevention Anorexia Nervosa. The full relapse rate for AN was $11 \%$, which is much lower than the relapse rates found in previous studies with an average follow-up period of 18 months, showing full relapse rates of $35 \%$ (Carter et al., 2012), $41 \%$ (Carter et al., 2004) and $41 \%$ (McFarlane et al., 2008). In these studies no structured methods for relapse prevention were applied.

Of the participants in the present study who experienced the first signs of a relapse (30\%), 19\% recovered within a three-month period and only $11 \%$ relapsed fully. When experiencing the first signs of relapse as described in their RPP, these patients contacted their professional within a week. It was therefore possible to intervene at an early stage, guided by the predefined actions elaborated in the RPP.

Although no definitive conclusions about the effectiveness of the intervention can be drawn in this cohort study, the findings support our hypothesis that working with the guideline relapse prevention has a preventive effect on the occurrence of full relapse in patients with AN. When combining the rates of both partial and full relapse, the percentage of $30 \%$ is in the lower range of relapse rates found in other studies.

The survival analysis shows the timing of full relapses in this sample and indicates that within the first four months after discharge (and after starting with the RPP) no full relapses occurred, whilst the highest risk of full relapse was between 4 and 16 months after discharge. When combining the data concerning timing of partial and full relapse, the findings indicate that the risk of relapse is increased throughout the entire period of 18 months, suggesting that monitoring of early signs of relapse is necessary during this complete period.
For the identification of predictors of relapse, the univariate Cox regression between the two groups (the partial and full relapse group versus the non-relapse group) on demographic and clinical variables revealed that they differed significantly on three variables. The first variable was 'Duration of treatment before the start of the aftercare program'. The longer a patient was in treatment, the higher the risk of relapse. Duration of treatment could point to relatively high vulnerability of patients and severity of illness, thus leading to a higher risk of relapse. This subgroup of patients should be offered extra attention during aftercare, with proper information about the increased risk of relapse, and intensive monitoring for a period of at least 18 months. The second variable was 'Type of treatment before the aftercare program', either outpatient treatment only or a combination of in- and outpatient treatment. Patients who received both in- and outpatient treatment had a higher risk of relapse than patients who received outpatient treatment only. It can be assumed that patients who require both inpatient and outpatient treatment are more severely affected by the eating disorder, compared to patients who require outpatient treatment only, leading to a higher risk of relapse. These findings are consistent with other studies on relapse (Carter et al., 2004; Kaplan et al., 2009; Richard et al., 2005; Strober et al.). The third variable was 'Age'. Patients older than 19 years had a higher risk of relapse, based on the univariate regression analysis. Previous studies also show higher relapse rates within adults (Carter et al. 2004, 2012; Herzog et al., 1999; Keel et al., 2005; Richard et al., 2005; Walsh et al., 2006) In the end none of the variables remained a significant predictor of relapse in the multivariate Cox regression analysis. The absence of unique contribution of any of the predictors might be due to correlation between these predictors.

A limitation of this retrospective study is that no standardized diagnostic instrument was used to determine relapse or detect predictors of relapse. The determination of relapse was based on BMl and the core diagnostic symptoms of AN according to the DSM IV, assessed by the clinical expert on eating disorders and next confirmed in a multidisciplinary consensus meeting. We do recommend the use of a standardized diagnostic interview in future prospective research to assess the occurrence of relapse. The characteristics and variables used in our analyses were collected from the participants' files. For this reason we could not explore the predictive value for relapse of relevant variables. Future prospective research on predictors of relapse should include validated questionnaires to systematically examine these variables are possible predictors of relapse.

These findings have clinical implications for relapse prevention of AN. The genera guidelines for the treatment of AN lack methodological support in the practical implementation of relapse prevention strategies in clinical practice. From the 
present study, there are indications that the GRP provides an effective tool for relapse prevention. Our tentative conclusion is that when early recognition strategies are applied in case of impending relapse, followed by targeted interventions to prevent further deterioration, the risk of a full relapse will decrease. This increases the chance for patients to eventually reach a stable and lasting recovery. The low relapse rate in our study supports the effectiveness of this strategy, although a limitation of this study is the non-experimental study design.

It is recommended to educate patients that the first 18 months after discharge is a high-risk period for relapse, requiring continuous efforts to prevent relapse using early recognition and intervention techniques. Motivational techniques applied by professionals are needed, in order for the patients to maintain awareness of the increased risk of relapse, which with proper preventive activities can be managed for a significant proportion of cases.

The strength of this study is the relatively large sample size of 83 participants. The research on relapse is scarce and sample sizes are usually small. A limitation of this study is the lack of a control group with randomization of patients. Our study was set up to descriptively obtain insight into relapse rates, timing and predictors. Despite the positive trends we found in this study concerning these relapse rates, the effectiveness of the guideline could therefore not be determined unequivocally. Future research would have to make use of a controlled study design to confirm the effectiveness of the proposed relapse prevention strategy.

\section{Conclusions}

Working with the relapse prevention guideline offers structured support to prevent relapse in patients with AN. We recommend that all patients with AN set up a RPP at the end of their treatment, with regular monitoring for a period of at least 18 months after discharge. Patients gain a better understanding of the relapse process when drawing up an RPP and working with it, enabling them to develop self-management skills to independently influence the course of their illness and ultimately prevent the occurrence of relapse.

\section{Declarations}

\section{Ethics and consent to participate}

This study was reviewed and approved by the Institutional Review Board of Altrecht Mental Health Institute (number: 2013-05/oz1302/ck).
In the present research project only data that were routinely collected during medical care / treatment was used. These data were retrieved from the patients' record and anonymized. The intervention that was applied, i.e. the Guideline Relapse Prevention, was already part of standard care in the healthcare setting where the study was performed. According to the Dutch Medical Research Involving Human Subjects Act (WMO) this type of evaluation research with anonymized standard data from the patients' records does not require formal informed consent of the patients. (source: http://www.ccmo.nl/attachments/files/wmo-engelse-vertaling29-7-2013-afkomstig-van-vws.pdf)

\section{Consent to publish}

Not applicable.

\section{Abbreviations}

AN: anorexia nervosa, ANR: anorexia nervosa restrictive, ANBP: anorexia nervosa binge purge, EDNOS: eating disorder not otherwise specified, GRP: guideline relapse prevention, RPP: relapse prevention plan, DSM-IV: diagnostic and statistical manual of mental Disorders IV, EDE: eating disorder examination, (SD) BMI: (standard deviation) body mass index, SPSS: statistical package for the social sciences

\section{Competing interests}

The authors declare that they have no competing interests.

\section{Funding}

There was no funding obtained for this study.

\section{Authors' contributions}

TB and BvM developed the original concept of the cohort study. TB, BVM, AvE, UD and $\mathrm{HH}$ drafted the original protocol, design and statistical methods. TB was responsible for data collection. TB, WN and MD performed the analysis and interpretation of the data. All authors revised and commented on the manuscript. All authors read and approved the final manuscript.

\section{Availability of data and materials}

Data will not be shared, it will be used for follow-up research. 


\section{References}

American Psychiatric Association. (1994). Diagnostic and Statistical Manual of Mental Disorders DSM-IV. APA. American Psychiatric Association. (2006). Practice Guideline: Treatment of patients with eating disorders. APA Arcelus, J., Mitchell, A. J., Wales, J., \& Nielsen, S. (2011). Mortality rates in patients with anorexia nervosa and other eating disorders. A meta-analysis of 36 studies. Archives of General Psychiatry, 68, 724-31.

Berends, T., van Meijel, B., \& van Elburg, A. (2010). Richtlijn Terugvalpreventie Anorexia Nervosa (Guideline Relapse Prevention Anorexia Nervosa). Koninklijke Van Gorcum.

Berends, T., van Meijel, B., \& van Elburg, A. (2012). The Anorexia Relapse Prevention Guidelines in practice; a case report. Perspectives in Psychiatric Care, 48, 149-155.

Carter, J. C., Blackmore, E., Sutandar-Pinnock, K., \& Woodside, D. B. (2004). Relapse in anorexia nervosa: a survival analysis. Psychological Medicine, 34, 671-679.

Carter, J. C., Mercer-Lynn, K. B., Norwood, S. J., Bewell-Weiss, C. V. Crosby, R. D. Woodside, D. B. \& Olmsted, M. P. (2012). A prospective study of predictors of relapse in anorexia nervosa: implications for relapse prevention. Psychiatry Research, 200, 518-523.

Dutch Committee for the Development of Multidisciplinary Guidelines in Mental Health Care. (2006) Multidisciplinary Guidelines Eating Disorders. Trimbos Institute.

Eckert, E. D., Halmi, K. A., Marchi, P., Grove, W., \& Crosby, R. (1995). Ten-year follow-up of anorexia nervosa: clinical course and outcome. Psychological Medicine, 1, 143-56.

Fairburn, C. G., \& Cooper, Z. (1993). The eating disorder examination. In: Fairburn, C. G., Wilson, G. T. (Eds.), Binge Eating: Nature, Assessment, and Treatment, 12 $2^{\text {th }}$ Ed. Guilford Press, New York, 317-360.

Herzog, D. B., Dorer, D. J., Keel, P. K., Selwyn, S. E., Ekeblad, E. R., Flores, A. T., Greenwood, D. N., \& Keller, M. B. (1999). Recovery and relapse in anorexia and bulimia nervosa: a 7.5-year follow-up study. Journal of the American Academy of Child and Adolescent Psychiatry, 38, 829-37.

Jansen, A. (2000). Eating Disorder Examination. Interview to determine the specific psychopathology of eating disorders (interview ter vaststelling van de specifieke psychopathologie van eetstoornissen); Translation and adaptation of Fairburn, C. G., \& Cooper, Z. (1993). The Eating Disorder Examination (12th edition). In: Fairburn, C. G. \& Wilson, G. T. (eds). Binge eating. Nature, Assessment, and Treatment, $317-$ 360. New York: Guilford Press. Swets \& Zeitlinger, Lisse.

Kaplan, A. S., Walsh, B. T., Olmsted, M., Attia, E., Carter, J. C, Devlin, M. J., Pike, K. M., Woodside, B., Rockert, W. Roberto, C. A., \& Parides, M. (2009). The slippery slope: prediction of successful weight maintenance in anorexia nervosa. Psychological Medicine, 39, 1037-1045.

Keel, P. K., Dorer, D. J., Franko, D.L., Jackson, S. C., \& Herzog, D. B. (2005). Postremission predictors of relapse in women with eating disorders. American Journal of Psychiatry, 162, 2263-2268.

Keski-Rahkonen, A., Hoek, H. W., Susser, E. S., Linna, M. S., Sihvola, E., Raevouri, A., Bulik, C. M., Kaprio, J., \& Rissanen, A. (2007). Epidemiology and course of anorexia nervosa in the community. American Journal of Psychiatry, 164, 1259-1265.

Le Grange, D., Lock, J., Accurso, E. C., Agras, S., Darcy, A., Forsberg, S., \& Bryson, S. W. (2014). Relapse From Remission at Two-to Four-Year Follow-Up in Two Treatments for Adolescent Anorexia Nervosa Journal of the American Academy of Child \& Adolescent Psychiatry, 53, $1162-1167$

McFarlane, T., Olmsted, M. P., \& Trottier, K. (2008). Timing and prediction of relapse in a transdiagnostic eating disorder sample. International Journal of Eating Disorders, 41, 587-593.

NICE clinical guideline. (2004). Eating disorders Core interventions in the treatment and management of anorexia nervosa, bulimia nervosa and related eating disorders. Retrieved from http://www.nice.org.uk/cg9 Richard, M., Bauer, S., \& Kordy, H. (2005). Relapse in Anorexia and Bulimia Nervosa-A 2.5-Year Follow-Up Study. European Eating Disorders Review, 13, 180-190.

Smink, F. R. E., van Hoeken, D., \& Hoek, H. W. (2012). Epidemiology of Eating Disorders: Incidence, Prevalence and Mortality Rates. Current Psychiatry Reports, 14, 406-414.
Strober, M. Freeman, R., \& Morrell, W. (1997). The long-term course of severe anorexia nervosa in adolescents: survival analysis of recovery relapse, and outcome predictors over $10-15$ years in a prospective study. International Journal of Eating Disorders, 22, 339-360.

van Elburg, A. A. (2007). Psychoneuroendrocrinological aspects of anorexia nervosa: predictors of recovery. PhD thesis. Enschede, The Netherlands.

Walsh, B. T., Kaplan, A. S., Attia, E., Olmsted, M., Parides, M., Carter, J. C., Pike, K. M., Devlin, M. J., Woodside, B, Roberto, C. A \& Rockert, W. (2006). Fluoxetine after weight restoration in anorexia nervosa: a randomized controlled trial. Journal of the American Medical Association, 295, 2605-2612. 


\section{Abstract}

One of the main aims of treatment after successful recovery from anorexia nervosa (AN) is to prevent a relapse. The Guideline Relapse Prevention (GRP) Anorexia Nervosa offers a structured approach to relapse prevention. This study explores how patients and their parents experience working with the guideline. It also describes the factors that support or hinder successful application of the guideline. A descriptive qualitative research design was chosen involving in-depth interviews with seventeen patients with anorexia nervosa and six sets of parents. Patients and family members were generally satisfied with the support provided by the GRP. It contributed significantly to a better understanding of the personal process of relapse. Patients and families valued being able to keep in touch with their professional during the aftercare program. The GRP supports the patient's use of self-management strategies for relapse prevention.

\section{KEY WORDS}

anorexia nervosa, patient's perspective, relapse intervention, relapse prevention, self-management.

\section{Introduction}

Anorexia nervosa (AN) is a severe mental disorder with an estimated lifetime prevalence among women of $2 \%$ (Keski-Rahkonen et al., 2007; Smink et al., 2012) and high mortality rates of $5 \%$ per decade (Marcellus et al., 2011; Smink et al., 2012;) Relapse is common among AN patients who previously showed full remission. In international studies with varying follow-up periods, the relapse rates range from 30 to 57\% (Carter et al., 2004, 2012; Eckert et al., 1995; Herzog et al., 1999; Keel et al., 2005; McFarlane et al., 2008; Strober et al., 1997; Richard et al., 2005; Walsh et al., 2006).

Leading guidelines in the field of eating disorders (American Psychiatric Association, 2006; Dutch Committee for the Development of Multidisciplinary Guidelines in Mental Health Care, 2006; NICE clinical guideline, 2004) generally agree that relapse prevention is crucial for patients with AN. One major problem, however, is the lack of methodological support in implementing relapse prevention strategies in practice. We have addressed this issue by developing the Guideline Relapse Prevention Anorexia Nervosa (GRP), an evidence-based tool for health professionals and patients that offers a structured approach to applying relapse prevention strategie (Berends et al., 2010). One of the main aims of this guideline is to improve the selfmanagement skills of patients and family members with regard to their illness, in particular relapse prevention. The five core self-management skills described by Lorig \& Holman (2003) are interwoven into the guideline; problem solving, decision making, resource utilization, forming of a patient/healthcare provider partnership, and taking action.

The GRP has been implemented in a specialized treatment centre for eating disorders in the Netherlands. A recent study (Berends et al., 2016) carried out in this setting among 83 participants showed that the rate of full relapse was $11 \%(n=9)$, and the rate of partial relapse $19 \%(n=16)$, with patients returning to full recovery within three months. Seventy percent $(n=58)$ did not relapse. The above rate of full relapse is much lower than in other studies (Carter et al., 2004, 2012; McFarlane et al., 2008), indicating that the GRP offers a promising form of intervention for reducing relapse in this patient group.

The aim of the present study is to understand how patients and parents experience working with the GRP, in particular the use of self-management strategies for relapse prevention. The study also aims to identify facilitators and barriers for applying this guideline successfully. 


\section{Method}

\section{Design}

The researchers selected a descriptive qualitative research design, based on Thematic Analysis (Braun \& Clarke, 2006), using semi-structured interviews to gain an in-depth understanding of how anorexia nervosa patients and their parents experienced working with the GRP Anorexia Nervosa. Thematic Analysis is an appropriate research design, since it aims to identify relevant themes derived from the experience of patients and parents, also referring to barriers and facilitators when using the Guideline. The study protocol was approved by the Institutional Review Board of the institution and the Medical Ethical Committee (protocol number: $12-424 / C)$.

\section{The Guideline Relapse Prevention Anorexia Nervosa}

To prevent relapse, the health professional, the patient and her family collaborate closely on gaining a better understanding of the patient's individual relapse process. Working together, they analyze and describe in detail the triggers and early warning signs of relapse, broken down into four stages: Stage 1) The patient is stable and functioning well; stage 2) Mild relapse, anorexic thoughts intensify and the patient occasionally shows signs of behavior indicating the recurrence of the eating disorder; stage 3) Moderate relapse, anorexic thoughts take the upper hand and the patient increasingly acts on those thoughts; stage 4) Full relapse, anorexic thoughts dominate the patient continuously and the weight drops below $85 \%$ of that expected. They also identify the actions to be carried out in the event of an impending relapse. This information is summarized in an individual relapse prevention plan (RPP). The content of the RPP is based on patients' and family members' experiences with previous relapses, as well as insights concerning relapse and the risk of relapse gained during treatment. Once preparation of the RPP has been completed in the final stage of treatment, the patient is ready to start the aftercare program. In our specialized treatment setting, the aftercare program is referred to as the Periodic Anorexia Check (PAC) program. It is a low-frequency aftercare program lasting at least 18 months. During PAC meetings, the patient's condition is closely monitored and discussed at length making use of the RPP.

The frequency of the PAC meetings depends on the patient's condition and the need for treatment and care. For example, patients who are stable will attend a PAC meeting after four to six months. Less stable patients may attend PAC meetings every two months. After 18 months, the patient and the health professional can decide to extend the aftercare period for a maximum of five years if there is a prolonged
Table 1: An overview of the guideline relapse prevention anorexia nervosa

\begin{tabular}{|c|c|c|}
\hline Step 1 & $\begin{array}{l}\text { Psycho-education to patient and relatives } \\
\text { about relapse and relapse prevention. }\end{array}$ & $\begin{array}{l}\text { For example: } \\
\text { Education about how the use of a relapse prevention plan could help to reduce the } \\
\text { risk of relapse }\end{array}$ \\
\hline Step 2 & $\begin{array}{l}\text { Identification of the patient's strengths with } \\
\text { respect to personality and functioning. }\end{array}$ & $\begin{array}{l}\text { For example: } \\
\text { The patient has excellent skills to connect with other people. Or: The patient is } \\
\text { persistent in achieving her goals. }\end{array}$ \\
\hline Step 3 & Identification of risk factors for relapse. & $\begin{array}{l}\text { For example: } \\
\text { Previous research shows that having difficulties in coping with stress is a risk factor } \\
\text { for relapse. }\end{array}$ \\
\hline Step 4 & $\begin{array}{l}\text { Identification of potential triggers for } \\
\text { relapse. }\end{array}$ & $\begin{array}{l}\text { For example: } \\
\text { Loss of structure and confrontation with foreign foods when going on vacation. }\end{array}$ \\
\hline Step 5 & $\begin{array}{l}\text { Identification of early warning signs which } \\
\text { precedes the onset of a relapse. }\end{array}$ & $\begin{array}{l}\text { For example: } \\
\text { 1. Eating pattern: I Ithrow away my lunch and therefore I miss one meal'. } \\
\text { 2. Physical symptoms: 'My hands and feet constantly feel cold'. } \\
\text { 3. Exercising: I I bike really fast when I'm going somewhere. And I don't feel well } \\
\text { during biking'. } \\
\text { 4. Cognition: I I worry more and more about how I look and whether others } \\
\text { appreciate me'. } \\
\text { 5. Social functioning: 'I stop visitiing my friends'. }\end{array}$ \\
\hline Step 6 & $\begin{array}{l}\text { Describing preventive actions, responding } \\
\text { to triggers and early warning signs. }\end{array}$ & 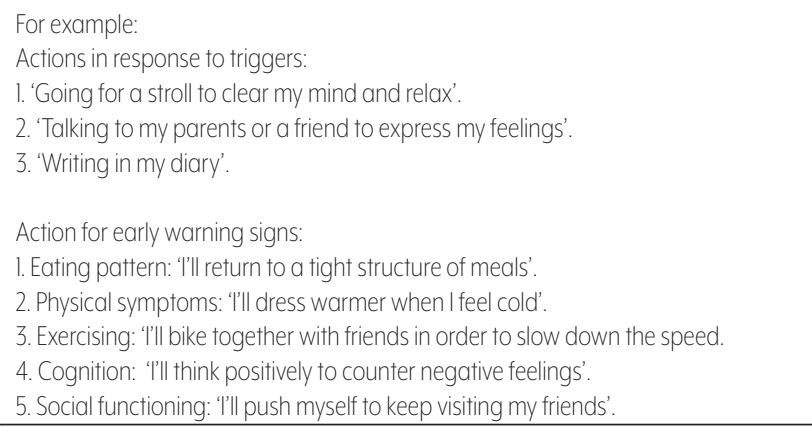 \\
\hline Step 7 & $\begin{array}{l}\text { Choosing informal caregivers (parents, } \\
\text { relatives, friends) who support the patient } \\
\text { in using the relapse prevention plan. }\end{array}$ & $\begin{array}{l}\text { For example: } \\
\text { '1. My mother, because she sees me every day and I can talk to her. } 2 \text {. My swimming } \\
\text { coach, because she was the first to find out about my eating disorder and she can } \\
\text { help me monitor my sport activities'. }\end{array}$ \\
\hline Step 8 & $\begin{array}{l}\text { Identification of motivating factors for the } \\
\text { patient when working with the relapse } \\
\text { prevention plan. }\end{array}$ & $\begin{array}{l}\text { For example: } \\
\text {-'Stability regarding my eating disorder increases the chance to enroll in a new } \\
\text { study program'. } \\
\text {-'The ability to go out with friends without being inhibited by the eating disorder'. }\end{array}$ \\
\hline Step 9 & $\begin{array}{l}\text { Drawing up the final relapse prevention } \\
\text { plan with the information from steps } 1 \text { to } 8 .\end{array}$ & \\
\hline Step 10 & $\begin{array}{l}\text { Start of the aftercare program during a } \\
\text { minimum of } 18 \text { months. }\end{array}$ & $\begin{array}{l}\text { Two scenarios can occur during these meetings: } \\
\text { 1) The patient is stable, in which case the focus is on maintaining this stable } \\
\text { condition by promoting good physical health and optimal personal and social } \\
\text { functioning. Actual or possible stressful life events in the near future are discussed } \\
\text { and anticipated on. } \\
\text { 2) The patient shows one or more early signs of impending relapse, in which case } \\
\text { the main focus during the visit is on obtaining a thorough understanding of the } \\
\text { actual triggers of relapse, and how to deal with these in order to promote recovery. } \\
\text { In this context specific arrangements are made and actions are planned, based on } \\
\text { the content of the previously established relapse prevention plan. }\end{array}$ \\
\hline
\end{tabular}


vulnerability to relapse (Berends et al., 2010). PAC meetings last 45 minutes and are attended by the patient and, if relevant, a family member. The patient is weighed and her condition is evaluated at each meeting. During the visit, two main topics are discussed: the patient's psychological and social functioning (overall mood, school, friends, sports, etc.) and the presence of AN symptoms (anorectic cognitions, abnormal eating habits, excessive exercise pattern, etc.). Between formal PAC meetings, the patient or a family member may contact the health professional at any time if help is needed. The patient's record contains the following information about each PAC meeting: weight, possible stage of relapse, and arrangements made during the visit. For an overview of the guideline see table 1. For a complete description of how the guideline is applied, see the case report by Berends et al. (2012). The guideline is freely accessible via the internet (www.relapse-an.com)

\section{Setting and Participants}

This study was carried out in a specialized treatment centre for eating disorders in the Netherlands. The treatment provided in this setting is based on the state-of-theart recommendations made in three sets of guidelines: the Dutch Multidisciplinary Guideline for Eating Disorders (2006), the NICE Guidelines for Eating Disorders (2004), and the American Psychiatric Association Practice Guideline: Treatment of Patients with Eating Disorders (2006). Treatment focuses on three areas: (1) eating habits, body weight and body image; (2) psychological aspects of functioning, such as self-esteem, perfectionism and traumas; and (3) social functioning within the family system and in society.

To qualify for inclusion in the present study, participants had to meet the following criteria: aged 12 or older; successfully completion of treatment, with weight restored to a normal (SD) BMI based on their age and height; in possession of a relapse prevention plan at the start of the aftercare program; participation in the aftercare program for at least 18 months.

Study participants were selected in two stages. The adult participants (age $>18$ years) were selected between the latter part of 2011 and the early part of 2012. The adolescents (age 12-18 years) and their parents were selected during a second round in spring 2013.

Twenty-two participants were eligible to participate, i.e. 14 adults and 8 adolescents. Two participants refused to participate without giving any reason. Three others refused because they did not want to discuss their illness history again. Seventeen participants were included in our sample, ten adults with a mean age of 22.5 (range
19 - 32) and seven adolescents with a mean age of 16.6 (range 14 - 18). The mean BMI $\left(\mathrm{kg} / \mathrm{m}^{2}\right)$ at the start of the treatment was 16.1 (SD 1.74); at the start of the PAC program, it was 19.7 (SD 1.33). The mean BMl at the end of the aftercare program was 19.5 (SD 1.71). The mean length of participation in the PAC program was 20.6 months (SD 5.32). The mean number of PAC meetings was 5.4 (SD 3.26). Three participants experienced a full relapse during the aftercare program, and six participants experienced a partial relapse. Six sets of parents participated in the study.

\section{Data collection and analysis}

Data collection took place by means of semi-structured interviews. To prepare for the interview, the researchers extracted the course of illness over the past 18 months of the PAC program from the participants' files. The researchers also produced a summary of the discussion between the health professional and the participant at every PAC meeting.

An interview protocol was constructed based on the structure of the GRP and focusing on the different components of the relapse prevention plans: the preparatory stage; identification of triggers and early signs of relapse; formulation of actions to prevent further relapse; and help by family members. The interview further involved evaluating the contribution of the health professionals and the usefulness of the PAC meetings. This meant exploring how the participants and their families experienced all these topics as well as perceived barriers to and facilitators for effective implementation and execution of the relapse prevention program.

The interviews with the participants lasted approximately 90 minutes, and the interviews with the parents approximately 30 minutes. The interviews took place at a location of the participant's choice and were recorded on audiotape, with the participant's permission. Audio-taped interviews were transcribed verbatim. Data analysis involved generating a category scheme with related code words, based on the structure of the GRP and the derived topic list. To ensure the highest possible coding consistency across the interviews, the two primary researchers coded the entire data set. Because they did not expect the definition of predetermined code words to bias subsequent data collection and analysis, they constructed a code tree in advance based on the structure of the GRP (Hsieh \& Shannon 2005). This initial code tree was adjusted during the process of data analysis.

Thematic analysis was performed to identify meaningful themes in the interview material. Thematic analysis involves the following six phases: (1) familiarization with data, (2) generating initial codes, (3) searching for themes among codes, (4) 
reviewing themes, (5) defining and naming themes, and (6) producing the final report. The software program Nvivol0 was used to support data analysis. For a further elaboration of these phases, we refer to Braun \& Clarke (2006).

\section{Research quality}

Two interviewers listened objectively and critically to the tape-recorded interviews to improve the quality of subsequent interviews (Polit \& Beck, 2008). The research team discussed four of the interviews to evaluate the interview structure and techniques. To evaluate and enhance the reliability of the data analysis process, the two primary researchers kept a log of decision points. The research team discussed the log to check the accuracy of the coded data and the implications for describing the findings (Creswell, 2007; Polit \& Beck, 2008). To obtain feedback on their individual interpretations during data analysis, the researchers presented their final results to a multidisciplinary peer review panel consisting of three professors (mental health nursing and psychiatry), one senior researcher, and five psychologists in training.

\section{Results}

The following three sections describe the experiences of the participants and parents who were interviewed, including the factors that they identified as facilitators and barriers for implementing the GRP.

\section{General evaluation}

Applying the GRP involves drawing up a relapse prevention plan (RPP) and working with this plan at home. Regular PAC meetings are meant to evaluate the process of working with the RPP, including systematic monitoring of early signs and symptoms of relapse. Participants and parents stated during the interviews that they were generally satisfied with the GRP. Participants on average gave the GRP a score of 7.4 (range 5 - 8.5), and parents a score of 7.5 (range 7 - 8) ( 1 = extremely poor; 6 = sufficient; 10 = excellent). Participants mentioned that drawing up a relapse prevention plan contributed significantly to their understanding of their individual relapse process. Participants and parents valued the fact that they could keep in touch with their health professional during the PAC program; it felt like a safety line to them.

With the PAC program, you know that you won't just be put out on the street after your treatment. It feels like you have a safety line to your own health professional. That really felt secure (Participant 5, age 28)
The most important point for us as parents was to have someone to fall back on when things were not going well. The relationship with the health professional, that back-up, gave us the confidence to let go (Parents 2)

Because participants and parents could stay in touch with the health professionals during the PAC program, they were able to get support in maintaining their balance and preventing a relapse. They experimented with personal relapse prevention strategies on their own, but could always fall back on the health professionals from the PAC program for support, and, if necessary, simply be referred to the treatmen centre for more intensive treatment.

I have heard many bad stories about waiting lists. So when I entered the PAC program, I was glad my patient file was not closed. And they would not have to put me on a waiting list, if it turned out to be necessary (Participant 9, age 20).

It was important to participants and parents to have easy access to the health professionals, not only at scheduled PAC meetings, but also on an ad-hoc basis by e-mail, phone and video calls.

The participant, their family members and the health professional decided together on the frequency of the PAC meetings, so the schedule could be tailored to the participant's preferences and needs. With the focus on self-management, a balance was sought between activities that could be employed independently or with minima coaching on the one hand, and activities that needed more intensive support on the other hand. This individualized approach made a positive contribution to the smooth transfer from (intensive) treatment to the low-frequency PAC program. Despite this generally positive appreciation of the program, a frequently mentioned barrier was that participants were not eager to come to PAC meetings in the eating disorder centre, because it meant being confronted with other patients who were still ill and recalling their own period of severe mental illness. However, the perceived need to actively work on relapse prevention prevailed and the confrontations did not prevent the participants from coming to the PAC meetings.

I just didn't want to think back to the time I was ill. I just wanted to be normal and go my own way, but I knew that the PAC meetings were important to attend and the contact with my health professional were pleasurable. (Participant 11, age 16) 


\section{The preparatory phase}

At the start of the PAC program, i.e. in the final stage of treatment just before discharge, the participant started by drawing up an individual RPP describing triggers, early warning signs of relapse, and actions to be taken in the event of impending relapse in four successive stages. Drawing up an RPP gave participants a clearer understanding of their personal experience of their eating disorder and the course of previous relapses. It helped make implicit knowledge explicit. Entering the different stages of relapse into a diagram was a cognitive strategy.

Itreally helped me to visualize my eating disorder, as well as my own stages ofrelapse. To know when there's a risk of severe relapse and how to act when this happens. Previously I was aware of certain signals, but thought they weren't important. But if you look at them at a deeper level, they are definitely relapse triggers. It's nice to understand myself better so I can intervene more quickly

\section{(Participant 8, age 23)}

Simultaneously, as they came to understand their relapse process better, participants were able to internalize the content of their RPP, making them less dependent on their detailed plan and giving them more opportunities to use the RPP content in everyday situations. Participants regarded drawing up an RPP as an important step, although it was not always easy to do. They found it confrontational to think back to the start of their eating disorder because it was a stressful period in their life. Participants were inclined to avoid thinking about periods of severe mental distress. They seemed to find it particularly difficult to further elaborate the early signs of relapse in different relapse stages, although feelings of satisfaction were often present after completing the task.

The early signs were vaguely present in my mind, and sometimes a little chaotic. It is quite confronting thinking about the past and the unpleasant time during my illness. I didn't want to think back really. But when you write down the early signs, it becomes clear what they actually mean. When I was finished, I found it enlightening. (Participant 7, age 18)

However, some participants were troubled by perfectionism, and remained dissatisfied when describing their process of relapse in detail. They also found it difficult to make time for it at home, as it is a time-consuming activity. Despite the perceived barriers, drawing up the RPP was experienced as an essential step to obtain a better insight into the process of relapse.
The GRP recommends that the participant's network be actively involved in drawing up the RPP. In the case of the adolescents, parents were commonly involved in decision making throughout the whole treatment, and so the younger participants did actively involve their parents in drawing up the RPP. In the case of the adul participants, however, their networks often did not become actively involved, making it hard for them to work with the plan at home with the help of network members. Participants often felt ashamed to ask for help or were convinced they should be able to do it by themselves, which was the main reason for them to keep their network members at a distance. Despite this restraint, the participants frequently ask the health professionals to support them involving their network in relapse prevention activities, both in the preparatory stage and the implementation stage.

Successful participation in the aftercare program depended in part on how the process of drawing up the RPP was timed in terms of the patient's motivation to work actively on her recovery and on preventing relapses. Starting the relapse prevention strategies at the right moment, i.e. when the patient was relatively stable and felt ready to end treatment, contributed to the patient's self-confidence and provided opportunities to gain more self-awareness. The change from intensive treatmen to the PAC program, with opportunities for personalized care, was experienced as smooth and felt secure.

I liked to move on and I felt more and more that I was doing well and was sufficiently stable. It was nice to work on the RPP to complete my treatment. (Participant 5, age 28).

I learned to know myself better by drawing up the RPP and that gave me confidence, I knew I would be able to do it on my own. (Participant 11, age 16)

Starting the relapse prevention strategies too soon, i.e. when the patient was still in intensive treatment, was confrontational and demoralizing for some participants because it made them realize that they were still too ill to participate in the aftercare program.

When I was drawing up the different stages of the RPP, I had to write down healthy behavior that I could show. But I was not able to show this behavior, because my anorexic thoughts and behaviors were still predominant (Participant 4, age 21). 


\section{The GRP in practice}

Once a participant had completed the RPP, she embarked on the stage of actively working with the plan within the context of the PAC program. It was especially important to participants to have easy access to health professionals if their situation deteriorated. Participants required competent health professionals with specialized knowledge and expertise concerning all the different aspects of the eating disorder. They further emphasized the value of a good therapeutic relationship with this health professional, one in which they could be open and honest about their health status.

I felt at ease with my health professional, that's why I dared to talk about subjects I was ashamed of and which I found very difficult to talk about (Participant 7, age 18)

My health professional played an important role during my treatment. During the PAC visits she focused on subjects that were really important to me. I only wanted to talk about everyday situations, but my health professional put emphasis on situations that were challenging to me, my real weaknesses and difficulties. (Participant 4, age 21)

During the PAC visit, two main topics were discussed: the patient's psychological and social functioning (overall mood, functioning at school, relationships with friends, sports, etc.) and the presence of AN symptoms (anorectic cognitions, abnormal eating habits, excessive exercise pattern, etc.). When discussing these topics both strengths and weaknesses of the participant could be explored, and opportunities to increase self-management skills were searched for. Despite the availability of easily accessible support, however, it was seemingly difficult for many participants to actually ask for this support when needed. They were hesitant and sometimes afraid to ask for help, or they feared the unknown.

It is very hard, I think I always try to avoid asking for help, so I don't need to think about the eating disorder that is playing up again. I go out with friends more, work harder, just make sure I have a busy schedule. When I think about it, then I tend to avoid it and find it very hard to ask for help. You know, you have to admit that it is not going well, and I was afraid, even though they are really professional, that they wouldn't take me seriously. I was afraid they wouldn't understand me (Participant 5, age 28)

The majority of the participants indicated that they did not work with the RPP actively during the aftercare period. They gave different reasons. For example, some said that it all went so well that the RPP wasn't of real value at that particular time. Others were convinced that they could manage their mental health status without explicit use of the RPP, so they put it away instead of keeping it in sight. Another common reason was that the participant had largely internalized the content of the RPP, so she was familiar with the plan and there was no need to use the detailed version.

It is not literally the plan that plays an important part when a relapse is starting but the thoughts and ideas I have written down in the plan that are useful. Those are integrated into the strategy I have and use every day of my life. I don't think that physically sitting down with the plan would help (Participant l, age 19)

Participants sometimes felt that they had failed if they used the plan actively in their daily life. They demanded of themselves that they could apply preventive strategies without using the RPP actively. They explained that the high standards they set for themselves played a significant role in this. Another crucial barrier to using the RPP actively was that some health professionals did not use the plan explicitly during the PAC meetings. As a result, the RPP faded into the background and new knowledge concerning the course of the disorder and use of self-management strategies was not integrated into the plan.

What I missed was using the RPP during the PAC meetings. I don't like the confrontation, but if we had used the RPP more actively, it might have been easier for me to admit that I was showing stage 2 or maybe even stage 3 signs of relapse. And what's difficult is that, because it wasn't used, it isn't up-to-date, it won't grow with your situation that way (Participant 4, age 21)

The respondents indicated that it would have helped them to make more active use of the RPP so as to avoid fooling others and/or themselves, and instead face their personal situation and the threat to their mental health status.

Some of the participants also used the RPP to work on relapse prevention at home, with the help of their social network. In the majority of the cases, their families were very helpful and played an important role in applying relapse prevention strategies, e.g. by talking to the participant when things were not going well and by asking questions that gave the participant a better understanding of their dysfunctiona eating or exercise patterns. Family members provided support in hard times and often were able to correct the participants in their (pre-)anorectic behaviors. They also supported the participant by just being there, and by listening without judging. Their support could also be very practical in nature, for example checking the participant's eating pattern. 
My stepmother is very good at helping me, she can calm me down. She shows me the world isn't going to crumble beneath me. She helps keep me on my feet. Just by talking and asking questions, and when I answer honestly it helps me understand my own behavior (Participant 6, age 19)

Every Sunday evening, we sit down together with our daughter for about 15 minutes. Just to talk about how the week went, and to talk through the list of triggers from the relapse prevention plan. Then we know exactly how our daughter is doing, and whether we could maybe help out in some way (Parents 4)

In other cases their network members were not actively involved. Some participants felt that their family members were too emotionally involved, so that they worried too much, grew critical when the participant's situation deteriorated, or interfered too much with the participant's eating pattern. Participants experienced this as oppressive, leading them not to involve family members in working with the RPP.

Checking up on me and getting angry and that kind of thing really only backfires. It makes me angry, depressed and l eat even less. Talking and listening, that helps, not becoming angry (Participant 8 , age 23)

For these participants, the PAC visits were even more important to obtain the necessary support, because they could not turn to their own network when they needed help, among other things with respect to the use of relapse prevention strategies.

\section{Discussion}

The GRP is used by the participant, her family members and health professionals to obtain a better understanding of the process of relapse, thus increasing opportunities to intervene at an early stage of deterioration. Participants and family members gave different explanations for how the guideline helped improve self-management skills. The five core self-management skills described in the introduction (Lorig \& Holman, 2003) can also be found in the interviewees' statements. 1) Drawing up the RPP improves problem solving skills, encouraging the participant to focus on finding adequate responses to everyday problems and the exacerbation of symptoms. 2) Decision making: by using the RPP and by internalizing its content, participants become more capable of making effective decisions regarding the challenges they are experiencing in relation to their eating disorder and a possible relapse.
3) Resource utilization: the RPP explicitly encourages participants to use external resources, e.g. make use of the support of their social network or parents, and if needed - seek professional help at the earliest possible stage during the overall aftercare program. 4) Forming of a patient-healthcare provider partnership: this is a core element of the GRP, i.e. working collaboratively toward the same goal of relapse prevention. Participants need to build a relationship of trust with the health professional, with quick access to professional support in the event of an impending relapse. In partnership, participant and professional caregiver can learn from previous and current experiences and events. 5) Taking action: the predetermined actions formulated in the RPP means the participant is prepared to take effective action in the event of destabilization. The improvement in self-management skills reduces the participant's dependence on health professionals or members of her social network.

These findings are in line with Keel et al. (2005), who found that poor psychosocial functioning and support of women with AN is a predictor of relapse. These women may be less equipped to cope with life stressors that could possibly influence the recurrence of symptoms. Working with the GRP within a good therapeutic relationship may contribute to the development of effective coping strategies to better deal with these psychosocial stressors that influence the recurrence of relapse.

Regarding the participant's social network, the interviews showed that this network can play either a helping or hindering role with respect to relapse prevention. This can be explained to a large extent by the nature of the relationship between the participant and family members. When the relationship was more detached and family members were supportive and took a non-critical attitude, they were better able to help the participant through the process of recovery, and relapse prevention in particular. By contrast, when family members were emotionally involved and had a critical attitude toward the participant's behavior, the participant could experience their presence as stressful and thus not helpful for further recovery and relapse prevention. These findings are in line with previous research findings concerning the concept of expressed emotion (EE), which also applies to patients with eating disorders (Butzlaff \& Hooley, 1998). Involving the social network in the process of relapse prevention is essential, but the timing and selection of the right person(s) are important. During their aftercare visits, health professionals are advised to explore whether this relationship is positive and supportive, and will thus contribute to relapse prevention. If it is not, psycho-education and coaching should be part of the aftercare intervention program to help the family member engage in more effective interaction with the patient 
The interviews revealed that use of the RPP during PAC meetings was inadequate in a number of cases. To ensure that the plan remains up to date and that the patient makes active use of it in her daily life, it is vital to discuss the RPP during PAC meetings and update it in line with recent experiences. During these meetings, the health professional should encourage patients to keep the RPP up to date and to discuss the RPP with their network.

\section{Strengths and limitations}

Studies on relapse prevention are scarce. Little is known about predictors of relapse, and no evidence-based relapse prevention strategies are available. There is clearly a need for more research on relapse and on relapse prevention strategies (Richard et al., 2005; Keel et al., 2005; Carter et al., 2012, Khalsa et al., 2017). This is the first qualitative study on how patients and their families experience the use of a structured relapse prevention strategy derived from evidence and practice-based guidelines. This research design allowed us to gain an in-depth understanding of the patients' and family members' experiences and their opinion of the guideline. One of the strengths of this study is that the researchers, who conducted the interviews, were not employed in the specialized setting themselves, thus increasing the objectivity of the qualitative research process. Participants and parents were free to describe their experiences and express their opinions about working with the GRP, and they valued the anonymity. In addition, an external researcher (BM) provided the main supervision for the study, as described in the method section.

The study achieved data saturation with a relatively small sample of seventeen participants because the participants were able to reflect on their experiences effectively. Once the 23 interviews had been conducted, no new essential information was added. Another strength of this study is that it investigated the perspectives of both adolescent patients and parents concurrently. Unfortunately, interviews with the adult participants' social network were not included, which is a weakness. In future research, the social network of the adult patients should also be included to gain a complete understanding of how patients experience working with the GRP.

\section{Conclusion}

The purpose of this study was to gain a deeper understanding of the experiences of AN patients and their families when applying the Guideline Relapse Prevention (GRP). Our conclusion is that participants and parents were generally satisfied with the support provided by the GRP. The plan gave them significant help in understanding their own relapse process. Most participants had internalized the content of the RPP in such a way that they relied on the plan less and could apply self-management strategies successfully. Participants and parents valued the fact that they could keep in touch with their health professional during the aftercare program; it felt like a safety line to them.

\section{Relevance for clinical practice}

When the GRP is applied in practice, it is essential to allow for variation between participants. Most participants were motivated to work with the GRP, and they were open about their vulnerability to possible relapse. They actively sought contact with their family or health professionals when they relapsed or felt at risk of doing so. Others, however, found it difficult and confrontational to work with the GRP and had a more avoidance coping style. Alongside these differences in attitude and context, factors such as intelligence level, cognitive skills, and insight into the illness must also be taken into account. At the individual level, these variables interact in a complex manner, requiring the relapse prevention strategies to be tailored to the individual characteristics and context of the patient.

It is evident from this qualitative study, but also from previous quantitative research into the preliminary effects of the GRP (Berends et al., 2016), that the guideline is a highly suitable tool for working with anorexia nervosa patients on preventing potential relapses. Future experimental and cost-effectiveness research will be required to improve and further establish the effectiveness of this guideline. 


\section{References}

American Psychiatric Association. (2006). Practice Guideline: Treatment of patients with eating disorders. APA. Berends, T., van Meijel, B., \& van Elburg, A. (2010). Richtlijn Terugvalpreventie Anorexia Nervosa (Guideline Relapse Prevention Anorexia Nervosa). Koninklijke Van Gorcum

Berends, T., van Meijel, B., \& van Elburg, A. (2012). The Anorexia Relapse Prevention Guidelines in practice; a case report. Perspectives in Psychiatric Care, 48, 149-155.

Berends, T., van Meijel, B., Nugteren, Deen, M., Danner, U. N., Hoek, H. W., \& van Elburg, A.A. (2016). Rate, timing and predictors of relapse in patients with anorexia nervosa following a relapse prevention program: a cohort study. BMC Psychiatry, 16, 316.

Braun, V., \& Clarke, V. (2006). Using thematic analysis in psychology. Qualitative Research in Psychology, 3, 93. Butzlaff, R. L., \& Hooley, J. M. (1998). Expressed emotion and psychiatric relapse: a meta-analysis. Archives of General Psychiatry, 55(6), 547-552.

Carter, J. C., Blackmore, E., Sutandar-Pinnock, K., \& Woodside, D. B. (2004). Relapse in anorexia nervosa: a survival analysis. Psychological Medicine, 34, 671-679.

Carter, J. C., Mercer-Lynn, K. B., Norwood, S. J., Bewell-Weiss, C. V., Crosby, R. D., Woodside, D. B., \& Olmsted, M.P. (2012). A prospective study of predictors of relapse in anorexia nervosa: implications for relapse prevention Psychiary Research, 200, 518-523.

Creswell, J. W. (2007). Quality Inquiry and Research Design: Choosing among Five Approaches. London, England: Sage Publications, Inc.

Dutch Committee for the Development of Multidisciplinary Guidelines in Mental Health Care. (2006) Multidisciplinary Guidelines Eating Disorders. Utrecht, The Netherlands: Trimbos Institute.

Eckert, E. D., Halmi, K. A., Marche, P., Grove, W., \& Crosby, R. (1995). Ten-year follow-up of anorexia nervosa clinical course and outcome. Psychological Medicine, 1, 143-56.

Herzog, D. B., Dorer, D. J., Keel, P. K., Selwyn, S. E., Ekeblad, E. R., Flores, A. T., Greenwood, D. N., \& Keller, M. B. (1999). Recovery and relapse in anorexia and bulimia nervosa: a 7.5-year follow-up study. Journal of the American Academy of Child and Adolescent Psychiatry, 38, 829-837.

Hsieh, H. F., \& Shannon, S. E. (2005). Three approaches to qualitative content analysis. Qualitative Health Research, 15, 1277-1288

Keel, P. K., Darer, D. J., Franco, D. L., Jackson, S. C., \& Herzog, D. B. (2005). Postremission predictors of relapse in women with eating disorders. American Journal of Psychiatry, 162, 2263-2268.

Keski-Rahkonen A., Hoek H. W., Susser E. S., Linna, M. S., Sihvola, E., Raevouri, A., Bulik, C. M., Kaprio, J., \& Rissanen, A. (2007). Epidemiology and course of anorexia nervosa in the community. American Journal of Psychiatry, 164, 1259-1265.

Khalsa, S. S., Portnoff, L. C., McCurdy-McKinnon, D., \& Feusner, J. D. (2017). What happens after treatment? A systematic review of relapse, remission and recovery in anorexia nervosa Journal of Eating Disorders, 5,20 .

Lorig, K. R., \& Holman, H. R. (2003). Self-Management Education: History, Definition, Outcomes, and Mechanisms. Annals of Behavioral Medicine, 26, 1-7.

Marcellus, J., Mitchell, A. J., Wales, J., \& Nielsen, S. (2011). Mortality rates in patients with anorexia nervosa and other eating disorders. A meta-analysis of 36 studies. Archives of General Psychiatry, 68, 724-731.

McFarlane, T., Olmsted, M. P., \& Trotter, K. (2008). Timing and prediction of relapse in a transdiagnostic eating disorder sample. International Journal of Eating Disorders, 41, 587-593.

NICE clinical guideline (2004). Eating disorders. Core interventions in the treatment and management of anorexia nervosa, bulimia nervosa and related eating disorders. [Cited 2 November 2016]. Available from URL (www.nice.org.uk/cg9)
Polit, D. F. \& Beck, C. T (2008). Nursing Research. Generating and Assessing Evidence for Nursing Practice Lippincott Williams \& Wilkins, a Wolters Kluwer business.

Richard M., Bauer S., \& Kordy H. (2005). Relapse in Anorexia and Bulimia Nervosa-A 2.5-Year Follow Up Study. European Eating Disorders Review, 13, 180-190.

Smink, F. R. E., van Hoeken, D., \& Hoek, H. W. (2012). Epidemiology of Eating Disorders: Incidence, Prevalence and Mortality Rates. Current Psychiatry Reports, 14, 406-414

Strober, M., Freeman, R., \& Morrell, W. (1997). The long-term course of severe anorexia nervosa in adolescents: survival analysis of recovery, relapse, and outcome predictors over 10-15 years in a prospective study. International Journal of Eating Disorders, 22, 339-360.

Walsh, B. T., Kaplan, A. S., Attia, E., Olmsted, M., Parides, M., Carter, J. C., Pike, K. M., Devlin, M. J., Woodside B., Roberto, C. A., \& Rockert, W. (2006). Fluoxetine after weight restoration in anorexia nervosa: randomized controlled trial. Journal of the American Medical Association, 295, 2605-2612 


\section{Abstract}

One out of three patients with anorexia nervosa relapses after treatment, the highest risk of relapse is during the first two years after discharge. There is no empirical research on the process of relapse, the triggers that cause relapse, or the early warning signs for relapse. More insight is needed to help patients and professionals with early recognition and early intervention to prevent relapse. This is why the Anorexia Relapse Prevention INventory (ARPIN) was developed for patients and professionals to help identify triggers and early warning signs of relapse. Quantitative and qualitative strategies were used to develop the ARPIN. Relapse prevention plans of 107 AN patients were studied in the content analysis and lists of triggers and early warning signs were established. An inventory draft was done by merging and categorizing triggers and early warning signs. Face validity was examined conform the COSMIN guidelines in a focus group of seven experts by experience. They considered the ARPIN to be a structured and easy to use tool. The ARPIN consists of 9 main items of triggers with 54 core examples and 15 categories of early warning signs.

\section{Keywords}

triggers, early warning signs, early detection, relapse prevention, anorexia nervosa.

\section{Clinical implications}

- ARPIN is a structured and easy to use tool for patients with anorexia nervosa and their professionals.

- ARPIN identifies triggers and early warning signs of relapse to gain insight in the process of relapse.

- The most common trigger is problems experienced in interpersonal contact with others.

\section{Introduction}

Anorexia nervosa (AN) is a severe mental disorder in which relapse after treatment is common. The lifetime prevalence of AN amongst women is up to 2-4\% (Galmiche et al., 2019; Keski-Rahkonen \& Mustelin, 2016), whereas the prevalence amongst men is ten times lower (Raevuori et al., 2014). The crude mortality rate is $5 \%$ per decade (Arcelus et al., 2011; Smink et al., 2013). The overall incidence rate has remained stable over the past decades (i.e. 6.0 per 100,000 total population) and the age-specific incidence is highest in the age group of $15-19$ years (Smink et al., 2016).

AN is one of the most chronic disorders in adolescence (Schmidt et al., 2016) and can result in so-called SE-AN (Severe and Enduring Anorexia Nervosa; Wonderlich et al. 2020). Outcome studies show remission rates for AN between $30-50 \%$ (Fichter et al., 2017; Eddy et al. 2017; Steinhausen, 2002). Prevention studies on anorexia nervosa often focus on primary prevention (Levine, 2020), knowledge on relapse prevention is still limited. One out of three patients $(31 \%)$ relapse after treatment, and the highest risk of relapse occurs during the first year after discharge and the risk of relapse continues for up to 2 years (Berends et al., 2018; Carter et al., 2004, 2012; Khalsa et al., 2017; Richard et al., 2005; Strober et al., 1997).

In leading guidelines in the field of eating disorders (Dutch Foundation for Quality Development in Mental Healthcare, 2017; National Institute for Health and Care Excellence (NICE), 2017; ANZAED guidelines, Hay et al., 2014; Hilbert et al., 2017) consensus exists that relapse of an eating disorder is common and relapse prevention is therefore essential. The Dutch practice guideline for the treatment of eating disorders (2017) advises to make relapse prevention strategies a crucia element of the treatment, and refers to the Guideline Relapse Prevention Anorexia Nervosa (Berends et al., 2010). This guideline is an evidence-based tool for health professionals and patients, which offers a structured approach to apply relapse prevention strategies. The guideline's primary aim is to gain a better understanding of the patient's individual process of relapse through a close collaboration of the professional, the patient and her relatives. To date, there is no empirical research that sheds light on this process of relapse, the triggers that cause it or the early warning signs for a relapse.

The objective of this study was to gain insight in the triggers and early warning sign of relapse from the patients' perspective, and to develop and validate a new tool with the aim to give AN patients more insight into their triggers and early warning signs in order to prevent a relapse. By following the Consensus-based Standards for 
the selection of health Measurement INstruments (COSMIN, Terwee et al., 2018), we developed the Anorexia Relapse Prevention INventory (ARPIN).

\section{Method}

\section{Design}

This study was carried out in three phases. With the purpose of gaining knowledge and understanding of the phenomenon studied (see Figure 1), qualitative and quantitative research strategies were used. In the first phase, a content analysis was carried out on all Relapse Prevention Plans (RPP) of patients working with the guideline during the first two years. All triggers and early warning signs from the relapse prevention plans (RPP) were collected. During the second phase, the content of the list of triggers and the list of early warning signs was analyzed, revised and categorized into specific items. In this part, of the study specific attention was given to item reduction. The analysis was done by three independent researchers who achieved consensus, resulting in the development of the ARPIN (Anorexia Relapse Prevention INventory). In the third phase, a focus group discussion was held to examine the face validity of the ARPIN. The study protocol was approved by the Institutional Research Comity of Altrecht mental health care service.

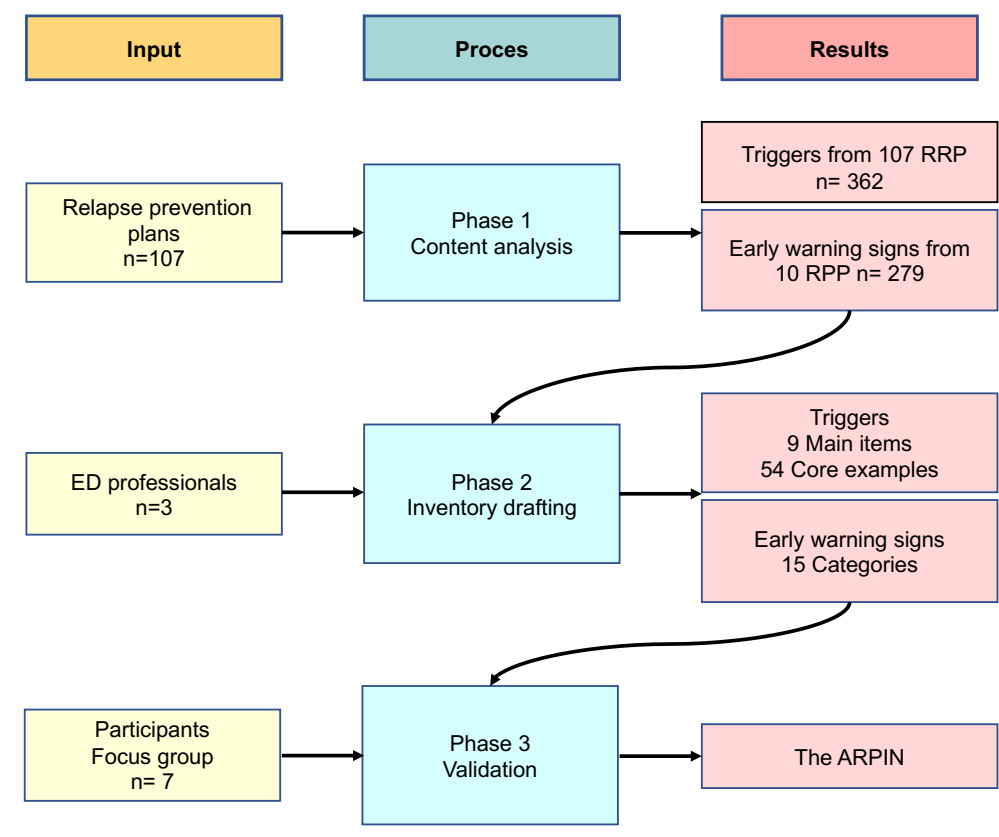

Figure 1: Flowchart of the study.

\section{Setting and participants}

This study was carried out in a highly specialized treatment centre for eating disorders in the Netherlands. The treatment for adolescents and adults provided in this setting is based on the state-of-the-art recommendations made in three sets of guidelines: the Dutch practice guideline for the treatment of eating disorders (2017), the NICE Guidelines for Eating Disorders (2017) and the Royal Australian and New-Zealand College of Psychiatrists clinical practice guidelines for the treatment of eating disorders (2014). Treatment focuses on three areas: (I) eating habits, body weight, and body image; (II) psychological aspects of functioning, such as selfesteem, perfectionism and traumas; and (III) social functioning within the family and in society.

To qualify for inclusion in this study, participants had to meet the following criteria: patients diagnosed with anorexia nervosa; aged 12 years and older and in possession of a relapse prevention plan in the aftercare program. Patients themselves were not involved in this inclusion process; their relapse prevention plans were anonymously retrieved from the medical files from our patients.

\section{Guideline Relapse Prevention (GRP)}

The primary aim of the relapse prevention guideline is that the professional, patient and her relatives collaborate closely in order to gain a better understanding of the patient's individual process of relapse. Triggers and early warning signs that preceded previous relapses are identified and elaborated for the individual patient Actions are formulated that can be performed in the event of a new impending relapse. This information is summarized in a Relapse Prevention Plan (RPP). In essence, the aim of the relapse prevention strategy is to ensure that appropriate action is taken as early as possible when early warning signs of relapse occur.

The guideline consists of three parts: (a) a theoretic framework for relapse and relapse prevention, developed on the basis of the literature as well as experts' and patients' clinical experience, leading to conclusions and recommendation for clinical practice; (b) a practical manual for professionals; and (c) a workbook for patients. For a complete description of the application of the GRP, see the case report by Berends et al. (2012). The GRP is freely accessible online, at www.relapsean.com.

During the aftercare program, an RPP is drawn-up, after which individual checks will take place at a low frequency, for a minimum of 18 months. During the aftercarevisits, the patient's condition is thoroughly monitored and discussed making use of 
the RPP. Between formal visits, patients or their relatives can contact the professional at any time should they need help.

\section{Phase 1 Content analysis}

In order to map triggers and early warning signs, the third author (MvZ) extracted these from the RPPs. The patient and the health professional worked together to identify triggers and early warning signs. The early warning signs were described using three stages of relapse: 1) mild relapse, describing early warning signs in a mild form; 2) moderate relapse, describing early warning signs in a moderate form; 3) complete relapse, describing the signs of a relapse. This content analysis resulted in two lists; 1) Triggers of relapse, 2) Early warning signs of relapse.

\section{Phase 2 Instrument drafting}

Further instrument drafting was done by categorizing and reducing the lists of triggers and early warning signs of relapse.

) Triggers of relapse; items were categorized and reduced according to these steps; 1) two researchers (MvZ and TB) separately grouped the triggers and appointed categories. All triggers were classified into these categories. 2) In a consensus meeting, these categories were debated until consensus was reached. 3) In a second consensus meeting a third researcher and expert on this topic (AvE) was involved and the final categories were established, and the triggers classified into the categories were grouped and reduced to core examples.

2) Early warning signs of relapse; items were categorized and reduced in four steps: 1) Ten RPP workbooks were scrutinized, from which the early warning signs were extracted. 2) Two researchers (AvE and TB) separately grouped and categorized the early warning signs. All early warning signs were classified into these categories. 3) In a consensus meeting ( $\mathrm{AVE}$ and TB), the categories were debated until consensus was reached. 4) Early warning signs from two separate, randomly chosen workbooks were used to test if they could be classified within the categories.

The final list of trigger categories and core examples and the final categories of early warning signs resulted in the ARPIN.

\section{Phase 3 Validation (face validity)}

For the validation of the ARPIN, we set up a focus group discussion with experts by experience. The steps of the COSMIN, box 2 (Terwee et al., 2018) to evaluate the quality of content validity were followed. Seven experts by experience (all women; age range 21-37; mean duration of recovery from AN was 5.1 years $(S D=2.3)$ ) participated in the focus group discussion which was led by a skilled interviewe $(\mathrm{HWH})$. An interview guideline was used during the focus group discussion. The discussion was recorded and transcribed verbatim. The data was analyzed using a thematic analysis; two experienced researchers were involved in the analysis (TB and NB).

\section{Results}

A total of 107 relapse prevention plans were examined thoroughly for triggers of relapse. This resulted in a list of 386 triggers. Triggers that described the same theme were clustered (for example; "winter holiday" and "summer holiday" were merged and named "holiday"), 375 triggers remained. Thirteen triggers were considered too diffuse or idiosyncratic to place into an item and were excluded, leaving 362 triggers; for example: "problems" was described as a trigger, or "getting out into the spotlights after my book was published". After item reduction, 9 main items and 53 core examples remained and were included in the first version of the ARPIN. The main item that was reported most frequently was "interpersonal contact" (34\%). To allow for more detailed outcomes, this item was split into four more distinctive main items of triggers in the ARPIN. Table 1 shows the frequency of main items of triggers.

\begin{tabular}{lll} 
Table 1. Frequency of main items of triggers $(\mathrm{n}=362)$ & $\mathrm{n}=$ & $\%$ \\
\hline Main Items & 124 & 34 \\
\hline Interpersonal contact* & 65 & 18 \\
School / work & 59 & 16 \\
Disturbance in mood or sense of self & 49 & 14 \\
Structure changes & 42 & 12 \\
Body & 23 & 6 \\
Eating pattern &
\end{tabular}

Ten relapse prevention plans were examined thoroughly for early warning signs of relapse. A total of 279 early warning signs were collected and used, data saturation occurred. After item reduction, 15 categories were selected within the main five themes of relapse (i.e. 1) eating pattern; 2) physical characteristics; 3) exercise pattern; 4) thoughts; and 5) social functioning). 
After a focus group discussion with seven experts by experience (all recovered former anorexia nervosa patients), a last round of additions was made. The experts by experience considered the ARPIN to be a structured and easy to use tool, with concrete examples, and thought the main items and core examples clear and recognizable. Because of this, they also felt the tool was confrontational. During the focus group discussion, the relevance of each item for the patients' experience with the condition, and the ARPIN's comprehensiveness and comprehensibility were discussed, as well as instructions, items, response options, and recall period. The focus group discussion did not lead to removal or addition of items. Minor adjustments were made to phrasing and vocabulary as the experts by experience advised to use informal language in the tool to make it less formal and more personal. Furthermore, they unanimously advised to insert comorbidity in the examples in the trigger section and to add space for personal examples in the early warning signs section to make the ARPIN more personalized. All participants considered the recall period of 18 months appropriate in length. The final version of the ARPIN is presented in table 2 and contains 9 main items with 54 core examples on triggers, and 15 categories of relapse.

\section{ARPIN (Anorexia Relapse Prevention INventory)}

People who have successfully completed treatment for anorexia nervosa are at increased risk of a relapse. One in three patients experience a relapse. As this is a heavy burden, we aim to avoid this as much as possible. Working on relapse prevention using a relapse prevention plan can contribute to this goal (www. relapse-an.com). The following are always among the aspects described in a relapse prevention plan:

What triggers a relapse for you? (For example, something that is very exciting or stressful for you)

What early signs of a relapse do you experience? (For example, you may notice you are exercising more or eating less)

- What steps (action) can you undertake to prevent relapsing further? (For example, ask a good friend to help you put together a healthy meal plan)

- Who could help you? (For example, your parents or a good friend with whom you can discuss the relapse prevention plan and what they can do to support you)

This ARPIN is based on experiences of recovered anorexia nervosa patients and has been created to help you identify 'Triggers' and 'Early warning signs' of a relapse.

\section{Triggers}

Triggers initiate the relapse process. A number of themes is listed below. Use an x to mark the position along the bar to indicate how much or how little this theme may apply to you Then check the examples, and tick the ones that may be relevant to you After that, you con include your personal considerations; are there any other incidents relating to this theme that may be a relapse trigger for you personally? Write them down

Problems in my relationships with others trigger a relapse in my eating disorder.

Examples:
O Starting all/hardly relationship/falling in love/ending a relationship
O Losing social contacts
○ Experiencing friction or resistance in contacts with friends
O Finding yourself part of a large group
O Meeting new friends
Personal considerations
O....




Negative interactions with others trigger a relapse in my eating disorder.
Not at all/hardly
Examples:
O A row/an argument
O Being teased or bullied
Personal considerations
O...

Stressful situations within my family trigger a relapse in my eating disorder

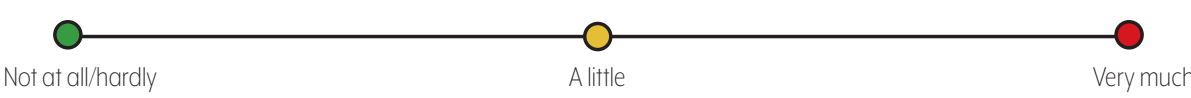

Not at allhar

little

o Difficult or stressful interactions within your immediate family (with parents/siblings)

o A death in your immediate family

o lllness of someone in your immediate family

o Problems within your immediate family (e.g. rowing/arguments, divorce, parents with mental illness)

Personal considerations

Changes in the contact with my counsellors trigger a relapse in my eating disorder.
Not at all/hardly
Examples:
O Starting follow-up therapy for additional problems
O Scaling back or ending your therapy
Personal considerations
○...

\section{Events or incidents at work / school trigger a relapse in my eating disorder.}

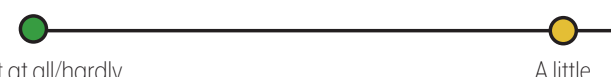

Alittle

Not at all/hardl

Examples:

O Exams

Changing school / programme

Pressure/stress/problems relating to school/work experience/work

OMore school) work or changes at work / changes relating to school assignments

o Negative recommendation regarding the continuation of your studies

○ Being made redundant/ being laid of

o Starting your own busines

○ Applying for a job

Personal considerations

Mood swings or negative feelings about myself trigger a relapse in my eating disorder

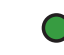

-

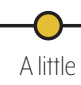

Alittle

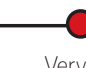

Examples:

o Feeling lonely

○ Feeling insecure

O Not being able to express your emotions

$\circ$ Anegative sell-image

Your mood getting worse

O-Taking about the past, the period of your eating disorder

O Fear of being thought of as fat/lazy/unathletic

o Worsening of symptoms triggered by another disorder

Personal considerations 
Early warning signs

Early warning signs are feelings, thoughts, behaviours and physical signals which, in the case of an eating disorder, may precede a relapse and, as such, can be considered signs of an impending relapse. Below, you will find descriptions of a number of themes for which early warning signs may occur. Use an $\mathrm{x}$ to mark the position along the bar to indicate how much or how liftle this theme may apply to you. This allows you to identify which themes you and the people around you should be most aware of, and on which themes your early warning signs will become apparent soonest. Below the themes there is room for you to indicate your personal early warning signs. The more detail you can put into your description of your early warning signs, the more insight you and the people around you will gain into the relapse process. As a result, a beginning relapse can be spotted early, allowing for faster intervention.

O Going on holiday

o Moving out of your parents' home/ living on your own

- Moving house

o Changing jobs

o Public/ religious holidays

O Being unable to get a grip on events around you

O Boredom

Personal considerations

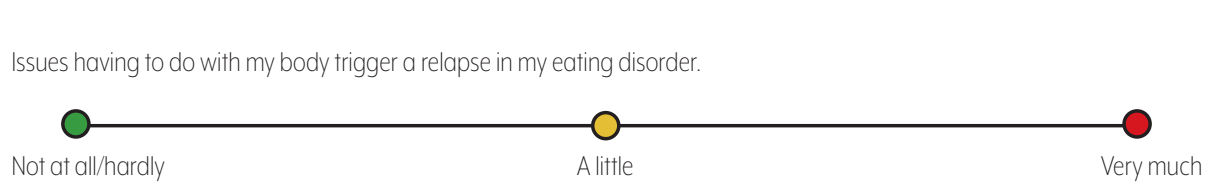

Not at all/hardly

Examples:

o Having to wear a swimsuit so that your body can be clearly seen

o Comparing your body to that of other people or models

o Fluctuations in your weight

Exercising or being unable to exercise (e.g. because classes ended or because of injury

o seeing people around you following a dief

o Summertime

o Spending a lot of time checking your body in the mirror

○ Being able to get pregnant (again), or the period after your pregnancy

Personal considerations

Changes in my eating habits trigger a relapse in my eating disorder

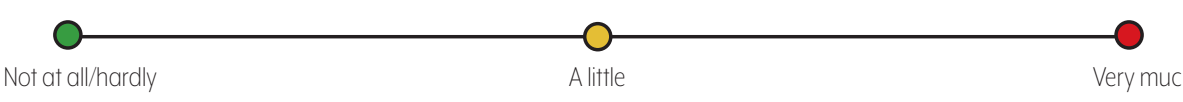

Examples:

o Going on holiday / going on a camp and having to eat there

o Missing a meal

O Having to eat more than usual (big dinner)

o Becoming ill and being able to eat less as a result

o Parties involving different food

- Eating at someone elsés house

o Charity events or religious festivals that require you not to eat for a while (e.g. Zipp Your Lipp, Ramadan)

Personal considerations
During a beginning relapse, I start..

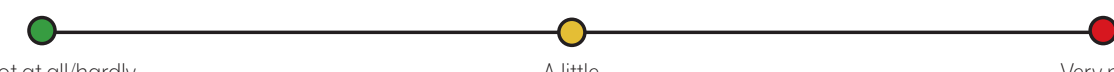

\begin{tabular}{l|l}
\hline Eating less & 0 \\
\hline
\end{tabular}

My early warning signs with regard to eating less are:

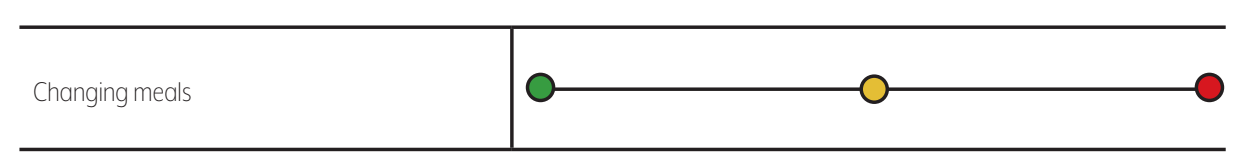

My early warning signs with regard to making changes in meals are

\begin{tabular}{l|l}
\hline Choosing different foods / ingredients & 0 \\
\hline
\end{tabular}

My early warning signs with regard to choosing different foods / ingredients are:

\begin{tabular}{l|l}
\hline $\begin{array}{l}\text { Showing compensatory behaviour (purging/ } \\
\text { using laxatives/exercising too much) }\end{array}$ & 0 \\
\hline
\end{tabular}

My early warning signs with regard to compensatory behaviour are:
Not at all/hardly Alittle 


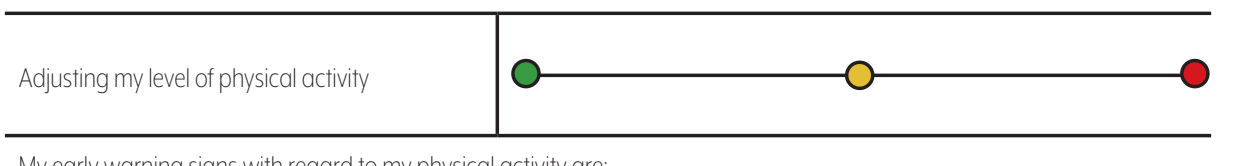

My early warning signs with regard to my physical activity are:

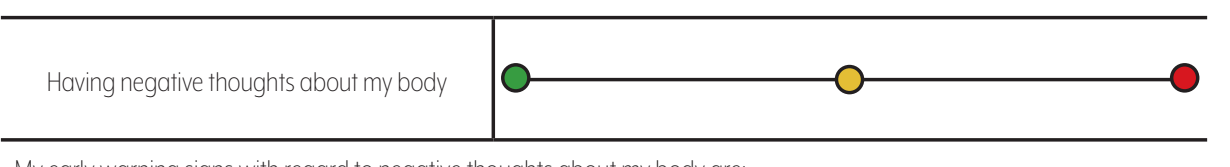

My early warning signs with regard to negative thoughts about my body are:

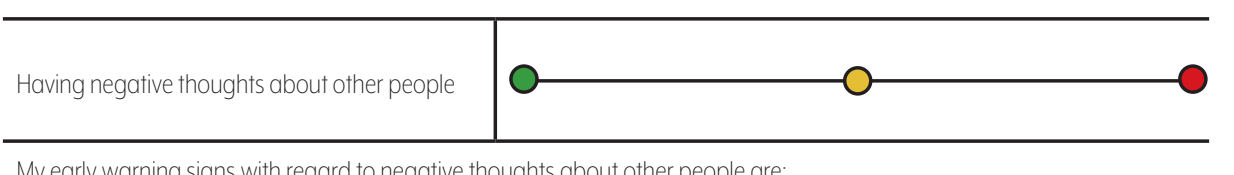

My early warning signs with regard to negative thoughts about other people are:

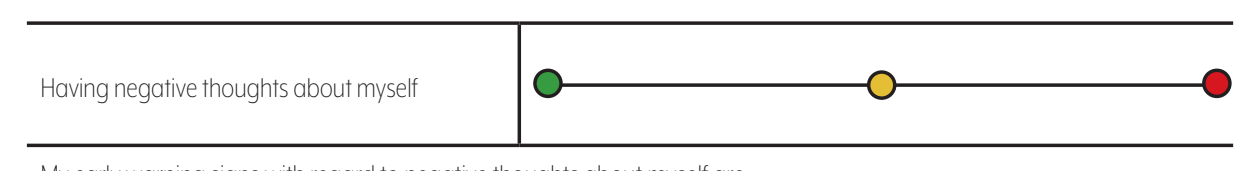

My early warning signs with regard to negative thoughts about myself are:

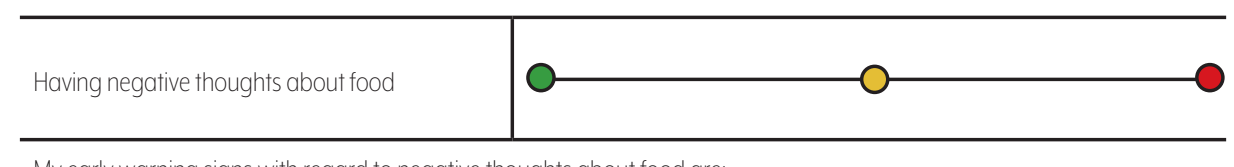

My early warning signs with regard to negative thoughts about food are:

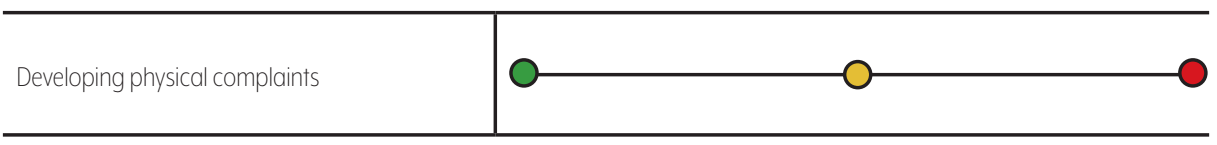

My early warning signs with regard to developing physical complaints are 


\section{Discussion}

We developed a structured tool for patients with anorexia nervosa and their therapists to allow them to inventory triggers and early warning signs of relapse. This Anorexia Relapse Prevention INventory (ARPIN) can be used to gain insight into the personal factors that may influence a relapse. The ARPIN contains 9 main items, 54 core examples of triggers and 15 categories of early warning signs. Its development process was based on the examination of triggers and early warning signs described in the relapse prevention plans of 107 AN patients. Face validity was tested in a focus group with experts by experience, who found ARPIN to be a clinically useful and easy to use tool.

Both patients and professionals can use the ARPIN to identify triggers and early warning signs, in order to improve early detection and promote early intervention of relapse. Insight into the process of relapse ensures that the patient is aware and in control of changing the course of the process and moving towards symptomatic recovery. One out of three patients with AN experiences a relapse, and the highest risk of relapse occurs during the first year after discharge and the risk of relapse continues for up to 2 years (Berends et al., 2018). Patients should be fully prepared for this phase, armed with knowledge and insight into their personal factors that may influence this process, and must be supported through this period.

In mental health care there are two predominant models for the conceptualization of treatment and recovery from mental illness; the medical model (Mountain \& Shah, 2008; Robert \& Wolfson, 2004) and the recovery model (Slade et al., 2008, 2014) The medical model has become the dominant approach in the field of eating disorders (Dawson et al., 2014a, 2014b). Therefore, treatment of AN often focuses on an absence of symptoms and a return to normal functioning. However, the main items in the trigger section of the ARPIN show that the triggers mainly are aspects of everyday life and not specifically linked to the eating disorder. This means that treatment should not only focus on the eating disorder, but also on the main items mentioned in this trigger section (e.g. interpersonal contact, school, work, disturbance in mood or sense of self and structure changes). Patients should learn the right personalized coping skills to deal with these everyday life events, so they can start the period of relapse prevention well-prepared. They also need to become aware of their eating disorder vulnerability (anorexia nervosa), what this means for their lives and how to use it, perhaps even as a strength, which is part of the recovery model.

Problems experienced in interpersonal contact showed the highest score within the list of triggers. Both positive and negative contacts can occur and be of influence. Many evidence-based treatments modularize treatment so that specific targets can be addressed (Peterson et al., 2016). They indicate that interpersonal difficulties can ac as maintaining factors (e.g. Fairnburn, 2008; Treasure \& Schmidt, 2013). In qualitative studies on the patients' perspective, social support and interpersonal relationships are cited as a key factor for recovery from AN (Dawson et al., 2014; Tozzi et al., 2003). A review of Cardi et al. (2018) also indicates that social difficulties are both risk factors and maintaining factors. There are evidence based AN treatment strategies that integrate interventions such as behavioural experiments on interpersonal contact, e.g. CBT-E (Fairburn, 2008), MANTRA (Maudsley Anorexia Nervosa Treatment for Adults; MANTRA Schmidt et al., 2015), and CREST (Cognitive Remediation and Emotion Skills Training; CREST; Tchanturia et al., 2015). Nevertheless, more attention should be paid in clinical practice to supporting patients with the development of their social emotional skills, to induce better use of social support in recovery (Harrison et al., 2019) as well as in relapse prevention. The use of the ARPIN can determine whether this component is still a trigger for the patient at the end of treatment.

There are a number of strengths and limitations to be mentioned. This is the first study on triggers and early warning signs of relapse in anorexia nervosa that uses patientsupplied data. Using patient-supplied data increases the credibility of this study. Also, the combination of qualitative and quantitative data increases the significance of the statements made (Collins et al., 2006). In addition, the findings were cross-validated not only by using a second and third researcher in the consensus procedure, but also by using a focus group of experts by experience for the face validity procedure conform COSMIN criteria. A limitation of this study is that only relapse prevention plans were used from a highly specialized eating disorder centre and is not yet tested in less specialized units.

The ARPIN seems to improve professionals' and patients' awareness of triggers and early warning signs, but its efficacy must be proven buy further use in clinical practice. Also, future research is needed to show whether this method is suitable for use in daily practice, and whether it indeed supports a reduction of relapse in AN.

\section{Acknowledgements}

The researchers would like to thank the focus group members for their cooperation and valuable contribution to this research

\section{Declaration of interest statement}

No 


\section{References}

Arcelus 」. Mitchell, A. J. Wales, \& \& Nielsen, S. (2011) Mortality rates in patients with anorexia nervosa and other eating disorders. A meta-analysis of 36 studies. Archives of General Psychiatry, 68, 724-731.

Berends T., van Meijel B., \& van Elburg A. (2010). Richtlijn Terugvalpreventie Anorexia Nervosa (Guideline Relapse Prevention Anorexia Nervosa). Assen, The Netherlands: Koninklijke Van Gorcum. http://www. relapse-an.com

Berends T., van Meijel B., \& van Elburg A. (2012). The Anorexia Relapse Prevention Guidelines in practice; a case report. Perspectives in Psychiatric Care, 48, 149-155.

Berends T., Boonstra N., \& van Elburg A. (2018). Relapse in anorexia nervosa: a systematic review and metaanalysis. Current Opinion in Psychiatry, 31(6), 445-455. doi:10.1097/YCO0000000000000453

Cardi, V., Tchanturia, K., \& Treasure, J. (2018). Premorbid and IIIness-related Social Difficulties in Eating Disorders: An Overview of the Literature and Treatment Developments. Current Neuropharmacology, 16 $1122-1130$.

Carter, J. C., Blackmore, E., Sutandar-Pinnock, K., \& Woodside, D. B. (2004). Relapse in anorexia nervosa: a survival analysis. Psychological Medicine, 34, 671-679.

Carter, J. C., Mercer-Lynn, K. B., Norwood, S. J., Bewell-Weiss, C. V., Crosby, R. D., Woodside, D. B., \& Olmsted, M. P. (2012). A prospective study of predictors of relapse in anorexia nervosa: implications for relapse prevention. Psychiatry Research, 200, 518-523.

Collins, K. M. T., Onwuegbuzie, A. J., \& Sutton, I. L. (2006). A model incorporating the rationale and purpose for conducting mixed methods research in special education and beyond. Learning Disabilities: A Contemporary Journal, 4, 67-100.

Dawson, L., Rhodes, P., \& Touyz, S. (2014a). 'Doing the impossible': The process of recovery from chronic anorexia nervosa. Qualitative Health Research, 24, 494-505. doi:10.1177/1049732314524029

Dawson, L., Rhodes, P., \& Touyz, S. (2014b). The recovery model and anorexia nervosa. Australian \& New Zealand Journal of Psychiatry, 48(11), 1009-1016.

Dutch Foundation for Quality Development in Mental Healthcare. (2017). Practice guideline for the treatment of eating disorders (Zorgstandaard Eetstoornissen). Utrecht, The Netherlands: Netwerk Kwaliteitsontwikkeling $\mathrm{GG}$

Eddy, K. T., Tabri, N., Thomas, J. J., Murray, H. B., Keshaviah, A., Hastings, E., Edkins, K., Krishna, M., Herzog, D. B., Keel, P. K., \& Franko, D. L. (2017). Recovery From Anorexia Nervosa and Bulimia Nervosa at 22-Year Follow-Up. Journal of Clinical Psychiatry, 78(2), 184-189. doi: 10.4088/JCP.15m10393

Fairburn, C. G. (2008). Cognitive behavior therapy and eating disorders. New York, NY: Guilford Press.

Fichter, M. M., Quadflieg, N., Crosby, R. D. \& Koch, S. (2017). Long-term outcome of anorexia nervosa: Results from a large clinical longitudinal study. International Journal of Eating Disorders, 50(9), 1018-1030. do 10.1002/eat.22736

Harrison A., Watterson S. V., \& Bennett S. D. (2019). An experimental investigation into the use of eye-contact in social interactions in women in the acute and recovered stages of anorexia nervosa. International Journal of Eating Disorders, 52, 61-70. doi.org/10.1002/eat.22993

Hay P., Chinn D., Forbes D., Madden, S., Newton, R., Sugenor, L., Touyz, S., \& Ward, W. (2014). The Royal Australian and New Zealand College of Psychiatrists clinical practice guidelines for the treatment of eating disorders. Australian and New Zealand Journal of Psychiatry, 48, 977-1008

Hilbert A., Hoek H. W., \& Schmidt R. (2017). Evidence-based clinical guidelines for eating disorders: international comparison. CurrentOpinion in Psychiatry, 30, 423-437. doi:10.1097/YCO.0000000000000360 Khalsa, S. S., Portnoff, L. C., McCurdy-McKinnon, D., \& Feusner, J. D. (2017). What happens after treatment? A systematic review of relapse, remission, and recovery in anorexia nervosa. Journal of Eating Disorders, 5 , 20. doi:10.1186/540337-017-0145-3
Keski-Rahkonen, A., \& Mustelin, L. (2016). Epidemiology of eating disorders in Europe prevalence, incidence, comorbidity, course, consequences, and risk factors. Current Opinion in Psychiatry, 29(6), 340-345. doi:101097/YCO 0000000000000278

Galmiche, M., Dechelotte, P., Lambert, G., \& Tavolacci, M. P. (2019). Prevalence of eating disorders over the 2000-2018 period: a systematic literature review. The American Journal of Clinical Nutrition, 109(5), 14021413.

Levine, M., P. (2020). Prevention on eating disorders, 2019 in review. Eating Disorder, 28(1), 6-20.

Mountain, D., \& Shah, P. J. (2008). Recovery and the medical model. Advances in Psychiatric Treatment, 14 $241-244$

National Institute for Health and Care Excellence (NICE). (2017). Eating disorders: recognition and treatmen full guideline. Retrieved from: http://www.nice.org.uk/guidance/ng69/

Peterson, C. B., Black-Becker, C., Treasure, J., Shafran, R., \& Bryant-Waugh, R. (2016). The three-legged stool of evidence-based practice in eating disorder treatment: research, clinical, and patient perspectives. BMC Medicine, 14, 69. doi:10.1186/s12916-016-0615-5

Raevuori A., Keski-Rahkonen A., \& Hoek H. W. (2014). A review of eating disorders in males. Current Opinion in Psychiatry, 27, 426-430.

Richard, M., Bauer, S., \& Kordy, H. (2005). Relapse in Anorexia and Bulimia Nervosa-A 2.5-Year Follow-U Study. European Eating Disorders Review, 13, 180-190.

Slade, M., Amering, M., \& Oades, L. (2008). Recovery: an international perspective. Epidemiology and Psychiatric Sciences, 17(2), 128-137.

Roberts, G. \& Wolfson, P. (2004). The rediscovery of recovery: Open to all. Advances in Psychiatric Treatment, $10,37-49$

Schmidt, U., Magill, N., Renwick, B., Keyes, A., Kenyon, M., Dejong, H., Lose, A. Broadbent, H. Loomes, R., Yasin, H., Watson, C., Ghelani, S., Bonin, E., Serpell, L., Richards, L., Johnson-Sabine, E., Boughton, N., Whitehead L., Beecham, J., ... Landau, L. (2015). The Maudsley outpatient study of treatments for anorexia nervosa and related conditions (MOSAC). Comparison of the Maudsley model of anorexia nervosa treatmen for adults (MANTRA) with specialist supportive clinical management (SSCM) in outpatients with broadly defined anorexia nervosa: A randomized controlled trial. Journal of Consulting and Clinical Psychology, $83(4), 796-807$

Schmidt, U., Adan, R., Böhm, I., Campbell, I. C., Dingemans, A., Ehrlich, S., Elzakkers, I., Favaro, A., Giel, K. Harrison, A., Himmerich, H., Hoek, H. W., Herpertz-Dahlmann, B., Kas, M. J., Seitz, J., Smeets, P., Sternheim, L., Tenconi, E., van Elburg, A., ... Zipfel, S. (2016) Eating Disorders: the big issue. The Lancet, 3, 313-315.

Slade, M., Amering, M., \& Oades, L. (2008). Recovery: an international perspective. Epidemiologia e psichiatria sociale, 17(2), 128-137.

Slade, M., Amering, M., Farkas, M., Hamilton, B., O'Hagan, M., Panther, G., Perkins, R., Shephert, G., Tse, S., \& Whitley, R. (2014). Uses and abuses of recovery: implementing recovery-orientated practices in menta health systems. World Psychiatry, 13, 12-20.

Smink, F. R. E., van Hoeken, D., \& Hoek, H. W. (2013). Epidemiology, course, and outcome of eating disorders. Current Opinion in Psychiatry, 26(6), 543-548. doi:10.1097/YCO.0b013e328365a24

Smink F. R. E., van Hoeken D., Donker G. A., Susser E. S., Oldehinkel, A. J., \& Hoek, H. W. (2016). Three decades of eating disorders in Dutch primary care: decreasing incidence of bulimia nervosa but not of anorexia nervosa. Psychological Medicine, 46, 1189-1196. doi:10.1017/5003329171500272X

Steinhausen H. C. (2002). The Outcome of Anorexia Nervosa in the 20th Century. American Journal of Psychiatry, 159, 1284-1293.

Strober, M., Freeman, R., \& Morrell, W. (1997). The long-term course of severe anorexia nervosa in adolescents: survival analysis of recovery, relapse, and outcome predictors over 10-15 years in a prospective study. International Journal of Eating Disorders, 22, 339-360. 
Tchanturia, K., Doris, E., Mountford, V., \& Fleming, C. (2015). Cognitive remediation and emotion skills training (CREST) for anorexia nervosa in individual format: Self-reported outcomes. BMC Psychiatry, 15(1), 53. doi: 10.1186/s12888-015-0434-9

Terwee, C. B., Prinsen, C. A. C., Chiarotto, A., De Vet, H. C. W., Westerman, M. J., Patrick, D. L., Alonso, J., Bouter, L. M., de Vet, H. C. W. \& Mokkink, L. B. (2018). COSMIN standards and criteria for evaluating the content validity of health-related Patient-Reported Outcome Measures: a Delphi study. Quality of Life Research, 27(5), 1159-1170. doi: 10.1007//11136-018-1829-0

Tozzi, F., Sullivan, P. F., Fear, J. L., McKenzie, J., \& Bulik, C. M. (2003). Causes and recovery in anorexia nervosa: The patient's perspective. International Journal of Eating Disorders, 33(2), 143-154.

Treasure, J., \& Schmidt, U. (2013). The cognitive-interpersonal maintenance model of anorexia nervosa revisited: A summary of the evidence for cognitive, socio-emotional and interpersonal predisposing and perpetuating factors. Journal of Eating Disorders, $1(1), 13$.

Wonderlich, S. A., Bulik, C. M., Schmidt, U., Steiger, H., \& Hoek H. W. (2020). Severe and Enduring Anorexia Nervosa: Update and Observations about the Current Clinical Reality. International Journal of Eating Disorders, online ahead of print. doi: 10.1002/eat.23283 

This final chapter provides a summary and reflection on the main findings of the various studies that are the basis of this thesis. We discuss these findings as a whole, and provide recommendations for clinical practice and future research.

This thesis describes the development and evaluation of the Guideline Relapse Prevention Anorexia Nervosa (GRP) and examines its effects when applied in daily practice. The guideline aims to prevent relapse in patients with anorexia nervosa (AN) and this thesis aims to gain more insight in the different aspects of the process of relapse in order to improve and substantiate the GRP. The gradually increasing process of relapse in patients with AN provides opportunities for preventive intervention. If early signs are recognized and action is taken at this early stage of the relapse process, a full relapse in AN may be avoided.

The general introduction in Chapter 1 gives an overview of the background information on anorexia nervosa, and specifically on the topic of relapse. AN is a severe mental disorder characterized by (the drive for) thinness, a low body weight for one's age and height, combined with a disturbed body image. Patients often see and experience themselves as fat while they are in fact severely underweight, and do not consider themselves ill, which contrasts with their physical status. They fear weight gain and/or exhibit behaviours that prevent weight gain, such as compulsive exercise or purging. Patients with AN can become extremely underweight, which seriously threatens their physical and mental functioning.

AN is a disorder that predominantly affects girls and young women. The lifetime prevalence in women is up to $2-4 \%$. AN has a high crude mortality rate of $5 \%$ per decade and a standardized mortality ratio of around 6. Recovery from an eating disorder like AN generally takes a long time. The mean duration of treatment before stable physical recovery may be achieved found across different studies is 4.7 years. Psychosocial recovery takes 6.5 to 9 years. The leading guidelines and treatment protocols in the field of AN and other eating disorders pay very limited attention to relapse prevention, although it is known that relapse rates are high. Rates in AN range from low (9\%) to high (52\%) following treatment, with the majority of studies reporting rates above $25 \%$; the risk of relapse is particularly high within the first year post-treatment. The need of a structured, evidence-based method for relapse prevention is reflected in this chapter by presenting a case in which a patient experiences a relapse, which unfortunately appears to be the rule, rather than the exception in daily practice.
Chapter 2 describes a case report through which we present the mechanisms of the GRP. First, the main elements of the guideline are briefly explained; including the process of relapse, and how to set up a personalized relapse prevention plan (RPP) and start the aftercare follow-up meetings. Next, each step is described based on the clinical vignette of Susan, a young woman of 21 years old who experienced a relapse and, after successful treatment, starts working on relapse prevention in the aftercare program. This case report shows how the guideline encourages open communication during the process of writing the RPP, which helps the patient to accept her own situation. Matters pertaining to the eating disorder are deliberately made explicit, making it impossible for patients to continue their strategy of denial. This also helps them cope with the feelings of sorrow and loss that are inherent in persons who suffer from this very serious eating disorder The active involvement of the patient and her parents also improves the patient's capacity for self-management and enhances communication between them. The use of the guideline requires specific skills by mental health professionals, including motivational techniques in order to motivate the patient, to remove resistance and to avoid the pitfalls of socially desirable responses by patients. The guideline offers mental health professionals a way to execute a well-structured procedure that is expected to yield a clear health benefit for the patient.

Chapter 3 presents the results of a literature review on rate, timing and factors associated with relapse. Based on 16 studies ( $n=1.477$ patients), this review shows that the average relapse rate in AN is $31 \%$, with the risk of relapse being the same for older and younger patients. The highest risk of relapse occurs during the first year after discharge, however, it appears that this risk remains high for up to 2 years. The reviewed studies show a substantial variability in the factors associated with relapse, as well as a use of different procedures, criteria and instruments. An overview of all factors ( $n=34)$ significantly associated with a higher risk of relapse is presented. Based on the thematic analysis, we extracted four informative clusters: eating disorder variables, comorbidity variables, process treatment variables and demographic variables. To identify factors of relapse in future research, the instruments used should include (at least) these four clusters in order to develop a standardized prognostic model. The review in Chapter 3 complements the review of Khalsa et al. (2017) on relapse, remission and recovery in anorexia nervosa, which provided a summary of the different definitions used and concluded that ther is limited consensus about these definitions. They propose a set of standardized criteria for relapse, recovery and remission for AN, which is internally consistent and can facilitate longitudinal assessment by clinicians and researchers: i.e. objective measures (BMI; observable behaviours of restricting, binging, and 
purging), subjective measures (fear of gaining weight, disturbance of body image), standardized ratings (Eating Disorder Examination; EDE), and specific durations of follow-up (1, 3, 6, and 12 months). The combined knowledge from the review of Khalsa together with our review described in chapter 3 can form the basis for the development of future relapse prevention programs for patients with AN. It also provides a good insight into what is necessary for future research into relapse in AN.

To examine the rate, timing and predictors of relapse in a group of AN patients using the GRP we set up a cohort study which is described in Chapter 4. We found a full relapse rate of $11 \%$ after the use of the GRP, which is much lower than the relapse rates found in previous studies with an average follow-up of 18 months but without the use of relapse prevention strategies. Of the participants in the present study who experienced the first signs of a relapse (30\%), two-thirds (19\%) recovered within a three-month period and only one-third (11\%) relapsed fully. When these patients experienced the first signs of relapse as described in their RPP, they contacted their mental health professional within a week. It was therefore possible to intervene at an early stage, guided by the predefined actions elaborated in the RPP. The findings of this cohort study support our hypothesis that working with the guideline relapse prevention has a preventive effect on the occurrence of full relapse in patients with AN. A survival analysis on these data shows the timing of full relapse, and found the highest risk between 4 and 16 months after discharge. When we combined the data of partial and full relapse, the findings indicate that the risk of relapse is increased throughout the entire period of 18 months, suggesting that monitoring of early signs of relapse is necessary during this entire period. We found three variables as predictors for relapse; 1) Duration of treatment before the start of the aftercare program; the longer a patient was in treatment, the higher the risk of relapse became. 2) Type of treatment before the aftercare program, in-and/or outpatient treatment; patients who received both in- and outpatient treatment had a higher risk of relapse than patients who received outpatient treatment only. 3) Age. Patients older than 19 years at the start of treatment had a higher risk of relapse.

From this cohort study, there are indications that the guideline provides an effective tool for relapse prevention. The tentative conclusion is that when early recognition strategies are applied in case of impending relapse, followed by targeted interventions to prevent further deterioration, the risk of a full relapse will decrease. This increases the chance for patients to reach stable and lasting recovery.
Chapter 5 is a qualitative study, which focuses on the experiences of patients and parents with the objective of coming to understand how they experience working with the guideline, in particular the use of self-management strategies. This study also aims to identify facilitators and barriers for the successful application of the guideline. We conducted a total of 17 interviews with patients, and 6 interviews with parents. Respondents were asked about the effects they observed while working with the guideline. Patients and family members offered different explanations on how the guideline helped to improve their self-management skills; these are discussed in detai in this chapter, referring to the five core self-management skills described by Lorig \& Holman (2003): problem solving, decision making, resource utilization, forming of a patient/healthcare provider partnership, and taking action. Patients and parents were generally satisfied with the support provided by the guideline. The relapse prevention plan (RPP) offered them significant help in understanding their own relapse process. Most patients internalized the content of the RPP. Participants and parents valued the fact that they could keep in touch with their mental health professional during the aftercare program; it felt like a safety line to them. The RPP should be updated regularly in line with recent experiences in daily life of the user.

The objective of the study described in Chapter 6, was to gain insight into the triggers and early warning signs of relapse from the patients' perspective, and to develop and validate a new tool with the aim to give AN patients more insight into their triggers and early warning signs in order to prevent a relapse. By following the Consensus-based Standards for the selection of health Measurement INstruments (COSMIN, Terwee et al., 2018), we developed the Anorexia Relapse Prevention INventory (ARPIN). Relapse prevention plans of 107 AN patients were studied in the content analysis and lists of triggers and early warning signs were established. Thre independent researchers performed an inventory draft by merging and categorizing triggers and early warning signs. A focus group discussion to examine the face validity of the ARPIN was held with seven experts by experience. They considered the ARPIN to be a structured, easy-to-use tool. The ARPIN consists of 9 main items of triggers with 54 core examples and 15 categories of early warning signs. Patients and mental health professionals can both use the ARPIN to inventory triggers and early warning signs. Detailed understanding of the triggers and early warning signs can support the process of early detection and early intervention when relapse occurs. Insight in the process of relapse ensures that the patient is aware and in control to change the course of the process and move towards recovery. 


\section{Reflections on main findings}

Evidence-based practice encourages clinicians to (1) use the best available research evidence in conjunction with (2) clinical expertise, whilst (3) considering patients' characteristics, values, and circumstances to inform care. These three aspects have been referred to as the 'three-legged stool' of evidence-based practice (Flemming \& Cullum, 1997; Sackett et al.,1996; Spring, 2007). Understanding that the foundations of evidence-based practice are grounded in the combination of all three of these elements is the necessary first step for the improvement of patient treatment in eating disorders as well as towards the integration of all three 'legs' of the stool in evidence-based practice (Peterson et al., 2016). The approach of the 'three-legged stool' has been utilized in this thesis. The Guideline Relapse Prevention Anorexia Nervosa (GRP) itself was drawn up based upon the available evidence from research, in combination with expert opinions and presented to patient panels (described in Chapter 2). However, evidence on relapse and relapse prevention is scarce, therefor the aim of the studies in this thesis was to gain more insight in the process of relapse also using the three 'legs' of the stool; using patients' perspective and patient-supplied data (Chapter 5 and 6), clinical data (Chapter 4) and evidence from existing studies on relapse (Chapter 3 ). Below, we will further elaborate on the three 'legs' of evidence-based practice compared to the studies of this thesis.

\section{Patients perspective}

Personality traits, which are determined by biological and unforeseeable factors during development, reflect interindividual differences. The relationship between personality and eating disorders has long been a subject of interest and remains so (Dufresne et al., 2020). Studies show traits such as perfectionism, harm avoidance, anxiety and inhibition in patients with anorexia nervosa (Hill et al., 2016, Klump et al., 2004). It is essential that both the mental health professional and the patients themselves take these traits into account while working on relapse prevention. They should use these traits as a strength during this part of treatment, to motivate the patient and to provide insight in the importance of working on relapse prevention, and in the patient's own process of recovery. Patients need guidance in setting up an RPP, as they often have difficulty facing their past and the hard time they experienced during their illness. They usually do not like to think back, but this is an essential part of working on relapse prevention (Chapter 5). Being able to look back to the start of their eating disorder and their treatment, makes patients learn more about future relapses and their personal process of relapse. Their own perfectionism can be used as a strength in this part. Patients in general are very precise in setting up their RPP, which also helps enhance their understanding of their process. At the end of treatment, most patients share the realization that their illness is not completely absent, which also causes anxiety. Although they have control over their eating disorder, they often still experience anorectic thoughts but do not act upon them. As a result, they find it difficult to end treatment, from the patients' as well as their relatives' perspective. Both have a need for guidance and a safety line during this phase, in their own strength of self-management and with the mental health professional at an appropriate distance (Chapter 5 and 6). This is endorsed in qualitative studies; patients share that, even in recovery, the normal ups and downs of life will persist and that recovery involves navigating these challenges in a healthy way, that they need to continue to learn how to cope (Kenny et al., 2019) and that working towards recovery is a long process (Stockford et al., 2019). Patients emphasize the importance of professional help in managing their process of recovery (Piot et al., 2019; Robinson et al., 2015). A balance has to be found between activities that could be employed independently or with minimal coaching on the one hand, and activities that need more support on the other hand. Patients prefer an individually tailored approach, in which the role of the network members and the treatment team is identified and tailored to their personal situation (Chapter 5 ).

\section{Clinical perspective}

In 2011, a new concept of health was introduced: "Health as the ability to adapt and to self manage, in the face of social, physical and emotional challenges (Huber et al., 2011). There has been a growing awareness that self-management plays an important role in empowering patients to manage their symptoms and promote recovery (Lorig \& Holmann, 2003). Promoting self-management requires tailor made interventions by the professional. For example for people with psychotic disorder since about fifteen years there are specific Illness Management and Recovery Programs in order to promote self-management (Mueser, et al. 2006; McGuire, et al. 2014). The professional should have experience with motivational techniques, and support the patient with improving their self-management skills. Specific self-management interventions in treatment of AN are still underexposed. The five core self-management skills described by Lorig \& Holman (2003) are woven into the GRP (Chapter 5). The improvement in self-management skills may reduce the participant's dependence on mental health professionals or members of her social network. The GRP guides and supports the mental health professional in this tailoring process while working on relapse prevention together with the patient and 
their network members. Together, they will examine the personal process of relapse, taking into account the skills of the patient and the required tailoring to their needs.

Two predominant models for the conceptualization of treatment and recovery from mental illness exist in health care: the medical model, in which recovery is positioned as an objective "cure", a condition defined by the absence of symptoms and a return to normal functioning (Mountain \& Shah, 2008; Robert \& Wolfson, 2004), and the recovery model, which is originally driven by consumers, positioning recovery as part of a personal journey, the product of empowerment and resulting in an improvement in quality of life (Slade et al., 2008, 2014). The medical model has long been the dominant approach in the field of eating disorders (Dawson et al., 2014a, 2014b), and treatment protocols of AN often focus on the absence of symptoms and a return to normal functioning. However, there has been a general shift to accepting that in addition to physical and behavioural indices, psychological/ cognitive symptoms are also important to recovery from eating disorders (BardoneCone et al., 2018). To empower patients against relapse, treatment should focus on all components. Mental health professionals should not only focus on enhancing the patient's competencies, but also on the entire network around the patient (e.g. interpersonal contact in daily life, their network members and social support, study/ work, structure in daily life) and the patients' needs in increasing their quality of life. Factors significantly associated with relapse $(n=34)$, as presented in Chapter 3 , show that these include topics related to the eating disorder itself, but also to coping mechanisms, psycho-social functioning and level of motivation.

Working with the guideline requires specific skills and competences on the part of the mental health professionals, in particular with regard to improving motivation and reducing resistance in patients. Only practitioners with sufficient work experience with the target group are competent enough to properly supervise this process and avoid the pitfall of socially desirable answers. In addition, methodical and analytical skills are required to work with the GRP. The GRP attempts to provide mental health professionals with a certain amount of structure, while at the same time leaving them sufficient room to make their own decisions to adapt the treatment in such a way as to do justice to the individual characteristics of the patient and their network members, the differences in perception, capabilities, wishes and needs.

Despite advances in clinical research on eating disorders, a growing body of literature demonstrates that individuals with eating disorders often do not receive an evidence-based treatment for their disorder (Hilbert et al., 2017). In the Netherlands, the treatment of mental health patients is under growing pressure due to an increasing shortage of mental health professionals, as well as financial pressure and fewer financial possibilities to make necessary investments in innovation (KPMG Healthcheck Mental Health Netherlands, 2019). In daily practice in AN mental health institutions, treatment protocols and mental health professionals focus more and more on quick recovery, reducing inpatient treatment and shortening the overal treatment duration. This may lead to insufficient holding for these severely ill patients, especially with regard to relapse prevention. The current leading treatment protocols for the treatment of adults and adolescents with AN are described in different reviews (Brockmeyer et al, 2019; van den Berg et al, 2019; Jansingh et al 2020). These protocols do address the importance of relapse prevention, bu their follow-up is too short when considering the length of the period of highest risk of relapse, i.e. up to 2 years. The Maudsley Model of Anorexia Treatment in Adults (MANTRA) (Schmidt et al., 2014, 2019) and the Specialist Supportive Clinical Management (SSCM) (Mclntosh et al., 2006) protocols both have a 4-month followup, the Cognitive Behavioral Therapy-Enhanced (CBT-E) (Fairburn, 2008) protoco has a 5-month follow-up, and the last phase of the Family-Based Treatment (FBT) (Lock, \& le Grange, 2005) insists on three completing sessions during 3 months without any follow-up. These treatment protocols should emphasize the need for a thorough aftercare procedure, as this may reduce the emergence of a chronic course in AN and in the end may be more cost-effective.

On the other hand, clinical avoidance (i.e., avoiding clinical techniques due to concerns that they are unworkable, intolerable, or harmful, despite existing evidence to the contrary) by the mental health professional could also play a role in the lack of follow-up. At the end of treatment, patients with AN often wish to avoid looking back on their illness as they find it confrontational (Chapter 5). Menta health professionals should not clash with the patient in this process but instead break through this barrier and support the patient to work on relapse prevention. This turns out to be difficult in daily practice, therefor we should invest in menta health professionals by providing additional education to improve implementation of the GRP in daily practice. The hypothesis of clinical avoidance by mental health professionals should also be one of the topics of future research.

\section{Research}

This thesis is based on a combination of qualitative and quantitative studies, including a systematic review and meta-analysis, a cohort study, a case-report, interviews, content analysis and focus group discussions. The value of this approach 
with multiple methods and data sources is the enrichment of data, both approaches are complementary (Chreswell \& Plano Clark, 2007; Collins et al., 2006; Pollit \& Beck, 2017).

Despite the seriousness and high chronicity of anorexia nervosa, it remains a relatively small research area with significantly fewer publications than other fields of mental disorders. Research and funding for research on AN has been particularly neglected (Herpertz-Dahlman et al., 2015; Treasure et al., 2020; Schmidt et al., 2016). As stated previously, evidence on relapse in AN is scarce and there is substantial variability on the definitions, procedures and instruments used. Unambiguous use of the same definitions, procedures and instruments on relapse is a precondition to improve treatment as well as relapse prevention strategies. Researchers should strive for comparability between studies. This would be a benefit to researchers, clinicians, patients and their network members, as all would speak the same language. A good framework for future research is needed. Consensus on these definitions, procedures and instruments should be achieved with the support of all science orientated eating disorder organizations (Chapter 3; Khalsa et al., 2017).

A strength of this thesis is the intensive use of the patient's perspective in the development of the GRP itself, and in several of the studies (Chapter 2, 5 and 6). In the evidence hierarchy, the positions with regard to the contribution of various types of evidence are less rigid than previously. Nevertheless, many published evidence hierarchies rank evidence sources according to the strength of the evidence they provide. There is some debate about what constitutes "rigorous" research and what qualifies as "best" evidence (Polit \& Beck, 2018). In our view, best evidence refers to research findings that are methodologically appropriate and clinically relevant for answering questions from daily clinical practice. The perspectives of the

patients and parents used in this thesis have provided a deeper layer of insight into their needs and the process of relapse, which resulted in improving and substantiating the GRP.

Future research on relapse prevention should preferably contain both quantitative and qualitative studies. Descriptive longitudinal studies should be performed with a follow-up of $\geq 24$ months, with the use of a controlled study design. Incidence and prevalence of relapse as well as factors associated with relapse should be better identified, to support development of a standardized prognostic model for relapse. In addition, cost-effectiveness could also be studied, since there is very little knowledge about this topic in AN. Although longitudinal studies on outcome in anorexia nervosa are available, and papers on research priorities for AN describe the need of more prospective longitudinal studies with sufficient power (Zipfel et al., 2015; Treasure et al., 2020), many of these unfortunately do not include explicit data on relapse and the process of relapse.

Future qualitative research on relapse prevention should focus on the perspectives of network members of adults with anorexia nervosa to improve their understanding of how they can be actively involved in relapse prevention strategies for this is still underexposed. Research is also needed on the efficacy of the Anorexia Relapse Prevention Inventory (ARPIN) in clinical practice (Chapter 6) and whether it supports patients in gaining a better understanding of their personal process of relapse.

A possible next step after the studies described in this thesis could be a controlled study design to further confirm the effectiveness of the proposed relapse prevention strategy. However, RCT's are notoriously challenging to conduct in AN, the relative rarity of AN makes recruitment difficult and often necessitates the use of multiple sites, drop-out in trials are high and a no-treatment or placebo comparison seems unethical given the severity and medical complications of the disorder (Watson et al., 2013). The question arises whether an RCT is necessary to improve treatmen on relapse prevention. We believe we can rely on the information of the present evidence from the three 'legs' of evidence-based practice that lies before us and which supports safe, effective and relevant clinical practice. Focus should be on implementation of the guideline in clinical practice and training of mental health professionals.

In conclusion, treatment of anorexia nervosa is not complete without sufficien attention to relapse prevention. Clinical practice for AN is still a work in progress, as there is a great deal of uncertainty as to the pathophysiology, treatment, and management of this severe mental disorder due to under-research (Treasure et al., 2020). Implementation of guidelines and treatment protocols in daily practice is a challenge. When patients and network members are suitably educated on the background information of relapse, they come to realize that working on relapse prevention is essential. Mental health professionals, on the other hand, may show clinical avoidance in a parallel process with their patient, keep a primary focus on treatment and underestimate the need of guidance during the period after treatment, to handle challenges in day-to-day life. The studies described in this thesis indicate that the GRP provides an effective tool for relapse prevention. We recommend that all patients with AN set up a personalized relapse prevention plan at the end of their treatment, with regular monitoring for a period of at least 18 
months after discharge. We will continue to refine the GRP, and continue to assist our patients with AN who face ongoing challenges post-treatment with everyday life events.

\section{References}

Bardone-Cone, A. M., Hunt, R. A., \& Watson, H. J. (2018). An Overview of Conceptualizations of Eating Disorder Recovery, Recent Findings, and Future Directions. Current Psychiatry Reports, 20(9). doi:10.1007/ s11920-018-0932-9

Brockmeyer, T., Friederich, H. C., \& Schmidt, U. (2018). Advances in the treatment of anorexia nervosa: A review of established and emerging interventions. Psychological Medicine, 48(8), 1228-1256. doi: org/10.1017 s0033291717002604

Chreswell, J. W., \& Plano Clark, V. L. (2007). Designing and conducting mixed methods research. Sage Publications.

Collins, K. M. T., Onwuegbuzie, A. J., \& Sutton, I. L. (2006). A model incorporating the rationale and purpose for conducting mixed methods research in special education and beyond. Learning Disabilities: A Contemporary Journal, 4, 67-100.

Dawson, L., Rhodes, P., \& Touyz, S. (2014a). 'Doing the impossible': The process of recovery from chronic anorexia nervosa. Qualitative Health Research, 24, 494-505. doi:10.1177/1049732314524029

Dawson, L., Rhodes, P., \& Touyz, S. (2014b). The recovery model and anorexia nervosa. Australian \& New Zealand Journal of Psychiatry, 48(11), 1009-1016.

Dufresne, L., Bussières, E., Bédard, A., Gringas, N., Blanchette-Sarrasin, A., \& Bégin, C. (2020). Personality traits in adolescents with eating disorder: A meta-analytic review. International Journal of Eating Disorders, 53(2), 157-173.

Fairburn, C. G. (2008). Cognitive Behavior Therapy and Eating Disorders. The Guilford Press

Flemming, K., \& Cullum, N. (1997). Doing the right thing. Nursing Standard, 12, 28-30

Herpertz-Dahlmann, B., van Elburg, A., Castro-Fornieles, J., \& Schmidt, U. (2015). ESCAP Expert paper: New developments in the diagnosis and treatment of adolescent anorexia nervosa-a European perspective. European Child and adolescent Psychiatry, 24, 1153-1167.

Hilbert A., Hoek H. W., \& Schmidt R. (2017). Evidence-based clinical guidelines for eating disorders: international comparison. Current Opinion in Psychiatry, 30, 423-437. doi:10.1097/YCO.0000000000000360

Hill, L., Knatz Peck, S., Wierenga, C. E., \& Kaye W. H. (2016). Applying neurobiology to the treatment of adults with anorexia nervosa. Journal of Eating Disorders, 4(31). doi.org/10.1186/540337-016-0119-x

Hubert, M., Knottnerus, J. A., Green, L., van der Horst, H., Jada, A. R., Kromhout, D., Leonard, B., Lorig, K. Loureiro, M. I., van der Meer, J. W. M., Schnabel, P., Smit, R., van Weel, C., \& Smid, H. (2011). How should we define health? British Medical Journal, 343. doi: 10.1136/bmj.d4163.

Jansingh, A., Danner, U. N., Hoek, H. W., \& van Elburg, A. (in press). Developments in the psychologica treatment of Anorexia Nervosa and their implications for daily practice. Current Opinion in Psychiatry.

Kenny, T. E., Boyle, S. L., \& Lewis, S. P. (2019). \#recovery: Understanding recovery from the lens of recoveryfocused blogs posted by individuals with lived experience. International Journal of Eating Disorders, 30 doi: 10.1002/eat.23221

Khalsa, S. S., Portnoff, L. C., McCurdy-McKinnon, D., \& Feusner, J. D. (2017). What happens after treatment? A systematic review of relapse, remission, and recovery in anorexia nervosa. Journal of Eating Disorders, 5, 20. doi: 10.1186/s40337-017-0145-3

Klump, K., Strober, M., Johnson, C., Thornton, L., Bulik, C., Devlin, C., Fichter, M. M., Halmi, K. A., Kaplan, A. S., Woodside, D. B., Crow, S., Mitchell, J., Rotondo, A., Keel, P. K., Berrettini, W. H., Plotnicov, K., Pollice, C. Lilenfeld, L. R., \& Kaye, W. H. (2004). Personality characteristics of women before and after recovery from an eating disorder. Psychological Medicine., 34(8), 1407-1418.

KPMG (2019). Healthcheck: Ontwikkelingen binnen de Healthcheck GZZ. (Healthcheck: The Development within the Healthcheck of mental health). https://assets.kpmg/content/dam/kpmg/nl/pdf/2019/sector healthcheck-ggz.pd 
Lock, D., \& le Grange, D. (2005). Family-Based Treatment for Eating Disorders. International Journal of Eating Disorders, 37, 64-67.

Lorig, K. R., \& Holman, H. R. (2003). Self-Management Education: History, Definition, Outcomes, and Mechanisms. Annals of Behavioral Medicine, 26,1-7.

McGuire, A. B., Kukla, M., Green, A., Gilbride, D., Mueser, K. T., \& Salyers, M. P. (2014). Illness Management and Recovery: A Review of the Literature. Psychiatric Services, 65(2), 171-179. doi: 10.1176/appi.ps.201200274

McIntosh, V. V., Jordan, J., Luty, S.E., Carter, F. A., McKenzie, J. M., Bulik, C. M., \& Joyce, P. R. (2006). Specialist supportive clinical management for anorexia nervosa. International Journal of Eating Disorders, 39, 625632. doi:10.1002/eat.20297

Mountain, D., \& Shah, P. J. (2008). Recovery and the medical model. Advances in Psychiatric Treatment, 14 $241-244$

Mueser, K. M., Meyer, P. S., Penn, D. L., Clancy, R., Clancy, D. M., \& Salyers, M. P. (2006). The Illness Management and Recovery Program: Rationale, Development, and Preliminary Findings. Schizophrenia Bulletin, 32, 32 43. doi: 10.1093/schbul/sbl022

Peterson, C. B., Black-Becker, C., Treasure, J., Shafran, R., \& Bryant-Waugh, R. (2016). The three-legged stool of evidence-based practice in eating disorder treatment: research, clinical, and patient perspectives. BMC Medicine, 14, 69. doi:10.1186/s12916-016-0615-5

Piot, M., Gueguen, J., Michelet, D., Orri, M., Köenig, M., Corcos, M., Cadwallader, J., \& Godart, N. (2019) Personal recovery of young adults with severe anorexia nervosa during adolescence: a case series. Eating and Weight Disorders. doi: 10.1007//40519-019-00696-7

Pollit, D. F., \& Beck, C. T. (2017). Nursing Research; Generating and Assessing Evidence for Nursing Practice, Tenth Edition. Wolters Kluwer Health

Pollit, D. F., \& Beck, C. T. (2018). Essentials of Nursing Research; Appraising evidence for nusing practice, Ninth Edition. Wolters Kluwer

Roberts, G., \& Wolfson, P. (2004). The rediscovery of recovery: Open to all. Advances in Psychiatric Treatment, $10,37-49$.

Robinson P. H., Kukucksa R., Guidetti, G., \& Leavey, G. (2015). Severe and Enduring Anorexia Nervosa (SEEDAN): Qualitative Study of Patients with 20+ Years of Anorexia Nervosa. European Eating Disorders Review, 23, 318-326.

Sackett, D. L., Rosenberg, W. M., Gray, J. A., Haynes, R. B., \& Richardson, W. S. (1996). Evidence based medicine: what it is and what it isn't. British Medical Journal, 312, 71-72

Schmidt, U., Adan, R., Böhm, l., Campbell, I. C., Dingemans, A., Ehrlich, S., Elzakkers, I., Favaro, A., Giel, K., Harrison, A., Himmerich, H., Hoek, H. W., Herpertz-Dahlmann, B., Kas, M. J., Seitz, J., Smeets, P., Sternhe L., Tenconi, E., van Elburg, A., ... Zipfel, S. (2016). Eating Disorders: the big issue. The Lancet, 3, 313-315.

Schmidt U, Wade TD, \& Treasure J. (2014). The Maudsley Model of Anorexia Nervosa Treatment for Adults (MANTRA): Development, key features and preliminary evidence. Journal of Cognitive Psychotherapy, 28, 48-71. doi.org/10.1891/0889-8391.28.1.48

Schmidt, U., Startup, H., \& Treasure, J. (2019). Therapy Workbook for Treating Anorexia Nervosa: The Maudsley Model. Routledge.

Slade, M., Amering, M., \& Oades, L. (2008). Recovery: an international perspective. Epidemiologia e psichiatria sociale, 17(2), 128-137.

Slade, M., Amering, M., Farkas, M., Hamilton, B., O’Hagan, M., Panther, G., Perkins, R., Shephert, G., Tse, S., \& Whitley, R. (2014). Uses and abuses of recovery: implementing recovery-orientated practices in mental health systems. World Psychiatry, 13, 12-20

Spring, B. (2007). Evidence-based practice in clinical psychology: what it is, why it matters; what you need to know. Journal of Clinical Psychology, 63(7), 611-631.

Stockford, C., Stenfert Kroese, B., Beesley, A., \& Leung, N. (2019). Women's recovery from anorexia nervosa: a systematic review and meta-synthesis of qualitative research. Eating Disorders, 27(4), 343-368,
doi:10.1080/10640266.2018.15123
Terwee, C. B., Prinsen, C. A. C., Chiarotto, A., De Vet, H. C. W., Westerman, M. J., Patrick, D. L., Alonso, I., Bouter, L. M., de Vet, H. C. W., \& Mokkink, L. B. (2018). COSMIN standards and criteria for evaluating the content validity of health-related Patient-Reported Outcome Measures: a Delphi study. Quality of Life Research 27(5). 1159-1170 doi: 10.1007/s11136-018-1829-0

Treasure, J., Duarte, T. A., \& Schmidt, U. (2020). Eating Disorders. The Lancet, 395, 899-911.

van den Berg, E., Houtzager, L., de Vos, J., Daemen, I., Katsaragaki, G., Karyotaki, E., Cuijpers, P., \& Dekker, J. (2019). Meta-analysis on the efficacy of psychological treatments for anorexia nervosa. European Eating Disorders Review, 27(4), 331-351. doi: org?10.1002/erv.2683

Watson, H., J., \& Bullik, C. M. (2013). Update on the treatment of anorexia nervosa: review of clinical trials, practice guidelines and emerging interventions. Psychological Medicine, 43, 2477-2500.

Zipfel, S., Kiel, K., E., Bulik, C. M., Hay, P., \& Schmidt, U. (2015). Anorexia nervosa: aetiology, assessment, an treatment. The Lancet Psychiatry, 2(12), 1099-1111. doi: 10.1016/52215-0366(15)00356-9 


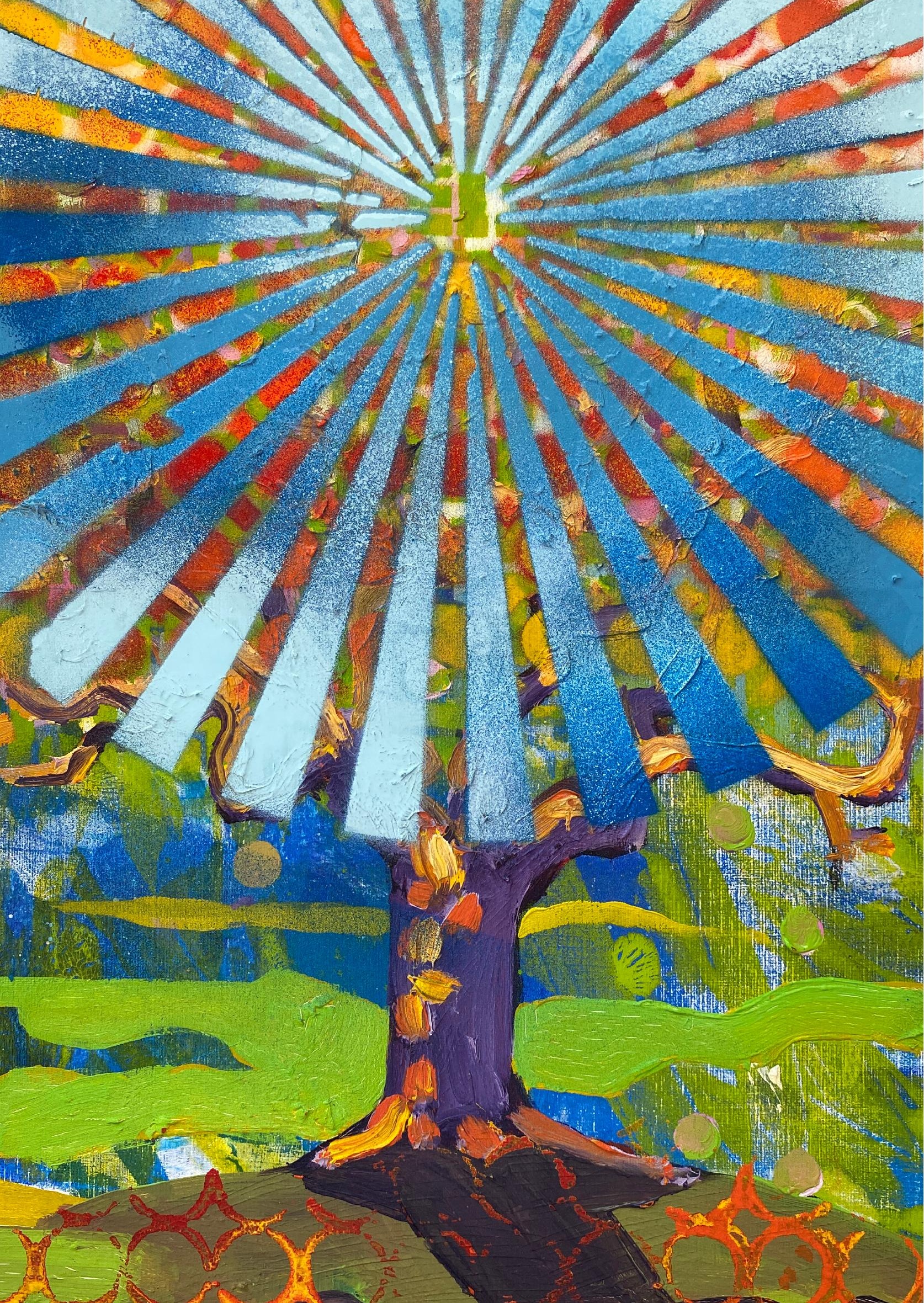

Hoofdstuk 8

Samenvatting en Discussie 
Dit laatste hoofdstuk bevat een samenvatting van en reflectie op de belangrijkste bevindingen uit de verschillende onderzoeken waarop dit proefschrift is gebaseerd. We bespreken deze bevindingen als geheel en formuleren aanbevelingen voor de klinische praktijk en toekomstig onderzoek.

Dit proefschrift beschrijft de ontwikkeling en evaluatie van de Richtlijn Terugvalpreventie Anorexia Nervosa en onderzoekt het effect wanneer de richtlijn wordt toegepast in de dagelijkse praktijk. De richtlijn heeft tot doel om terugval bij patiënten met anorexia nervosa (AN) te voorkomen, en dit proefschrift heeft tot doel om meer inzicht te verkrijgen in de verschillende aspecten van het terugvalproces om daarmee de richtlijn te verbeteren en staven. Doordat het terugvalproces van patiënten met AN een geleidelijk verloop kent, is er gelegenheid voor preventieve interventie. Wanneer vroege voortekenen worden herkend en er in dit vroege stadium van het terugvalproces actie wordt ondernomen, kan een volledige terugval in AN mogelijk worden voorkomen.

De algemene inleiding in Hoofdstuk 1 biedt een overzicht van de achtergrondinformatie over anorexia nervosa, en dan vooral over het onderwerp terugval. AN is een ernstige psychische stoornis die wordt gekenmerkt door (het streven naar) slankheid, een laag lichaamsgewicht voor iemands leeftijd en lengte, in combinatie met een verstoord lichaamsbeeld. Patiënten zien en ervaren zichzelf vaak als dik terwijl ze in feite ernstig ondergewicht hebben, en vinden niet dat ze ziek zijn, wat niet overeenkomt met hun fysieke toestand. Ze zijn bang voor gewichtstoename en/of vertonen gedrag waardoor gewichtstoename wordt voorkomen, zoals dwangmatig bewegen of purgeren. Patiënten met AN kunnen extreem ondergewicht ontwikkelen, wat hun fysieke en mentale functioneren ernstig bedreigt.

AN is een stoornis die vooral meisjes en jonge vrouwen treft. De levensprevalentie in vrouwen is $2-4 \%$. AN kent een hoog bruto-sterftecijfer van $5 \%$ per decennium en een gestandaardiseerd sterftecijfer van rond de 6 . Het duurt meestal lang voor een patiënt is hersteld van een eetstoornis zoals AN. Uit de verschillende onderzoeken blijkt een gemiddelde behandelduur van 4,7 jaar voordat stabiel fysiek herstel wordt bereikt. Het psychosociale herstel duurt 6,5 tot 9 jaar. In de leidende richtlijnen en behandelprotocollen op het gebied van AN en andere eetstoornissen wordt zeer beperkt aandacht besteed aan terugvalpreventie, hoewel bekend is dat het terugvalcijfer hoog is. Het terugvalpercentage bij AN loopt uiteen van laag (9\%) tot hoog (52\%) na afronding van de behandeling; uit de meeste studies blijken percentages van meer dan $25 \%$. Het risico op terugval is vooral hoog in het eerste jaar na afronding van de behandeling. Ter illustratie van de noodzaak voor een gestructureerde, evidence-based methode voor terugvalpreventie wordt in dit hoofdstuk de casus gepresenteerd van een patiënte die een terugval meemaakt, iets wat in de dagelijkse praktijk helaas eerder regel dan uitzondering lijkt te zijn.

In Hoofdstuk 2 presenteren we de mechanismen van de richtlijn door middel van de beschrijving van een casusverslag. Allereerst worden de belangrijkste elementen van de richtlijn kort toegelicht, waaronder het terugvalproces, het opstellen van een gepersonaliseerd terugvalpreventieplan (TPP), en het opstarten van nazorgfollow up-bijeenkomsten. Vervolgens beschrijven we elke stap in de klinische vignette van Susan, een jonge vrouw van 21 die een terugval heeft meegemaakt en na een succesvolle behandeling in het nazorgprogramma begint te werken aan terugvalpreventie. Uit dit casusverslag blijkt hoe de richtlijn open communicatie tijdens het schrijven van het TPP stimuleert, wat eraan bijdraagt dat de patiënte haar eigen situatie leert accepteren. Zaken die betrekking hebben op de eetstoornis worden doelbewust expliciet gemaakt, waardoor het voor patiënten onmogelijk wordt hun strategie van ontkenning vol te houden. Dit draagt er ook aan bij da ze leren omgaan met de gevoelens van rouw en verlies die eigen zijn aan mensen die lijden aan deze zeer ernstige eetstoornis. Doordat de patiënte en haar ouders actief betrokken zijn, verbetert het zelfmanagement-vermogen van de patiënte en wordt de communicatie tussen de patiënte en haar ouders versterkt. Om de richtlijn te kunnen gebruiken is het noodzakelijk dat GGZ-behandelaars over specifieke vaardigheden beschikken, waaronder motivatietechnieken om de patiënte te motiveren, weerstand weg te nemen en de valkuilen van sociaal wenselijke antwoorden door patiënten te vermijden. De richtlijn biedt GGZ-behandelaars een manier om een goed gestructureerde procedure uit te voeren, die naar verwachting een duidelijk gezondheidsvoordeel voor de patiënte zal opleveren.

In Hoofdstuk 3 presenteren we de uitkomsten van een literatuurreview ove percentages, timing en factoren die betrekking hebben op terugval. Op basis van 16 onderzoeken ( $n=1477$ patiënten) blijkt uit deze review dat het gemiddelde terugvalpercentage bij AN $31 \%$ is, waarbij het terugvalrisico even hoog is bij oudere als jongere patiënten. Het eerste jaar na afloop van de behandeling kent het hoogste risico op terugval; er is echter gebleken dat het risico tot 2 jaar na afloop van de behandeling hoog blijft. Uit de gereviewde onderzoeken blijkt een aanzienlijke variabiliteit in de factoren die verband houden met de terugval, alsook een gebruik van verschillende procedures, criteria en instrumenten. We presenteren een overzicht van alle factoren $(n=34)$ die significant in verband worden gebracht met een hoger terugvalrisico. Op basis van de thematische analys hebben we vier clusters gevormd: eetstoornisvariabelen, comorbiditeitsvariabelen, 
procesbehandelingsvariabelen, en demografische variabelen. Voor het bepalen van ferugvalfactoren in toekomstig onderzoek moeten de gebruikte instrumenten (ten minste) deze vier clusters bevatten om een gestandaardiseerd prognostisch model te ontwikkelen. De review in Hoofdstuk 3 vormt een aanvulling op de review van Khalsa et al. (2017) over terugval, remissie en herstel bij anorexia nervosa. De auteurs bieden een samenvatting van de verschillende gebruikte definities en concluderen dat er met betrekking tot deze definities slechts beperkte consensus bestaat. Hun voorstel omvat een set gestandaardiseerde criteria voor terugval, herstel en remissie voor AN, die intern consistent is en longitudinale beoordeling door clinici en onderzoekers kan faciliteren: d.w.z., objectieve meetwaarden (BMl; waarneembaar gedrag op het gebied van beperken, eetbuien en purgeren), subjectieve meetwaarden (angst om aan te komen, verstoordheid van lichaamsbeeld), gestandaardiseerde ratings (Eating Disorder Examination; EDE) en specifieke looptijden voor follow-up (1, 3, 6 en 12 maanden). Gecombineerd kan de kennis uit de review van Khalsa en onze review zoals beschreven in Hoofdstuk 3 de basis vormen voor het ontwikkelen van toekomstige terugvalpreventieprogramma's voor patiënten met AN. Deze gecombineerde kennis biedt ook een goed inzicht in wat er nodig is voor toekomstig onderzoek naar terugval in AN.

Om onderzoek te doen naar de percentages, timing en voorspellers van terugval in een groep AN-patiënten die gebruik maakten van de richtlijn, hebben we een cohortstudie opgezet die wordt beschreven in Hoofdstuk 4. Hieruit bleek een terugvalpercentage van $11 \%$ na gebruik van de richtlijn, wat veel lager is dan de terugvalpercentages die bleken uit eerdere onderzoeken met een gemiddelde followup van 18 maanden, maar zonder gebruik van terugvalpreventiestrategieën. Van de deelnemers aan ons onderzoek die de eerste tekenen van een terugval ervoeren (30\%) herstelde twee derde (19\%) binnen een periode van drie maanden. Slechts een derde $(11 \%)$ kreeg een volledige terugval. Toen deze patiënten de eerste tekenen van een terugval ervoeren zoals omschreven in hun TPP, namen ze binnen een week contact op met hun GGZ-behandelaar. Hierdoor kon al in een vroeg stadium worden ingegrepen, waarbij werd uitgegaan van de vooraf vastgelegde acties en stappen zoals beschreven in het TPP. De bevindingen uit deze cohortstudie ondersteunen onze hypothese dat het gebruik van de richtlijn een preventieve uitwerking heeft op het optreden van een volledige terugval in patiënten met AN. Een survivalanalyse van deze gegevens laat de tijdlijn van een volledige terugval zien, en hieruit blijkt dat het hoogste risico ligt tussen 4 en 16 maanden na beëindiging van de behandeling. Uit het samenvoegen van de gegevens over gedeeltelijke en volledige terugval blijkt dat het risico op een terugval gedurende de gehele periode van 18 maanden verhoogd is, wat erop wijst dat het tijdens deze gehele periode nodig is om de vroege voortekenen van een terugval te monitoren. We vonden drie variabelen als voorspeller voor een terugval: 1) Duur van de behandeling voorafgaand aan de start van het nazorgprogramma; hoe langer een patiënt in behandeling was (geweest) hoe hoger het risico op een terugval werd. 2) Behandelvorm voorafgaand aan het nazorgprogramma, klinische of ambulante behandeling; patiënten die zowe klinisch als ambulant waren behandeld liepen een groter risico op terugval dan patiënten die alleen ambulant waren behandeld. 3) Leeftijd; patiënten die aan he begin van de behandeling ouder waren dan 19 liepen een hoger risico op terugval.

Op basis van deze cohortstudie zijn er indicaties dat de richtlijn een effectief instrument is om terugval te voorkomen. De voorzichtige conclusie is dat het risico op volledige terugval zal afnemen indien strategieën voor vroege herkenning in het geval van een dreigende terugval worden toegepast, gevolgd door gerichte interventies om verdere verslechtering te voorkomen. Dit vergroot de kans op stabiel, langdurig herstel voor patiënten.

Hoofdstuk 5 is een kwalitatief onderzoek, gericht op de ervaringen van patiënten en hun ouders. Hiermee wilden we inzicht verkrijgen in de manier waarop zij het werken met de richtlijn ervaren, met name als het gaat om het gebruiken van de zelfmanagementstrategieën. Daarnaast heeft het onderzoek tot doel de bevorderende en belemmerde factoren voor succesvolle toepassing van de richtlijn in kaart te brengen. We hebben 17 interviews met patiënten en 6 interviews met ouders uitgevoerd. De respondenten kregen vragen over de effecten die ze hadden waargenomen tijdens het werken met de richtlijn. Patiënten en familieleden noemden verschillende verklaringen voor de manier waarop de richtlijn bijdroeg aan het verbeteren van hun zelfmanagementvaardigheden. Deze worden in dit hoofdstuk gedetailleerd besproken, waarbij wordt gerefereerd aan de vijf kernvaardigheden op het gebied van zelfmanagement zoals beschreven door Lorig \& Holman (2003) problemen oplossen, beslissingen nemen, gebruik van hulpbronnen, vormen van een samenwerking tussen patiënt en zorgverlener, en actie ondernemen. Patiënten en ouders waren over het algemeen tevreden met de steun die de richtlijn bood. Het terugvalpreventieplan (TPP) leverde een significante bijdrage aan het leren begrijpen van hun eigen terugvalproces. De meeste patiënten internaliseerden de inhoud van het TPP. Deelnemers en ouders vonden het waardevol dat ze tijdens het nazorgprogramma in contact konden blijven met hun GGZ-behandelaar; dit voeld aan als een vangnet. Het TPP moet regelmatig worden bijgewerkt met recente ervaringen uit het dagelijks leven van de gebruiker. 
De studie die wordt beschreven in Hoofdstuk 6 had tot doel inzicht te krijgen in de uitlokkers en vroege voortekenen van terugval vanuit het perspectief van de patiënt. En daarnaast een nieuw instrument te ontwikkelen en valideren dat AN-patiënten meer inzicht moet bieden in hun uitlokkers en vroege voortekenen om daarmee een terugval te voorkomen. Door de Consensus-based Standards for the selection of health Measurement INstruments (COSMIN, Terwee et al., 2018) te volgen, hebben we de Anorexia Relapse Prevention INventory (ARPIN) ontwikkeld. In de contentanalyse werden de terugvalpreventieplannen van 107 AN-patiënten onderzocht, en werden lijsten van uitlokkers en vroege voortekenen opgesteld. Drie onafhankelijke onderzoekers stelden een eerste inventarisatie op, door uitlokkers en vroege voortekenen samen te voegen en te categoriseren. Er werd een focusgroep met zeven ervaringsdeskundigen georganiseerd waarin de indruksvaliditeit van de ARPIN werd onderzocht. De ervaringsdeskundigen vonden de ARPIN een gestructureerde, eenvoudig te gebruiken inventarisatie lijst. De ARPIN bestaat uit 9 hoofdcategorieën 'uitlokkers' met 54 kernvoorbeelden en 15 categorieën vroege voortekenen. Zowel patiënten als GGZ-behandelaars kunnen de ARPIN gebruiken om uitlokkers en vroege voortekenen te inventariseren. Een gedetailleerd inzicht in de uitlokkers en vroege voortekenen kan bijdragen aan het proces van vroege herkenning en vroege interventie bij een terugval. Inzicht in het terugvalproces zorgt ervoor dat de patiënt zich bewust is van de richting van het proces en dit kan bijsturen om zo toe te werken naar herstel.

\section{Reflectie op belangrijkste bevindingen}

Evidence-based practice stimuleert clinici om (1) het beste beschikbare onderzoeksbewijs te gebruiken in combinatie met (2) klinische expertise, terwijl (3) de geboden zorg rekening houdt met de eigenschappen, waarden en omstandigheden van de patiënt. Deze drie aspecten worden gezamenlijk de 'three-legged stool' van evidence-based practice genoemd, oftewel 'de kruk met drie poten' (Flemming \& Cullum, 1997; Sackett et al., 1996; Spring, 2007). Het besef dat de combinatie van al deze drie elementen de basis vormt van evidence-based practice is de eerste stap die noodzakelijk is voor het verbeteren van de behandeling van patiënten met een eetstoornis, alsmede voor het integreren van alle drie de 'poten' van de kruk in evidence-based practice (Peterson et al., 2016). Dit proefschrift maakt gebruik van de benadering van de 'kruk met drie poten'. De Richtlijn Terugvalpreventie Anorexia Nervosa is zelf opgesteld op basis van het beschikbare onderzoeksbewijs, de mening van experts en de uitkomst van presentatie aan patiëntenpanels (beschreven in Hoofdstuk 2). Er is echter beperkt bewijs over terugval en terugvalpreventie. Daarom had het onderzoek uit dit proefschrift ten doel meer inzicht te verkrijgen in het terugvalproces en in het gebruik van de drie 'poten' van de kruk; gebruik van het perspectief van patiënt en door de patiënt verstrekte data (Hoofdstukken 5 en 6), klinische data (Hoofdstuk 4), en bewijs uit bestaande onderzoeken naar terugva (Hoofdstuk 3). Hieronder gaan we uitgebreider in op de drie 'poten' van evidencebased practice vergeleken met de onderzoeken uit dit proefschrift.

\section{Patiëntperspectief}

Karaktereigenschappen die worden bepaald door biologische factoren en onvoorzienbare factoren tijdens de ontwikkeling, weerspiegelen onderlinge individuele verschillen. Het verband tussen persoonlijkheid en eetstoornissen is a lange tijd onderwerp van interesse, en zal dat ook blijven (Dufresne et al., 2020) Onderzoek toont aan dat eigenschappen als perfectionisme, conflictvermijding, angst en geremaheid voorkomen bij patiënten met anorexia nervosa (Hill et al., 2016 Klump et al., 2004). Het is van essentieel belang dat zowel de GGZ-behandelaars als de patiënten zelf rekening houden met deze eigenschappen tijdens het werken aan terugvalpreventie. Deze eigenschappen moeten worden gebruikt als bron van kracht tijdens dit deel van de behandeling, om de patiënt te motiveren en begrip te kweken voor het belang van terugvalpreventie, en tijdens het eigen herstelproces van de patiënt. Patiënten hebben begeleiding nodig bij het opzetten van een TPP, omdat ze het vaak moeilijk vinden hun verleden en de nare ervaringen tijdens hun ziekte onder ogen te zien. Meestal willen ze liever niet terugkijken, maar dat is juis een essentieel onderdeel van het werken aan terugvalpreventie (Hoofdstuk 5). Wanneer patiënten in staat zijn terug te kijken op het begin van hun eetstoornis en hun behandeling, leren ze meer over toekomstige terugvallen en hun persoonlijke terugvalproces. Tijdens deze fase kan hun eigen perfectionisme worden ingezet als kracht. Over het algemeen gaan patiënten zeer precies te werk bij het opzetten van hun TPP, wat ook bijdraagt aan het ontwikkelen van hun inzicht in het eigen proces. Aan het eind van de behandeling delen de meeste patiënten het besef dat hun ziekte niet volledig afwezig is, wat angst en onrust veroorzaakt. Hoewel ze hun eetstoornis onder controle hebben, ervaren ze vaak nog steeds anorectische gedachten. Ze handelen hier echter niet meer naar. Hierdoor vinden zowel patiënten als hun familie het vaak moeilijk om de behandeling af te sluiten. Zowel patiënten als hun familieleden hebben tijdens deze fase behoefte aan begeleiding en een vangnet, ter ondersteuning van hun eigen mate van zelfregulering en met de GGZ-behandelaar op gepaste afstand (Hoofdstukken 5 en 6). Dit wordt bevestigd in kwalitatieve onderzoeken; patiënten delen dat de normale ups en downs van het leven gewoon 
doorgaan, ook tijdens de herstelfase, en dat het bij hun herstel hoort om op een gezonde manier met deze uitdagingen te leren omgaan, en dat ze moeten blijven leren hoe ze dat kunnen aanpakken (Kenny et al., 2019) en dat het werken aan hun herstel een langdurig proces is (Stockford et al., 2019). Patiënten benadrukken het belang van professionele ondersteuning bij het doorlopen van hun herstelproces (Piot et al., 2019; Robinson et al., 2015). Er moet een balans worden gevonden tussen enerzijds activiteiten die zelfstandig of met beperkte coaching kunnen worden uitgevoerd, en anderzijds activiteiten waarbij meer ondersteuning nodig is. Patiënten hebben een voorkeur voor een aanpak op maat, waarbij de rol van de leden van hun netwerk en het behandelteam is toegesneden op hun persoonlijke situatie (Hoofdstuk 5).

\section{Klinisch perspectief}

In 2011 werd er een nieuw concept van gezondheid geïntroduceerd: "Gezondheid als het vermogen om zich aan te passen en een eigen regie te voeren, in het licht van de fysieke, emotionele en sociale uitdagingen in het leven" (Huber et al., 2011). De afgelopen jaren is het besef gegroeid dat zelfmanagement een belangrijke rol speelt bij het in staat stellen van patiënten om hun eigen symptomen te beheersen en bij te dragen aan herstel (Lorig \& Holmann, 2003). Om het zelfmanagement te versterken moet de zorgprofessional op maat gemaakte interventies uitvoeren. Zo zijn er voor mensen met een psychotische stoornis sinds een jaar of vijftien specifieke Illness Management and Recovery Programs beschikbaar om hun zelfmanagement te stimuleren (Mueser et al., 2006; McGuire et al., 2014). De professional moet ervaring hebben met motivatietechnieken en de patiënt kunnen ondersteunen bij het verbeteren van haar zelfmanagementvaardigheden. $\mathrm{Er}$ is nog steeds onvoldoende aandacht voor specifieke zelfmanagement-interventies bij de behandeling van AN. De vijf kernvaardigheden op het gebied van zelfmanagement zoals beschreven door Lorig \& Holman (2003) zijn verweven in de richtlijn (Hoofdstuk 5). Dankzij de verbetering van haar zelfmanagement-vaardigheden kan de patiënte minder afhankelijk worden van GGZ-behandelaars of leden van haar sociale netwerk. De richtlijn biedt de GGZ-behandelaar handvatten en ondersteuning bij dit maatwerkproces, terwijl hij samen met de patiënte en de leden van haar netwerk werkt aan terugvalpreventie. Samen onderzoeken zij het persoonlijke terugvalproces, waarbij rekening wordt gehouden met de vaardigheden van de patiënte en de benodigde afstemming op haar behoeften.
In de gezondheidszorg wordt voornamelijk gebruik gemaakt van twee modellen voor het conceptualiseren van behandeling en herstel van psychische aandoeningen: he medische model, waarin herstel wordt gepositioneerd als een objectieve "genezing", een toestand die wordt gedefinieerd door de afwezigheid van symptomen en een terugkeer naar normaal functioneren (Mountain \& Shah, 2008; Robert \& Wolfson, 2004), en het herstelmodel, oorspronkelijk gedreven door cliënten, waarin herstel wordt gepositioneerd als onderdeel van een persoonlijk traject, als uitkomst van persoonlijke groei ('empowerment') en resulterend in een verbetering van de kwaliteit van leven (Slade et al., 2008, 2014). Het medische model heeft lange tijd de overhand gehad op het gebied van eetstoornissen (Dawson et al., 2014a, 2014b), en behandelprotocollen voor AN zijn vaak gericht op de afwezigheid van symptomen en een terugkeer naar normaal functioneren. $\mathrm{Er}$ is echter een verschuiving zichtbaar richting de acceptatie dat, naast gedrags- en fysieke indices, ook psychologische/ cognitieve symptomen een belangrijke rol spelen in het herstel van eetstoornissen (Bardone-Cone et al., 2018). Om patiënten in staat te stellen zich tegen terugval te wapenen, zou de behandeling zich op al deze componenten moeten richten. GGZ-behandelaars zouden zich niet alleen moeten richten op het verbeteren van de competenties van de patiënt, maar ook op het gehele netwerk rond de patiënt (bijv. interpersoonlijk contact in het dagelijks leven, leden van hun netwerk en hun sociale steun, opleiding/werk, structuur in het dagelijks leven) en de behoefte van de patiënte als het gaat om het verbeteren van haar kwaliteit van leven. Uit de factoren die significant in verband worden gebracht met terugval (N=34), (zie Hoofdstuk 3) blijkt dat hier onderwerpen onder vallen die verband houden met de eetstoornis zelf, maar ook met copingmechanismen, psychosociaa functioneren en mate van motivatie.

Om de richtlijn te kunnen gebruiken is het noodzakelijk dat GGZ-behandelaars ove specifieke vaardigheden en competenties beschikken, met name op het gebied van het verbeteren van de motivatie en het doen afnemen van de weerstand bi patiënten. Alleen behandelaars met voldoende werkervaring met de doelgroep zijn competent genoeg om dit proces op de juiste manier te begeleiden en de valkuil van sociaal wenselijke antwoorden te vermijden. Daarnaast moet de behandelaar ove methodische en analytische vaardigheden beschikken om met de richtlijn te kunnen werken. Het is de bedoeling dat de richtlijn de GGZ-behandelaar een zekere mate van structuur biedt, maar tegelijk voldoende ruimte biedt om eigen beslissingen te nemen en de behandeling zodanig aan te passen dat deze optimaal aansluit bij de individuele eigenschappen van de patiënte en de leden van haar netwerk, verschillen in beleving, capaciteiten, wensen en behoeften. 
Hoewel er vooruitgang is geboekt op het gebied van klinisch onderzoek naar eetstoornissen, blijkt uit een groeiende hoeveelheid literatuur dat personen met een eetstoornis vaak geen evidence-based behandeling voor hun stoornis krijgen (Hilbert et al., 2017). In Nederland staat de behandeling van patiënten in de GGZ onder almaar toenemende druk door een tekort aan GGZ-behandelaars, financiële druk en een gebrek aan financiële mogelijkheden om te investeren in innovatie (Healthcheck Geestelijke Gezondheidszorg 2019, KPMG). In de dagelijkse praktijk van GGZ-instellingen waar AN wordt behandeld, zijn behandelprotocollen en GGZbehandelaars steeds meer gericht op een snel herstel, het beperken van intramurale zorg en het verkorten van de behandelduur. Dit kan ertoe leiden dat deze ernstig zieke patiënten ontoereikend behandeld worden, met name als het gaat om terugvalpreventie. De huidige leidende behandelprotocollen voor het behandelen van volwassenen en adolescenten met AN zijn beschreven in verschillende reviews (Brockmeyer et al., 2019; Van den Berg et al., 2019; Jansingh et al., 2020). Deze protocollen gaan wel in op het belang van terugvalpreventie, maar hebben een follow-up die te kort is wanneer we kijken naar de duur van de periode waarin het terugvalrisico het hoogst is, te weten tot 2 jaar. Het MANTRA-protocol (Maudsley Model of Anorexia Treatment in Adults, Schmidt et al., 2014, 2019) en het SSCM-protocol (Specialist Supportive Clinical Management, Mclntosh et al., 2006) voorzien beide in een follow-up van 4 maanden. Het CBT-E-protocol (Cognitive Behavioral TherapyEnhanced, Fairburn, 2008) heeft een follow-up van 5 maanden, en de laatste fase van het FBT-protocol (Family-Based Treatment, Lock, \& le Grange, 2005) dringt aan op drie afsluitende sessies over een periode van 3 maanden zonder verdere followup. Deze behandelprotocollen zouden moeten wijzen op de noodzaak van een zorgvuldige nazorgprocedure, aangezien dit de ontwikkeling van de chronische vorm van AN kan beperken en uiteindelijk mogelijk kosteneffectiever zal blijken.

Anderzijds kan de mogelijkheid dat de GGZ-behandelaar klinische technieken vermijdt uit vrees dat deze onwerkbaar, ondraaglijk, of schadelijk zijn, ondanks bestaand bewijs dat dat niet zo is (clinical avoidance) ook een rol spelen in het gebrek aan follow-up. Na afloop van hun behandeling willen patiënten met AN vaak niet meer terugkijken op hun ziekte, omdat ze dit confronterend vinden (Hoofdstuk 5). GGZ-behandelaars moeten in dit proces niet de confrontatie met de patiënte aangaan, maar in plaats daarvan proberen deze muur te doorbreken en de patiënte te steunen bij het werken aan de terugvalpreventie. In de dagelijkse praktijk blijkt dit moeilijk te zijn. Daarom moeten we investeren in GGZ-behandelaars door bijscholing aan te bieden om de implementatie van de richtlijn in de dagelijkse praktijk te verbeteren. De hypothese van clinical avoidance door GGZ-behandelaars zou ook een van de onderwerpen van toekomstig onderzoek moeten zijn.

\section{Onderzoek}

Dit proefschrift is gebaseerd op een combinatie van kwalitatieve en kwantitatieve onderzoeken, waaronder een systematische review en meta-analyse, een cohortstudie, een casusverslag, interviews, contentanalyse en focusgroepdiscussies. De waarde van deze aanpak met verschillende methodes en databronnen ligt in de verrijking van de onderzoeksdata, aangezien de benaderingen elkaar aanvullen (Chreswell \& Plano Clark, 2007; Collins et al., 2006; Pollit \& Beck, 2017).

Ondanks de ernst en hoge chroniciteit blijft anorexia nervosa een relatief klein onderzoeksgebied, met aanzienlijk minder publicaties dan in andere gebieden van psychische stoornissen. Zowel onderzoek naar AN als de financiering van onderzoek naar AN zijn ernstig verwaarloosd (Herpertz-Dahlman et al., 2015; Treasure et al. 2020; Schmidt et al., 2016). Zoals eerder vermeld is er weinig bewijs met betrekking tot terugval in $\mathrm{AN}$, en bestaat er een aanzienlijke variabiliteit met betrekking tot de gebruikte definities, procedures en instrumenten. Eenduidig gebruik van dezelfde definities, procedures en instrumenten met betrekking tot terugval is een voorwaarde voor het verbeteren van zowel behandeling als terugvalpreventiestrategieën. Onderzoekers moeten ernaar streven dat hun onderzoeken met elkaar vergeleken kunnen worden. Dit zou gunstig zijn voor onderzoekers, clinici, en patiënten en de leden van hun netwerk, omdat iedereen dan dezelfde taal zou spreken. Er is een goed kader nodig voor toekomstig onderzoek. Consensus over deze definities, procedures en instrumenten moet worden bereikt met steun van alle wetenschappelijk georiënteerde organisaties op het gebied van eetstoornissen (Hoofdstuk 3; Khalsa et al., 2017).

Een sterk punt van dit proefschrift is het intensieve gebruik van het patiëntperspectief bij het ontwikkelen van de richtlijn zelf, en in een aantal onderzoeken (Hoofdstukken 2, 5 en 6). In de bewijshiërarchie zijn de posities met betrekking tot de bijdrage van verschillende soorten bewijs minder rigide dan voorheen. Desalniettemin worden bronnen van bewijs in veel gepubliceerde bewijshiërarchiën gerangschikt op basis van de kracht van het bewijsmateriaal. Er is nog enige discussie over wat nu precies "rigorous research" (kritisch onderzoek) is, en over wat we kwalificeren als "best evidence" (het beste bewijs) (Polit \& Beck, 2018). Wij zijn van mening dat best evidence verwijst naar onderzoeksbevindingen die methodologisch passend en klinisch relevant zijn voor het beantwoorden van vragen vanuit de dagelijkse behandelpraktijk. De perspectieven van de patiënten en ouders die in dit proefschrift zijn gebruikt, hebben gezorgd voor een dieper inzicht in hun behoeften en het terugvalproces, wat heeft geresulteerd in verbetering en verdere onderbouwing van de richtlijn. 
Toekomstig onderzoek naar terugvalpreventie moet bij voorkeur zowel kwantitatieve als kwalitatieve studies bevatten. Beschrijvend longitudinaal onderzoek moet worden uitgevoerd met een follow-up van $\geq 24$ maanden, waarbij een gecontroleerde onderzoeksopzet wordt gebruikt. Incidentie en prevalentie van terugval en factoren die met terugval in verband worden gebracht moeten beter worden vastgesteld, om te kunnen bijdragen aan de ontwikkeling van een gestandaardiseerd prognostisch model voor terugval. Verder zou er ook onderzoek gedaan kunnen worden naar kosteneffectiviteit ten aanzien van terugval, aangezien er binnen het vakgebied van AN erg weinig bekend is over dit onderwerp. Hoewel er longitudinaal onderzoek naar de afloop van AN beschikbaar is, en er artikelen over onderzoeksprioriteiten voor AN zijn die de behoefte aan meer prospectieve longitudinale studies met voldoende kracht beschrijven (Zifpel et al., 2015; Treasure et al., 2020), bevatten deze veelal helaas geen expliciete data over terugval en de preventie van terugval.

Toekomstig kwalitatief onderzoek naar terugvalpreventie moet gericht zijn op het perspectief van leden van het netwerk van volwassenen met anorexia nervosa, zodat zij beter kunnen leren begrijpen hoe ze actief betrokken kunnen zijn bij de terugvalpreventiestrategieën, aangezien dit aspect nog steeds onderbelicht is. Ook is er onderzoek nodig naar de werkzaamheid van de Anorexia Relapse Prevention Inventory (ARPIN) in de klinische praktijk (Hoofdstuk 6) en de vraag of de ARPIN eraan bijdraagt dat patiënten een beter inzicht in hun persoonlijke terugvalproces ontwikkelen.

$\mathrm{Na}$ de onderzoeken die in dit proefschrift worden beschreven, is een volgende stap mogelijk; een gecontroleerde onderzoeksopzet om de effectiviteit van de voorgestelde terugvalpreventiestrategie verder te bevestigen. In het geval van AN is het echter buitengewoon lastig om RCT's (gerandomiseerde gecontroleerde studies) uit te voeren. Door de relatieve zeldzaamheid van AN is het moeilijk om deelnemers te vinden en is het vaak nodig meerdere locaties te gebruiken, er vallen veel deelnemers uit, en door de ernst en mogelijke medische complicaties van de stoornis lijkt het verstrekken van een placebo of onthouden van behandeling onethisch (Watson et al., 2013). De vraag dient zich aan of een RCT noodzakelijk is om de behandeling op het gebied van terugvalpreventie te verbeteren. Wij zijn van mening dat we kunnen vertrouwen op de informatie van het bestaande bewijs uit de drie 'poten' van evidence-based practice waarover we beschikken. Dit bewijs ondersteunt een veilige, effectieve en relevante klinische werkwijze. De nadruk zou moeten liggen op de implementatie van de richtlijn in de klinische praktijk en het opleiden van GGZ-behandelaars.
Concluderend kan worden gesteld dat de behandeling van anorexia nervosa niet compleet is zonder voldoende aandacht voor terugvalpreventie. Er wordt nog steeds gewerkt aan de klinische praktijk voor AN, aangezien er door een gebrek aan onderzoek nog veel onzekerheid bestaat over de pathofysiologie, behandeling en wijze van omgaan met deze ernstige psychische stoornis (Treasure et al., 2020). De implementatie van richtlijnen en behandelprotocollen in de praktijk is een uitdaging. Wanneer patiënten en leden van hun netwerk zijn voorzien van passende achtergrondinformatie over terugval, komen ze tot het besef dat het essentieel is om aan terugvalpreventie te werken. Anderzijds is het mogelijk dat GGZ-behandelaars, in een proces dat parallel loopt aan dat van hun patiënt, zelf terugvalpreventie technieken vermijden, zich voornamelijk richten op de behandeling, en de behoefte aan begeleiding bij het omgaan met dagelijkse uitdagingen na afloop van de behandeling onderschatten. Uit de onderzoeken die in dit proefschrift worden beschreven blijkt dat de richtlijn een effectieve tool is voor de preventie van terugval. Wij bevelen aan dat alle patiënten met AN na afloop van hun behandeling een gepersonaliseerd terugvalpreventieplan opstellen, waarbij gedurende een periode van ten minste 18 maanden na het afronden van de behandeling regelmatige evaluatie plaatsvindt. Wij blijven de richtlijn verfijnen en blijven ondersteuning bieden aan onze patiënten met AN die na afloop van hun behandeling nog altijd uitdagingen ervaren op het gebied van alledaagse gebeurtenissen. 


\section{Literatuur}

Bardone-Cone, A. M., Hunt, R. A., \& Watson, H. J. (2018). An Overview of Conceptualizations of Eating Disorder Recovery, Recent Findings, and Future Directions. Current Psychiatry Reports, 20(9). doi:10.1007/ s11920-018-0932-9

Brockmeyer, T., Friederich, H. C., \& Schmidt, U. (2018). Advances in the treatment of anorexia nervosa: A review of established and emerging interventions. Psychological Medicine, 48(8), 1228-1256. doi: org/10.1017/ 50033291717002604

Chreswell, J. W., \& Plano Clark, V. L. (2007). Designing and conducting mixed methods research. Sage Publications.

Collins, K. M. T., Onwuegbuzie, A. J., \& Sutton, I. L. (2006). A model incorporating the rationale and purpose for conducting mixed methods research in special education and beyond. Learning Disabilities: A Contemporary Journal, 4, 67-100.

Dawson, L., Rhodes, P., \& Touyz, S. (2014a). 'Doing the impossible': The process of recovery from chronic anorexia nervosa. Qualitative Health Research, 24, 494-505. doi:10.1177/1049732314524029

Dawson, L., Rhodes, P., \& Touyz, S. (2014b). The recovery model and anorexia nervosa. Australian \& New Zealand Journal of Psychiatry, 48(11), 1009-1016.

Dufresne, L., Bussières, E., Bédard, A., Gringas, N., Blanchette-Sarrasin, A., \& Bégin, C. (2020). Personality traits in adolescents with eating disorder: A meta-analytic review. International Journal of Eating Disorders, 53(2), 157-173.

Fairburn, C. G. (2008). Cognitive Behavior Therapy and Eating Disorders. The Guilford Press.

Flemming, K., \& Cullum, N. (1997). Doing the right thing. Nursing Standard, 12, 28-30.

Herpertz-DahImann, B., van Elburg, A., Castro-Fornieles, J., \& Schmidt, U. (2015). ESCAP Expert paper: New developments in the diagnosis and treatment of adolescent anorexia nervosa-a European perspective. European Child and adolescent Psychiatry, 24, $1153-1167$.

Hilbert A., Hoek H. W., \& Schmidt R. (2017). Evidence-based clinical guidelines for eating disorders: international comparison. CurrentOpinion in Psychiatry, 30, 423-437. doi:10.1097/YCO.0000000000000360

Hill, L., Knatz Peck, S., Wierenga, C. E., \& Kaye W. H. (2016). Applying neurobiology to the treatment of adults with anorexia nervosa. Journal of Eating Disorders, 4(31). doi.org/10.1186/540337-016-0119-x

Hubert, M., Knottnerus, J. A., Green, L., van der Horst, H., Jada, A. R., Kromhout, D., Leonard, B., Lorig, K., Loureiro, M. I., van der Meer, J. W. M., Schnabel, P., Smit, R., van Weel, C., \& Smid, H. (2011). How should we define health? British Medical Journal, 343. doi: 10.1136/bmj.d4163.

Jansingh, A., Danner, U. N., Hoek, H. W., \& van Elburg, A. (in press). Developments in the psychological treatment of Anorexia Nervosa and their implications for daily practice. Current Opinion in Psychiatry.

Kenny, T. E., Boyle, S. L., \& Lewis, S. P. (2019). \#recovery: Understanding recovery from the lens of recoveryfocused blogs posted by individuals with lived experience. International Journal of Eating Disorders, 30. doi: 10.1002/eat.23221

Khalsa, S. S., Portnoff, L. C., McCurdy-McKinnon, D., \& Feusner, J. D. (2017). What happens after treatment? A systematic review of relapse, remission, and recovery in anorexia nervosa. Journal of Eating Disorders, 5, 20. doi: 10.1186/540337-017-0145-3

Klump, K., Strober, M., Johnson, C., Thornton, L., Bulik, C., Devlin, C., Fichter, M. M., Halmi, K. A., Kaplan, A. S., Woodside, D. B., Crow, S., Mitchell, J., Rotondo, A., Keel, P. K., Berrettini, W. H., Plotnicov, K., Pollice, C., Lilenfeld, L. R., \& Kaye, W. H. (2004). Personality characteristics of women before and after recovery from an eating disorder. Psychological Medicine., 34(8), 1407-1418.

KPMG (2019). Healthcheck: Ontwikkelingen binnen de Healthcheck GZZ. (Healthcheck: The Development within the Healthcheck of mental health). https://assets.kpmg/content/dam/kpmg/nl/pdf/2019/sector/ healthcheck-ggz.pdf
Lock, D. \& le Grange, D. (2005). Family-Based Treatment for Eating Disorders. International Journal of Eating Disorders, 37, 64-67.

Lorig, K. R., \& Holman, H. R. (2003) Self-Management Education. History, Definition, Outcomes, an Mechanisms. Annals of Behavioral Medicine, 26, 1-7.

McGuire, A. B., Kukla, M., Green, A., Gillbride, D., Mueser, K. T., \& Salyers, M. P. (2014). Illness Managemen and Recovery: A Review of the Literature. Psychiatric Services, 65(2), 171-179. doi: 10.1176/appi.ps.201200274

McIntosh, V. V., Jordan, J., Luty, S.E., Carter, F. A., McKenzie, J. M., Bulik, C. M., \& Joyce, P. R. (2006). Specialist supportive clinical management for anorexia nervosa. International Journal of Eating Disorders, 39, 625632. doi:10.1002/eat.20297

Mountain, D., \& Shah, P. J. (2008). Recovery and the medical model. Advances in Psychiatric Treatment, 14 241-244

Mueser, K. M., Meyer, P. S., Penn, D. L., Clancy, R., Clancy, D. M., \& Salyers, M. P. (2006). The lllness Managemen and Recovery Program: Rationale, Development, and Preliminary Findings. Schizophrenia Bulletin, 32, 32 43. doi: 10.1093/schbul/sbl022

Peterson, C. B., Black-Becker, C., Treasure, J., Shafran, R., \& Bryant-Waugh, R. (2016). The three-legged stool of evidence-based practice in eating disorder treatment: research, clinical, and patient perspectives. BMC Medicine, 14, 69. doi:10.1186/s12916-016-0615-5

Piot, M., Gueguen, J., Michelet, D., Orri, M., Köenig, M., Corcos, M., Cadwallader, J., \& Godart, N. (2019). Personal recovery of young adults with severe anorexia nervosa during adolescence: a case series. Eating and Weight Disorders. doi: 10.1007/s40519-019-00696-7

Pollit, D. F., \& Beck, C. T. (2017). Nursing Research; Generating and Assessing Evidence for Nursing Practice, Tenth Edition. Wolters Kluwer Health.

Pollit, D. F., \& Beck, C. T. (2018). Essentials of Nursing Research; Appraising evidence for nusing practice, Ninth Edition. Wolters Kluwer.

Roberts, G., \& Wolfson, P. (2004). The rediscovery of recovery: Open to all. Advances in Psychiatric Treatment, 10, 37-49

Robinson P. H., Kukucksa R., Guidetti, G., \& Leavey, G. (2015). Severe and Enduring Anorexia Nervosa (SEEDAN): Qualitative Study of Patients with 20+ Years of Anorexia Nervosa. European Eating Disorders Review, 23, 318-326.

Sackett, D. L., Rosenberg, W. M., Gray, J. A., Haynes, R. B., \& Richardson, W. S. (1996). Evidence based medicine what it is and what it isn't. British Medical Journal, 312, 71-72.

Schmidt, U., Adan, R., Böhm, I., Campbell, I. C., Dingemans, A., Ehrlich, S., Elzakkers, I., Favaro, A., Giel, K. Harrison, A., Himmerich, H., Hoek, H. W., Herpertz-Dahlmann, B., Kas, M. J., Seitz, J., Smeets, P., Sternheim L., Tenconi, E., van Elburg, A., ... Zipfel, S. (2016). Eating Disorders: the big issue. The Lancet, 3, $313-315$.

Schmidt U, Wade TD, \& Treasure J. (2014). The Maudsley Model of Anorexia Nervosa Treatment for Adults (MANTRA): Development, key features and preliminary evidence. Journal of Cognitive Psychotherapy, 28 48-71. doi.org/10.1891/0889-8391.281.48

Schmidt, U., Startup, H., \& Treasure, J. (2019). Therapy Workbook for Treating Anorexia Nervosa: The Maudsley Model. Routledge.

Slade, M., Amering, M., \& Oades, L. (2008). Recovery: an international perspective. Epidemiologia psichiatria sociale, 17(2), 128-137.

Slade, M., Amering, M., Farkas, M., Hamilton, B., O'Hagan, M., Panther, G., Perkins, R., Shephert, G., Tse, S., \& Whitley, R. (2014). Uses and abuses of recovery: implementing recovery-orientated practices in menta health systems. World Psychiatry, 13, 12-20

Spring, B. (2007). Evidence-based practice in clinical psychology: what it is, why it matters; what you need to know. Journal of Clinical Psychology, 63(7), 611-631.

Stockford, C., Stenfert Kroese, B., Beesley, A., \& Leung, N. (2019). Women's recovery from anorexia nervosa: a systematic review and meta-synthesis of qualitative research. Eating Disorders, 27(4), 343-368, doi:10.1080/10640266.2018.15123 
Terwee, C. B., Prinsen, C. A. C., Chiarotto, A., De Vet, H. C. W., Westerman, M. J., Patrick, D. L., Alonso, J., Bouter, L. M., de Vet, H. C. W., \& Mokkink, L. B. (2018). COSMIN standards and criteria for evaluating the content validity of health-related Patient-Reported Outcome Measures: a Delphi study. Quality of Life Research, 11136-018-1829-0

Treasure, J., Duarte, T. A., \& Schmidt, U. (2020). Eating Disorders. The Lancet, 395, 899-911.

van den Berg, E., Houtzager, L., de Vos, J., Daemen, I., Katsaragaki, G., Karyotaki, E., Cuijpers, P., \& Dekker, (2019). Meta-analysis on the efficacy of psychological treatments for anorexia nervosa. European Eating Disorders Review, 27(4), 331-351. doi: org?10.1002/erv.2683

Watson, H., J., \& Bulik, C. M. (2013). Update on the treatment of anorexia nervosa: review of clinical trials, practice guidelines and emerging interventions. Psychological Medicine, 43, 2477-2500.

Zipfel, S., Kiel, K., E., Bulik, C. M., Hay, P., \& Schmidt, U. (2015). Anorexia nervosa: aetiology, assessment, and treatment. The Lancet Psychiatry, 2(12), 1099-1111. doi: 10.1016/S2215-0366(15)00356-9 



\section{Dankwoord}




\section{Doorzetten; 1) Krachtiger worden 2) Volharden 3) lets (ondanks bezwaren) laten doorgaan}

(van Dale Woordenboek)

Het was lang, het pad wat ik gelopen heb om tot dit proefschrift te komen (10 jaar ongeveer). Ik kan dan ook niet zeggen dat ik mijn hele leven opzij heb gezet om aan mijn promotie te werken. Ik denk eerder dat mijn promotietraject een onderdeel is geworden van mijn leven. Het was gewoon altijd bij me, tijdens het alledaagse leven, verjaardagen, leuke uitjes, vele vakanties, windsurfsessies en etentjes met vrienden. Maar ook tijdens alle grotere life-events en moeilijkere tijden die er zijn geweest. Soms als een irriterend deeltje wat aan me knaagde in mijn achterhoofd als er even geen tijd was en het vooral een gevoel van tekortschieten gaf. Maar bovenal een continu bubbelend deeltje in mijn hoofd dat op de meest eigenaardige momenten, en juist vaak in mijn vrije tijd, zorgde dat de puzzelstukjes op zijn plek vielen zodat ik weer verder kon komen. Dat heeft me laten zien dat doorzetten iets moois is en maakt dat ik iets heb bereikt wat ik zelf nooit had gedacht. Doorzetten in de onderzoekswereld doe je nooit alleen, en daarom wil ik graag een aantal mensen bedanken die mij in dit traject hebben geholpen.

Beste Annemarie, mijn eerste promotor, wat kennen we elkaar al lang, wat hebben we veel meegemaakt en hoe bijzonder is onze werkrelatie gevormd. Ik als net twintigjarige eigenwijze verpleegkundige op de kliniek, en jij als psychiater op dezelfde afdeling. En nu ben je naast al die jaren collega, al 10 jaar mijn promotor, die altijd vertrouwen heeft uitgestraald in mijn werk en visie en zich soms verbaasde over waar ik allemaal mee bezig was. En als ik dan weer vastliep in mijn hoofd over de uitvoering of analyse van het onderzoek, dan gaf je aan; als je vastloopt dan klopt het niet en maak je het te moeilijk, doe maar een paar stappen terug. Jouw gave om die stap terug te doen en mij in de "simpele" overstijgende lijn van mijn onderzoek terug te brengen heeft mij enorm geholpen. Jouw vermogen om in begrijpelijke taal de moeilijkste dingen uit te leggen of over te brengen is inspirerend.

Beste Wijbrand, mijn tweede promotor, jouw kennis en kunde op het gebied van eetstoornissen en brede kijk op onderzoek is bijzonder en ik heb erg veel van je geleerd. Ik zal nooit vergeten dat je voor het eerst tegen me zei "Kill your darlings!". Met andere woorden, je moet je meest kostbare passages verwijderen voor het grotere goed van je werk. Oh, en dat waren er gaandeweg aardig wat. Waar ik in het begin erg moest slikken om dit soort stappen te zetten, ben ik er door jou in getraind geraakt en kan ik het nu ook al zelf toepassen. Dankjewel voor de ondersteuning die je hebt gegeven tijdens dit traject, en door oog te hebben voor mij als persoon.

Beste Nynke, mijn copromotor, gedurende het traject ben jij erbij gekomen. Een doelgroep voor jou buiten je comfortzone, maar juist dat is de kracht van jouw bijdrage geweest. Jouw open vragen over de behandeling van patiënten met anorexia nervosa en jouw kennis vanuit de psychose wereld en onderzoek zorgde voor verdieping. Wat fijn dat jij als mede Verpleegkundig Specialist een onderdee was van mijn begeleidingsteam.

Ik wil graag Altrecht Eetstoornissen Rintveld bedanken voor de mogelijkheid om me te ontwikkelen op het gebied van innovatie en onderzoek. Dat ik gefaciliteerd werd met tijd om aan de slag te gaan met het thema terugvalpreventie en zo een nieuwe uitdaging aan kon gaan in mijn werk als Verpleegkundig Specialist als bruggenbouwer tussen de wetenschap en de praktijk. Lukas Heijs, algemeen manager destijds, wil ik in het bijzonder hiervoor bedanken. Daarnaast wil ik alle collega's van Rintveld bedanken voor hun tomeloze inzet voor onze eetstoornis patiënten, hun lange adem in de behandeling zelf, hun kennis en kritische blik, de continue ruimte voor innovatie en verbetering van zorg, hun enthousiasme in het werk en voor wie ze als persoon zijn. Dit alles maakt dat Rintveld een hele inspirerende omgeving is om in te mogen werken.

En dan mijn coauteurs van de verschillende artikelen, zonder jullie was het nie gelukt. Bedankt Willem, gewoon voor het feit dat je een man bent, een verademing in de vrouwenwereld van de eetstoornissen. Daarnaast natuurlijk voor de gezellige woensdagen op mijn kantoor en het mij meenemen in de wereld van de statistiek. Bedankt Marleen, voor het opzetten van de interviews, het afnemen ervan en deels mee coderen van de data. Bedankt Jasmijn, voor het afnemen van de tweede rond interviews. Bedankt Mirjam, voor het opstellen van de dataset uit de werkboeken, een enorm monnikenwerk. Bedankt Mathijs, voor jouw geweldige statistische kennis. Bedankt Unna, voor het keer op keer meelezen van stukken. En naast de coauteurs wil ik zeker ook alle andere collega's die aan mijn onderzoeken meegewerkt hebben enorm bedanken, voor het meedoen aan focusgroepen, het doornemen van honderden abstracts voor de review (wat een werk Janine, Jiska en Suzanne), en voor het mee categoriseren van data.

Zonder de inzet en input van patiënten en ervaringsdeskundigen was ik nergen geweest. Dankzij jullie medewerking is de richtlijn terugvalpreventie ontstaan en verfijnd, en het proces van terugval beter in kaart gebracht. Ik hoop dat we menig 
terugval kunnen gaan voorkomen, ik weet dat dat ook jullie insteek was om mee te werken. In het speciaal nog dank aan de Familie de Theije, die een financiële ondersteuning hebben geboden voor het laatste onderzoek. Dit gaf een extra boost om door te gaan, omdat je voelt dat je werk gewaardeerd wordt.

Hierbij ook een woord van dank aan de leden van de leescommissie, prof. dr. P. A. Boelen, prof. dr. R. Geenen, prof. dr. M. van den Hout, prof. dr. M. J. Schuurmans en prof. dr. A. A. N. Mulkens. Hartelijk dank voor de bereidheid om dit proefschrift te beoordelen.

Lieve Super nurses; Sonja, Ineke, Hans, Judith en Annemiek. De VS-opleiding en het ontmoeten van jullie als gelijkgestemden daar heeft me enorm geïnspireerd. Jullie waren altijd vol ongeloof over mijn doorzettingsvermogen en bleven steeds enthousiast vragen hoe het ging. Ik hoop dat we onze etentjes nog lang laagfrequent voort zullen zetten

Beste Jackie, Dick, Marianne, Judith en Maaike, mijn intercollegiale toetsing groep. Al bijna twaalf jaar lang spreken wij elkaar 4 a 5 keer per jaar over ons vak als VS en alle aspecten die daarbij komen kijken. Op patiënten-, professioneel-, maar zeker ook op persoonlijk-vlak. En al die tijd horen jullie mij al aan over mijn artikelen en onderzoeken. Onze regel om bij zowel Nederlandse als internationale publicaties te trakteren hield mij actief (wel geteld 20x, ik weet niet zeker of ik zo vaak getrakteerd heb, volgens mij hebben jullie nog wat te goed).

Lieve vriendinnen en vrienden (jullie weten zelf precies wie ik hier bedoel ;-)), bedank $\dagger$ voor de avondjes uit, foute films, het sushi eten, de urenlange gesprekken en dagjes op pad. Voor de ontspanning, een altijd aanwezig luisterend oor, jullie schouders, vele appjes, uitgesproken liefde, langs zowel pieken als dalen. Door en met jullie is het leven leuk!

Mijn twee paranimfen wil ik even speciaal bedanken, vooral omdat ze deze rol ook op zich willen nemen. Lieve Sonja, we zijn beide sinds we elkaar kennen (2007) intensief bezig met onze Best Practice thema's, ik met terugvalpreventie en jij met leefstijl. Daarin hebben we beide een vasthoudendheid, die ons ook verbindt. ledere keer als ik je zie en spreek inspireer je me hiermee. Lieve Bianca, grote zus, jij hebt stiekem op de achtergrond een rol gespeeld door alle jaren van mijn promotietraject. Alle schema's, afbeeldingen, de cover van de richtlijn en ook de cover van dit proefschrift zijn jouw product. Jouw doorzettingsvermogen in doen wat je leuk vindt, dat zelf ook organiseren, zelf creëren en hoe jij je passie volgt is zo mooi om te zien. Een groot voorbeeld.
Lieve Berno, we zaten samen in een restaurantje in Volendam, waar we overheerlijke mosselen hebben gegeten, uitkijkend over het water. Jij gaf aan; een goed promotietraject heb je binnen een half uur uitgedacht. En zo stond in zeer korte tijd mijn promotietraject op een bierviltje geschreven. Je bent gedurende dit traject mijn steun geweest en mijn kritische noot. Van een intensieve samenwerking in het begin, naar een respectvol en losgelaten eind. Ik ben je eeuwig dankbaar voor het mooiste in mijn leven, onze zoon Bart.

En dan de grote broers (zoals Bart jullie allemaal noemt): Sam \& Anouk, Tom, Bob \& Belle. Jullie ontwikkeling in het leven is ontroerend om te zien en ik ben blij dat ik daar een onderdeel van uit mag maken.

Lieve Anouk en Michel, Bianca en Thomas. ledere keer als ik jullie op de hoogte bracht van mijn voortgang vlogen de aanmoedigingsappjes en GIF'jes mij om de oren! Dat pepte mij altijd weer op. Lieve pap en mam, jullie mogen jezelf ook we echt de experts op het gebied van terugvalpreventie bij anorexia nervosa noemen Jullie hebben al mijn stukken meerdere keren gelezen, voorzien van opmerkingen en taal aanpassingen. We hebben zelfs discussies gevoerd over onderdelen van de artikelen, omdat jullie echt wilden begrijpen wat er allemaal stond en vonden da ik meer trots mocht schrijven over de bevindingen. De regels van de wetenschap vonden jullie soms maar saai en streng. Ik ben jullie altijd dankbaar voor het warme veilige nest waar ik in mocht opgroeien, samen met Bianca en Anouk, waarbij jullie onvoorwaardelijke steun en liefde altijd voelbaar is.

Lieve Bart, je bent mijn mooiste wonder. Je laat mij de wereld zien door jouw ogen je stelt vragen die mij aan het denken zetten, je trekt me uit mijn werk en laat me spelen. Je laat me enorm lachen, en geeft altijd liefde. Jij die iedere avond bij het naar bed gaan heel hard roept: je bent de allerliefste van de hele wereld en de hele dag; waardoor ik alles weer aankan. 
About the author 
Tamara Berends was born on the $12^{\text {th }}$ of November 1976 in Willemstad, Curaçao (The Netherlands Antilles). With her parents and two older sisters Bianca and Anouk, she lived in different countries over the world until she was seven years old. That is when they settled in the Netherlands. From 1995 to 1999 she attended the Utrecht University of Applied Sciences, where she obtained her bachelor degree in nursing. She worked at the Department of Psychiatry of the University Medical Centre Utrecht (UMCU), at the inpatient unit for adolescents with eating disorders. In 2005 she started working in Rintveld, Centre for Eating Disorders, Altrecht Mental Health Institute. At first she worked at the inpatient unit for adolescents with anorexia nervosa. In 2007 she enrolled in the Master Advanced Nursing Practice at the Utrecht University of Applied Sciences and started working as an outpatient Nurse Practitioner in training. In 2009 she obtained her master degree.

Her Best Practice during her Master focused on relapse prevention and that is when she developed the Relapse Prevention Guideline Anorexia Nervosa. To further investigate this structured evidence-based method for daily practice, she developed a PhD research proposal. Rintveld supported her PhD research by facilitating time and supervision.

Tamara started with her PhD in 2010. In addition to her research she continued to work as a Nurse Practitioner at the outpatient department of Rintveld.

Tamara currently lives in IJsselstein with her son Bart, and continues to work as a Nurse Practitioner and as a Trainer for Nurse Practitioners in training at Altrecht Mental Health Institute. She is involved in the research group of the eating disorder centre and plays a role in disseminating knowledge by presenting at symposia and workshops. In her spare time, she enjoys time with Bart, windsurfing, cycling, travelling to the sun and spending time with her friends. 
List of Publications 
Berends, T., van Elburg, A., \& van Meijel, B. (2010). Richtlijn terugvalpreventie anorexia nervosa. Werken met een signaleringsplan ter preventie van terugval bij patiënten met anorexia nervosa. Koninklijke Van Gorcum, Assen. (www.relapse-an.com)

Berends, T., van Meijel, B., \& van Elburg, A. (2010). Werken met de richtlijn Terugvalpreventie bij jeugdige patiënten met anorexia nervosa. PsychoPraktijk, 2(2), 30-33.

Berends, T., van Meijel, B., \& van Elburg, A. (2010). Terugvalpreventie bij jeugdigen met anorexia nervosa. TvZ Tijdschrift voor Verpleegkundigen, 120(1), 43-46.

Berends, T., van Driel, I., \& Exterkate, C. (2011). Werken aan terugvalpreventie bij anorexia nervosa. Evidence Based Practice, 3, 4-6

Berends, T., van Meijel, B., \& van Elburg, A. (2012). The Anorexia Relapse Prevention Guidelines: A case report. Perspectives in Psychiatric Care, 48(3), 149-155. doi:10.1111/ j.1744-6163.2011.00322.x

Berends, T., \& van Elburg, A. (2012). Eetstoornissen. Nurse Academy, 4, 50-55

Bos, A., Hoekstra, T., Polhuis, D., Timmermans, G., Visscher, P., Cusveller, B., \& Huijdink, M. (2012). Verplegen in de geestelijke gezondheidszorg, basisboek 4. Berends, T., Hoofdstuk 5, Verplegen van cliënten met een eetstoornis. ThiemeMeulenhof, Amersfoort.

Verschueren, S., Berends, T., Kool-Goudzwaard, N., van Huigenbosch, E., Gamel, C., Dingemans, A., van Elburg, A., \& van Meijel, B. (2014). Patients With Anorexia Nervosa Who Self-Injure: A Phenomenological Study. Perspectives in Psychiatric Care, 51(1), 63-70. doi:10.1111/ppc.12061

Verschueren, S., van Elburg, A., Berends, T., \& van Meijel, B. (2014). Eetstoornissen en zelfverwonding. Nurse Academy, 2, 19-23.

Beukers, L., Berends, T., de Man-van Ginkel, J. M., van Elburg, A. A., \& van Meijel, B. (2015). Restoring normal eating behavior in adolescents with anorexia nervosa: A video analysis of nursing interventions. International Journal of Mental Health Nursing, 24(6), 519-26. doi:10.1111/inm.12150
Berends, T., van Meijel, B., Nugteren, W., Deen, M., Danner, U. N., Hoek, H. W., \& van Elburg, A. A. (2016). Rate, timing and predictors of relapse in patients with anorexia nervosa following a relapse prevention program: a cohort study. BMC Psychiatry,16(1), 316. doi:10.1186/s12888-016-1019-y

Berends, T., \& van Elburg, A. (2016). Behandeling van patiënten met anorexia nervosa. Nederlands Tijdschrift voor Evidence Based Practice, 5, 8-10.

Berends, T., van de Lagemaat M., van Meijel B., Coenen J., Hoek H. W., \& van Elburg A. A. (2018). Relapse prevention in anorexia nervosa: Experiences of patients and parents. International Journal of Mental Health Nursing, 27(5), 1546-1555. doi:10.1111/ inm.12456

Berends, T., (2018). Anorexia nervosa, hoe te (be)handelen in een algemeen ziekenhuis. Nurse Academy, 1, 12-16.

Berends, T., (2018). Hoofdstuk 27, Terugvalpreventie. In A.A. van Elburg \& G. Noordenbos (red), Handboek Eetstoornissen. Utrecht: De tijdstroom.

Berends, T., Boonstra, N., \& van Elburg, A. (2018). Relapse in anorexia nervosa: a systematic review and meta-analysis. Current Opinion in Psychiatry, 31(6), 445-455. doi:10.1097/YCO0000000000000453

Smithuis, L., Kool-Goudzwaard, N., de Man-van Ginkel, J. M., van Os-Medendorp, H. Berends, T., Dingemans, A., Claes, L., van Elburg, A. A., \& van Meijel, B. (2018). Selfinjurious behaviour in patients with anorexia nervosa: a quantitative study. Journal of Eating Disorders, 6, 26, doi: org/10.1186/s40337-018-0214-2

Rhoen, M., (2019). En dan sta je op eigen benen (interview met Tamara Berends over terugvalpreventie). Weet Magazine, 14, 30-33.

Akkermans-Smithuis, L., Kool-Goudzwaard, N., de Man-van Ginkel, J. M., van OsMedendorp, H., Berends, T., Dingemans. A., Claes, L., van Elburg, A. A., \& van Meijel, B. (2019). Zelfverwondend gedrag bij patiënten met anorexia nervosa. Verpleegkunde. Nederlands-Vlaams wetenschappelijk tijdschrift voor verpleegkundigen, 3, 14-22.

Berends, T., Boonstra, N., van Zon, M., Hoek, H. W., \& van Elburg. The Development of the Anorexia Relapse Prevention INventory (ARPIN). (submitted) 